\title{
ANALYSIS OF THE IMPACTS OF EXTREME WEATHER EVENTS ON ONTARIO'S ELECTRICITY GRID USING AGENT-BASED MODELING
}

by

\author{
Ailiya Saeed \\ Bachelor of Engineering, Chemical Engineering \\ NED University of Engineering and Technology \\ Pakistan, 2014 \\ A thesis \\ presented to Ryerson University \\ in partial fulfillment of the \\ requirements for the degree \\ of Master of Applied Science \\ in the Program of \\ Environmental Applied Science and Management
}

Toronto, Ontario, Canada, 2017

(C) Ailiya Saeed 2017 
I hereby declare that I, Ailiya Saeed, am the sole author of this thesis. This is a true copy of the thesis, including any required final revisions, as accepted by my examiners.

I authorize Ryerson University to lend this thesis to other institutions or individuals for the purpose of scholarly research.

I further authorize Ryerson University to reproduce this thesis by photocopying or by other means, in total or in part, at the request of other institutions or individuals for the purpose of scholarly research.

I understand that my thesis may be made electronically available to the public. 


\title{
ANALYSIS OF THE IMPACTS OF EXTREME WEATHER EVENTS ON ONTARIO'S ELECTRICITY GRID USING AGENT-BASED MODELLING
}

\author{
Ailiya Saeed \\ Master of Applied Science, 2017 \\ Environmental Applied Science and Management \\ Ryerson University
}

\begin{abstract}
Extreme weather events have increased and are causing severe impacts on the electricity grid. Heat waves and ice storms are becoming more intense and frequent in Ontario, Canada. During an extreme weather event, the electricity demand fluctuates and the reliability of the electrical grid decreases due to equipment failure and shortage of electricity supply, which leads to blackouts. An initial stage simulation model is developed using the computational technique agent-based model. This thesis analyzed the impact of extreme weather events based on severity and frequency levels on two sector of Ontario's electricity grid which are generation plants and distribution network. The simulation output showed multiple grid failures in different regions during extreme severity levels and increased frequencies of weather events. The model also showed heat waves and ice storms resulting differently depending on the month, extreme temperature months were more prone to failures than average temperature months.
\end{abstract}




\section{ACKNOWLEDGEMENTS}

I would like to start by thanking my supervisor Dr. Aziz Guergachi for offering me the privilege of working with him. His instructions were both helpful and challenging. Without his continuous guidance, support, and patience, the field of research would have been difficult to navigate.

I would also like to take this opportunity to thank my mother, Dr. Rafia Azmat, and father, Syed Saeed Akhter, for their unconditional love and support in every step of my life. I thank my immediate family and all my friends for their encouragement and support.

Tal Zaitsev, from Electrical and Computer Engineering, thank you for your continuous support and understanding of my ideas. I am grateful to Hossam Abdel Rahman, Khadijah Moinuddin, Nabila Alibhai and Salomeh Chegini from the EnSciMan Department; thank you all for supporting me throughout this journey.

I want to thank all my instructors in the EnSciMan Department at Ryerson University; your teachings have been a great addition to my knowledge and provided me an opportunity to grow.

I would like to thank my committee members, Dr. Sharareh Taghipour and Dr. Farid Shirazi for accepting to be my committee members and supporting my research. 


\section{TABLE OF CONTENTS}

AUTHOR'S DECLARATION ........................................................................................ ii

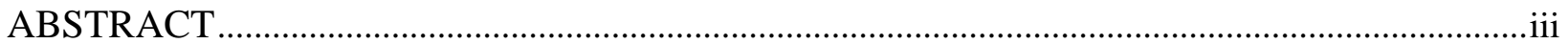

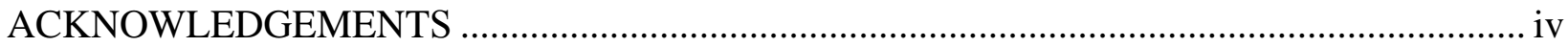

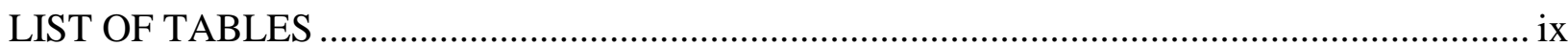

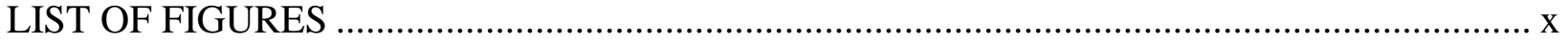

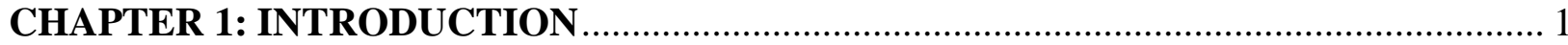

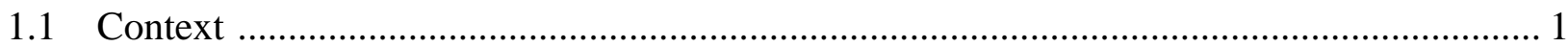

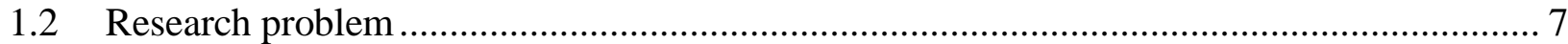

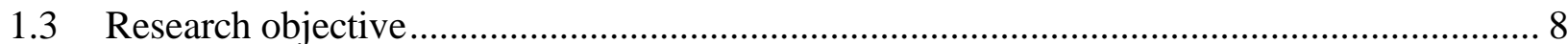

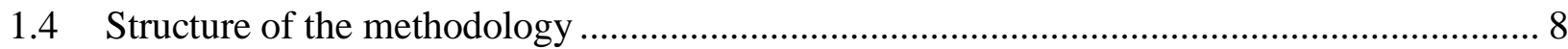

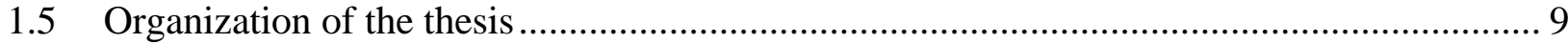

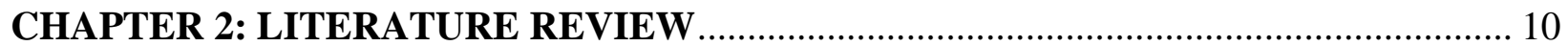

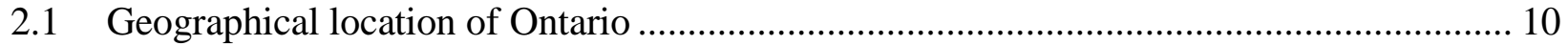

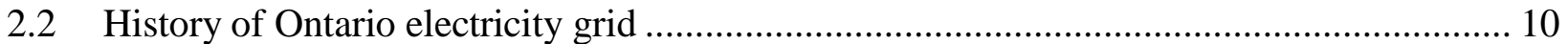

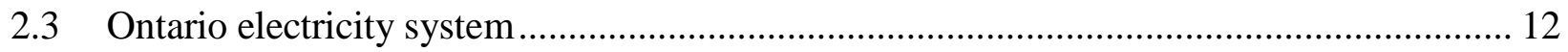

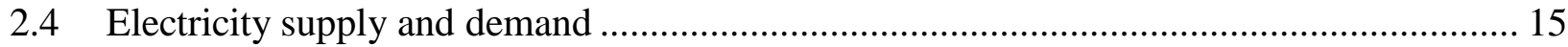

a) Planning reserves and operation reserves ................................................................ 17

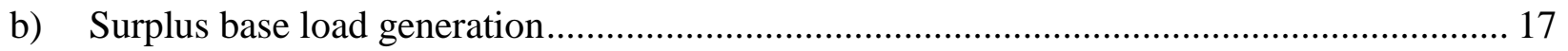


2.5 Introduction to Modeling and Computer Simulations ................................................. 18

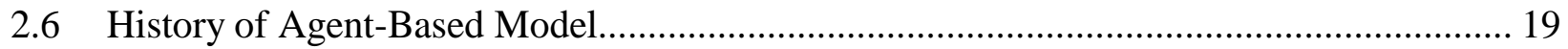

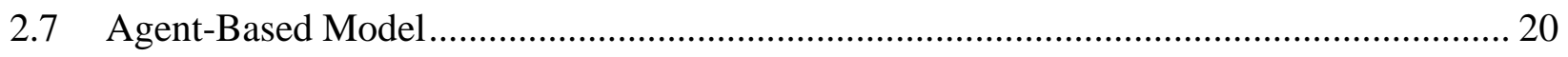

2.8 Components of Agent-Based Model ..................................................................... 22

2.9 Why use Agent-Based Model? ............................................................................ 24

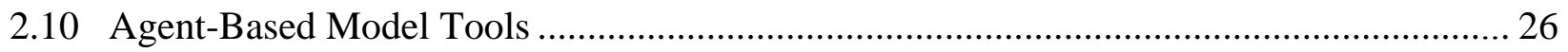

2.11 Agent-Based Model Software: Anylogic ........................................................... 26

2.12 General advantages of Agent-Based Model ............................................................ 27

2.13 Agent-Based Model and electricity market....................................................... 28

2.14 Literature Review: Extreme weather event (Heat wave) and impact on electrical

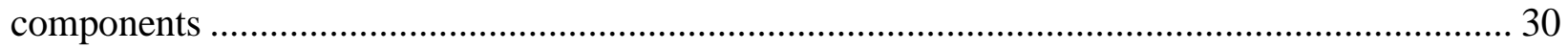

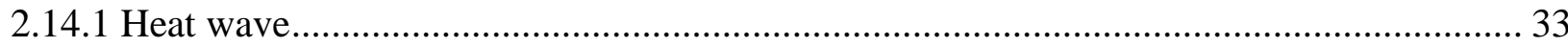

2.15 Literature Review: Extreme weather event (Ice storm) and impact on electrical components

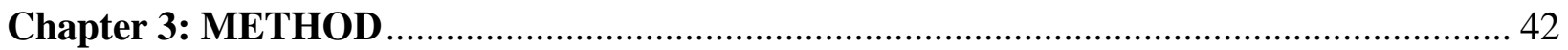

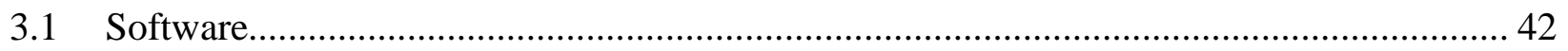

3.2 Data

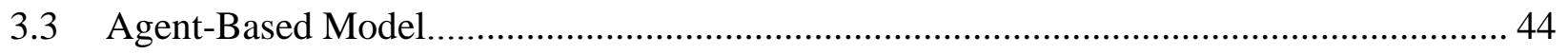

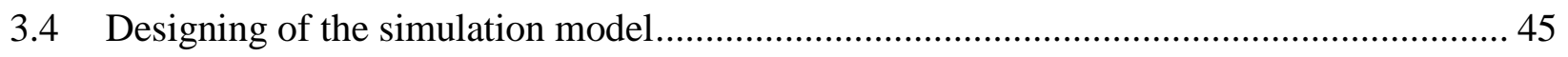

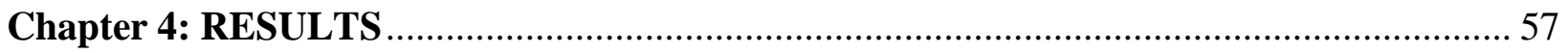


Simulation Run: Frequency: 2 and 3, Severity level: Low, Regions: West, Greater Toronto Area, Bruce, Ottawa, Southwest, Essa and East 59

Simulation Run: Frequency: 2, Severity level: Moderate, Regions: West, Greater Toronto Area, Bruce, Ottawa, Southwest, Essa and East...... 61

Simulation Run: Frequency: 3, Severity level: Moderate, Regions: West, Greater Toronto Area, Bruce, Ottawa, Southwest, Essa and East 64

Simulation Run: Frequency: 2, Severity level: Extreme, Regions: West, Greater Toronto Area, Bruce, Ottawa, Southwest, Essa and East 66

Simulation Run: Frequency: 3, Severity level: Extreme, Regions: West, Greater Toronto Area,

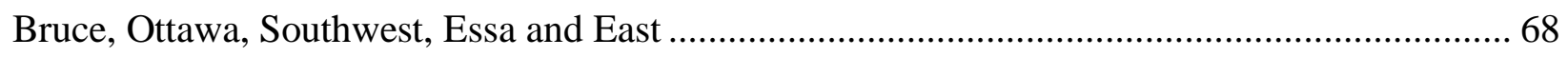

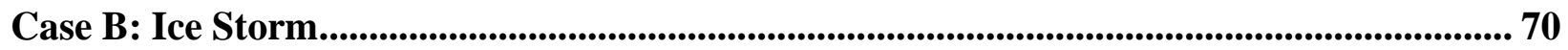

Simulation Run: Frequency: 2, Severity level: Low, Regions: West, Greater Toronto Area, Bruce, Ottawa, Southwest, Essa and East. 70

Simulation Run: Frequency: 2, Severity level: Moderate, Regions: West, Greater Toronto Area, Bruce, Ottawa, Southwest, Northwest, Northeast, Essa and East ....................................... 71

Simulation Run: Frequency: 2, Severity level: Extreme, Regions: West, Greater Toronto Area,

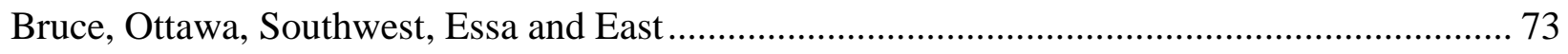

CHAPTER 5: DISCUSSION AND CONCLUSION ...................................................... 75

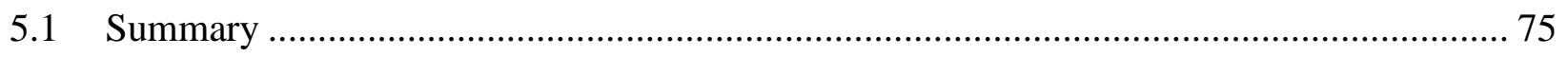

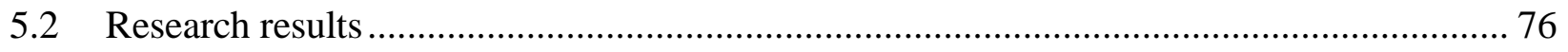




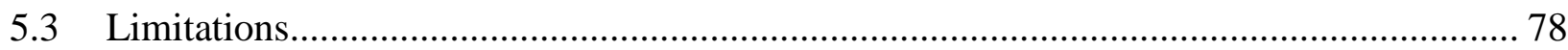

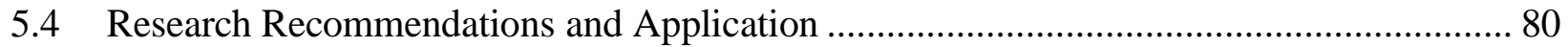

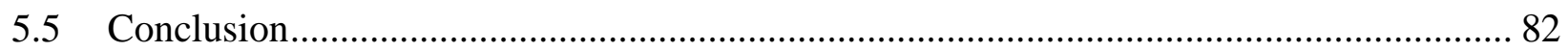

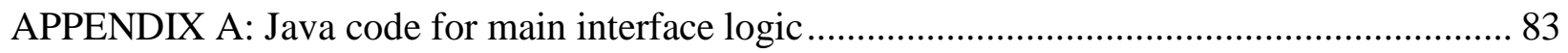

APPENDIX B: Java code for triggering the weather event ................................................. 84

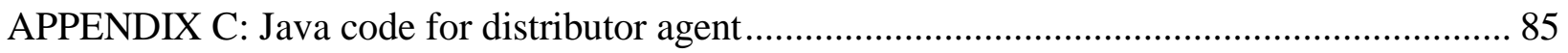

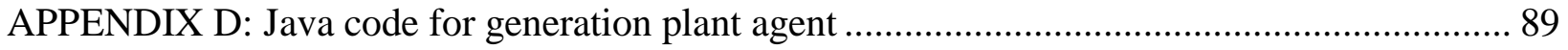

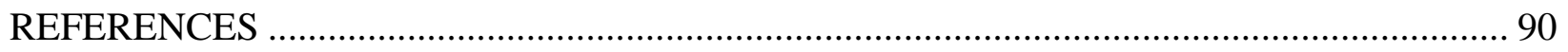




\section{LIST OF TABLES:}

Table 1: Breakdown of Major Grid Failures by cause (McLinn, 2009)................................... 3

Table 2: Severity level (low, moderate and extreme) based on duration of heat wave and ice storm 51

Table 3: Severity level (low, moderate and extreme) based on change in demand for heat wave 51

Table 4: Severity level (low, moderate and extreme) based on change in demand for ice storm

Table 5: Severity level (low, moderate and extreme) based on temperature for heat wave........ 52

Table 6: Severity level (low, moderate and extreme) based on temperature for ice storm

Table 7: Downtime of 148 generation plants based on the size (capacity in MW) 55

Table 8: Simulation results based on frequency and severity level of heat waves and ice storm 


\section{LIST OF FIGURES:}

Figure 1: Illustration of primary electricity system (Liscouski \& Elliot, 2004) .......................... 2

Figure 2: Example of Ontario's electricity demand during a heat wave in June 2012

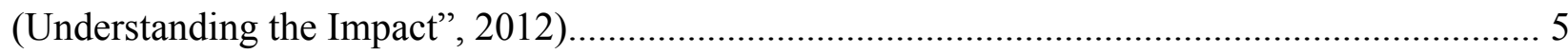

Figure 3: Generating resources as of September 22, 2016 (IESO supply mix, 2016) ................ 12

Figure 4: Illustration of a load duration curve which shows different generating resources that meet the supply demand at/or above a particular level at the lowest cost(Pfeifenberger, Spees

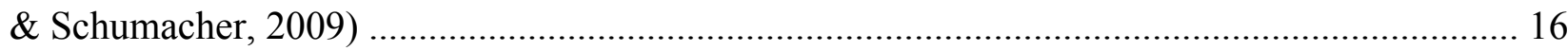

Figure 5: Conceptual description of an agent (Macal \& North, 2005)..................................... 23

Figure 6: Causes of the power grid failure resulting in a blackout. Data from NERC records (1984-2006) (as cited in Hines, Balasubramaniam \& Sanchez, 2009)......

Figure 7: The number of major blackouts in North America for 1984-2006 (as cited in Hines, Balasubramaniam \& Sanchez, 2009) 32

Figure 8: Maximum temperature percentile is shown during the summer $\left(1^{\text {st }}\right.$ June $-31^{\text {st }}$ August.) the data is recorded for Canadian cities (1961-1990). Temperature data is recorded close/within the city or the airport's weather station. The dashed line on the right-hand side represents cities with maximum temperature percentile (95th percentile), temperature $>25^{\circ} \mathrm{C}$ and $30^{\circ} \mathrm{C}$ (as cited in Smoyer-Tomic, Kuhn \& Hudson, 2003) ............................................................................ 34

Figure 9: Illustration of impacts of heat waves on power system operation (Ke etal., 2016)...... 36 Figure 10: Map view of the electricity grid of Ontario on Anylogic, generation plants (white circles) are connected by transmission lines (dotted lines) to distributor agents (yellow icon) (Anylogic, 2016) 47

Figure 11: Setup of a distributor agent in Anylogic (Anylogic, 2016)................................... 49

Figure 12: Map view of Northwest region shows an error state (Anylogic, 2016).................... 54 
Figure 13: User-friendly interface which test several scenarios with the help of the primary interface of the simulation, which defines the event type, severity, frequency for ten regions in Ontario (Anylogic, 2016) 56

Figure 14A: For May 2013, Simulation interface shows the output of the electricity grid on severity level: low and frequency: 2 and 3, the system is handling the heat wave for the selected regions. No errors observed throughout the month (Anylogic, 2016).....

Figure 14B: Map view for August 2013, Simulation interface shows the output of the electricity grid on severity level: low and frequency: 2 , the system is handling the heat wave for the selected regions. State: None, no errors observed throughout the month (Anylogic, 2016) 60

Figure 15A: For July 2013, Simulation interface shows the output of the electricity grid on severity level: moderate and frequency: 2 , the system is handling the heat wave for the selected regions. One error in Southwest is observed throughout the month (Anylogic, 2016).

Figure 15B: Distributor interface shows the output of the electricity grid on severity level: moderate and frequency: 2 , the system is handling the heat wave for the selected regions (Anylogic, 2016).

Figure 15C: Map view for July 2013, Simulation interface shows the output of the electricity grid on severity level: moderate and frequency: 2 , the system is handling the heat wave for the selected regions. State: Error, one error is observed throughout the month (Anylogic, 2016) 63 Figure 16A: For July 2013, Simulation interface shows the output of the electricity grid on severity level: moderate and frequency: 3 , the system is handling the heat wave for the selected regions. Two errors in Ottawa and Southwest are observed throughout the month (Anylogic, 2016) 64

Figure 16B: Distributor interface shows the output of the electricity grid on severity level: moderate and frequency: 3 , the system is handling the heat wave for the selected region (Anylogic, 2016) 
Figure 17A and 17B: For July 2013, Simulation interface shows the output of the electricity grid on severity level: extreme and frequency: 2 , the system is handling the heat wave for the selected regions. Five errors in West, GTA, Ottawa, East and Niagara are observed throughout the month (Anylogic, 2016) 66

Figure 17C: For July 2013 Distributor interface shows the output of the electricity grid on severity level: extreme and frequency: 2 , the system is handling the heat wave for the selected regions (Anylogic, 2016). 67

Figure 18A and 18B: For July 2013, Simulation interface shows the output of the electricity grid on severity level: extreme and frequency: 3 , the system is handling the heat wave for the selected regions. Errors in GTA, Niagara, Ottawa, Southwest and Essa, are observed throughout the month (Anylogic, 2016). 68

Figure 18C: For July 2013 Distributor interface shows the output of the electricity grid on severity level: extreme and frequency: 3 , the system is handling the heat wave for the selected regions (Anylogic, 2016).

Figure 19A: For December 2013, Simulation interface shows the output of the electricity grid on severity level: low and frequency: 2 , the system is handling the Ice Storm for the selected regions. No errors observed throughout the month (Anylogic, 2016). 70

Figure 20A and 20B: For January 2013, Simulation interface shows the output of the electricity grid on severity level: moderate and frequency: 2, the system is handling the Ice Storm for the selected regions. Errors are observed in Northwest and Northeast throughout the month (Anylogic, 2016) 71

Figure 20C: Distributor interface shows the output of the electricity grid on severity level: moderate and frequency: 2, the system is handling the ice storm for the selected regions (Anylogic, 2016). 72 
Figure 21A and 21B: For December 2013, Simulation interface shows the output of the electricity grid on severity level: extreme and frequency: 2, the system is handling the Ice Storm for the selected regions. Errors observed in West, GTA, Niagara, Southwest Northwest and Northeast and Essa throughout the month (Anylogic, 2016).................................................................... 73

Figure 21C: Distributor interface shows the output of the electricity grid on severity level: extreme and frequency: 2, the system is handling the ice storm for the selected regions

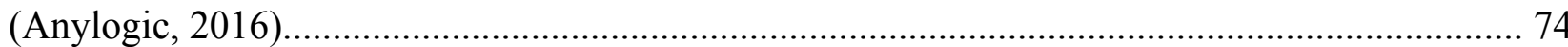




\section{CHAPTER 1: INTRODUCTION}

\subsection{Context}

Extreme weather events are a major concern for present and future generations. Engineering strategies and techniques have tried to provide high-level protection to counteract the damage done by extreme weather, which disturbs the function of energy infrastructures. Due to hazardous contributions from natural disasters in weather, electricity systems including transmission, generation and distribution have faced severe consequences. A stable electric power system can be relied upon to deliver the required electricity supply and generation. However, failure to provide a reliable system can have adverse consequences resulting in a blackout (Barben, 2010).

The Intergovernmental Panel on Climate Change defines extreme weather as an event that is rare at a particular place or a time annually. The definition states, "Extreme weather can be as rare as the $10^{\text {th }}$ or the $90^{\text {th }}$ percentile of a probability density function estimated from observations," (Intergovernmental Panel on Climate Change [IPCC], p.123, 2014). According to Bollinger and Dijkema (2016), the disruptions in electricity grid can cause by the intensity of extreme weather conditions. The variability and rarity of a severe weather event can impede the power infrastructure. The probability of power grid failure during an extreme weather event is higher as compared to standard weather parameters. An increase in severity and frequency of occurrences of an extreme weather event is a threat to the supply electricity. 
In a reliable and secure power grid, the electricity demand is monitored by a suitable level of production. Transmission and distribution companies assure the transfer of electrons from power plants to end-users. The transmission network comprised of a large capacity of highvoltage power lines, which connect the power plants to electrical distributor companies (Barben, 2010).

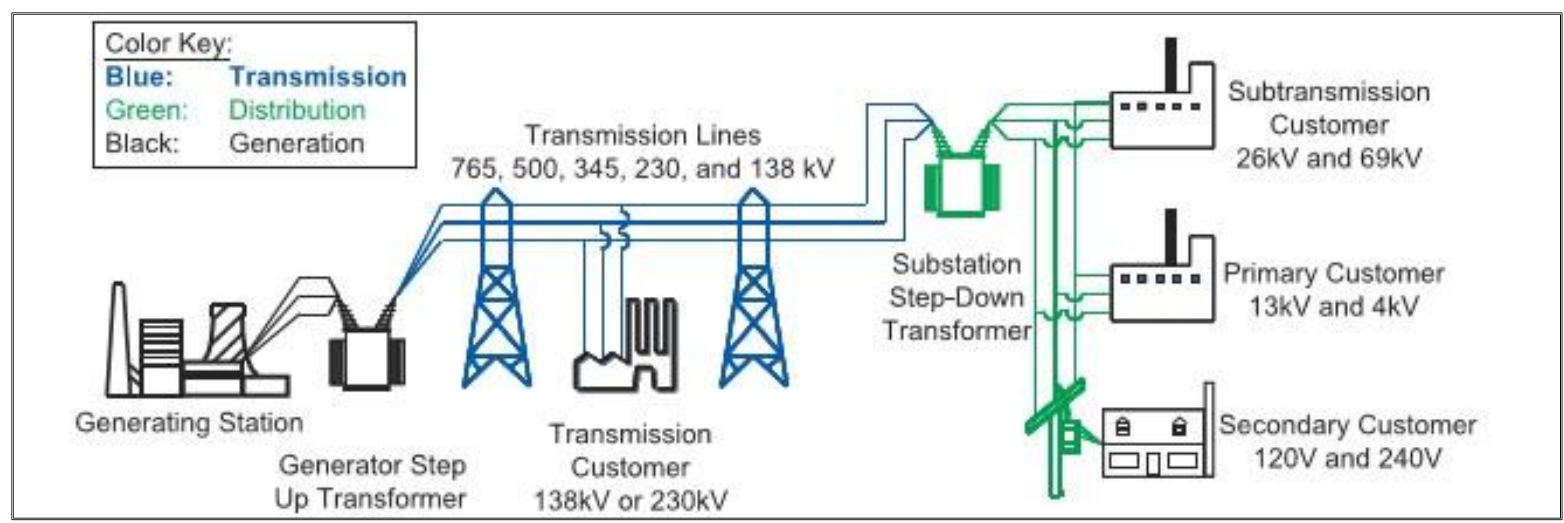

Figure 1: Illustration of primary electricity system (Liscouski \& Elliot, 2004)

Climate variables such as temperature, wind speed, precipitation, heat and cold intensity, and wind direction influence power distribution and production. If there is a change in these variables, the thermal and non-thermal electric supply can suffer (Mideksa \& Kallbekken, 2010). Heat waves significantly impact power system operations, such as increased peak loads on the lines, generation capacity and reduction in transmission (Ke et al., 2016).

Table 1 represents a summary of the main power outages over the past 45 years. It shows the outages in the United States (US), Canada, Europe and the other parts of the world. The electric system failures are categorized by the date of occurrence, weather conditions, location of the failure, size of the population suffered by the failure, and the duration of 
the electricity outage. The major cause of the grid failure is snow storms (including ice storms), and mainly occurs in the United States and Canada from December to March (McLinn, 2009).

Table 1: Breakdown of Major Grid Failures by cause (McLinn, 2009)

\begin{tabular}{|l|l|l|l|}
\hline Main Causes & US \& Canada & Europe & International \\
\hline "Snow Storm" & 13 failures & 3 failures & 3 failures \\
\hline Summer Storm & 11 failures & 2 failures & 1 failures \\
\hline Hurricane & 8 failures & None & None \\
\hline High Winds & 8 failures & 1 failures & 3 failures \\
\hline Unknown & 3 failures & 8 failures & 11 failures \\
\hline Substation & 3 failures & 2 failures & 7 failures \\
\hline Transmission line & 3 failures & 2 failures & 4 failures \\
failures & & & 4 failures \\
\hline Lightning strike & 3 failures & None & Nailures \\
\hline "Heat wave" & 2 failures & 2 failures & 12 failures \\
\hline Other & 4 failures & 7 failures & 27 failures \\
\hline Total & 57 failures & & 4 \\
\hline
\end{tabular}

Out of 57 outages in the US and Canada, 41 outages occurred in the US and 14 in Canada ( 2 events are in common due to intense winter storms). Canada has more power failures than expected. The summer and winter storms, high winds and hurricanes constituted 11 out of 14 in Canada (McLinn, 2009). 
Ontario has a strategic plan regarding its energy system that consists of administering and governing the long-term requirement of electricity. Electricity is generated through sources like wind, solar, hydropower, bioenergy, natural gas and nuclear power (Lysyk, 2015). Energy consumers are encouraged to conserve by cutting down their electricity consumption during peak hours (Lysyk, 2015). The transmission system in Ontario is responsible for moving electricity at large voltages, over distances starting from generation sites to the local distribution companies, who are assigned to deliver electricity to consumers (Lysyk, 2015). Ontario's energy sector currently serves 13.8 million customers ("population by year”, 2016). Ontario has a generation capacity of total 37,313 megawatts (MW); the energy sources comprise of 3 nuclear power stations (12,947 MW), 154 hydroelectric stations (8505.4 MW), 26 oil/natural gas stations (10,037.5 MW) and 29 other renewable sources such as solar, wind and biomass etc. (Lysyk, 2015). The demand is supplied through local generation as well as available imports (Lysyk, 2015). At present, the power demand is 18,131 MW ("Power data," 2016). In August 2006, the highest summer peak demand recorded at $27,005 \mathrm{MW}$, which is a $3 \%$ increase as compared to the previous peak demand in July 2005 at 26,160 MW (Zareipour, Caizares \& Bhattacharya, 2007).

On December 21, 2013, an ice storm came in Southern Ontario, Quebec and the Maritimes produced extreme high wind, freezing rain and ice pellets. There was a sharp drop in temperature, which caused 30 millimeters of ice accumulation on infrastructures and trees. Due to the ice storm, more than 600,000 electricity users were without electric power (McGillivray, Conway \& Marchionda, 2014). The power outage lasted up to ten days, causing damages in 27 municipalities across Ontario (McGillivray et al., 2014). The city of Toronto suffered critically and lost over 106 million dollars in damages caused by the shutdown. The 
cost of insured losses was up to 200 million dollars (Armenakis \& Nirupama, 2014).

The highest electricity demand in Ontario is seen in the summers as users tend to use more electricity for air conditioning to battle hot climate and humidity ("Understanding the Impact", 2012). Due to increase in the electricity demand at businesses, schools, and homes, extreme heat can cause damage to the infrastructure, causing inefficiency in the power lines and overheat the grid (OCCIAR, 2015). Low power supply and an increased demand can worsen the situation and severely affect the reliability and sustainability of the power plant, resulting in blackouts (Franco \& Sanstad, 2008).

Figure 2 shows Ontario's electricity demand during a heat wave that occurred between June $19^{\text {th }}$ and $21^{\text {st }}, 2012$. On June $13^{\text {th }}$, the peak demand was above $17,000 \mathrm{MW}$ when the weather was sunny and the temperature was $20^{\circ} \mathrm{C}$. On June $20^{\text {th }}$, the temperature rose to $34^{\circ} \mathrm{C}$ resulting in an increase of the electricity demand by $40 \%$ ("Understanding the Impact", 2012).

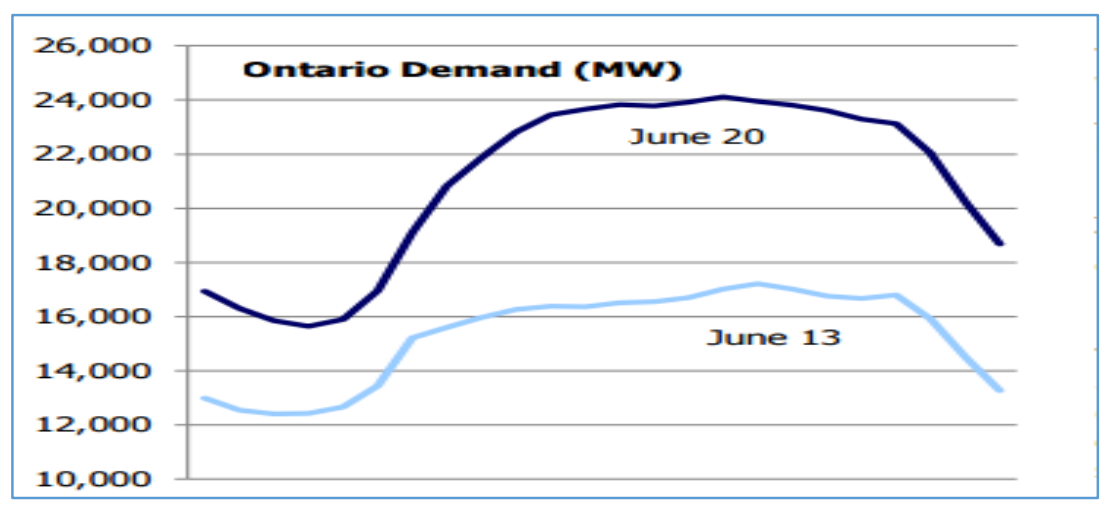

Figure 2: Example of Ontario's electricity demand during a heatwave in June 2012 (Understanding the Impact", 2012)

Climate change adaptation measures are needed to lower the chances of the system failure in an extreme weather event. These actions can help to prevent blackouts in the future and build a strong sustainable system. In past years, the emergence of the energy market has 
drastically updated the operation planning activities of power systems. There is a greater need to develop new technologies to fulfill the requirements of the generation and distribution sectors of electricity so that they can respond appropriately to additional energy requirements and challenges caused by extreme weather events.

The agent-based model (ABM) proposed in the context of conceptual models will test the complexity of Ontario's electric grid in extreme weather and check the resilience of grid structure. The research focuses on the generation and distribution sectors, which are affected in the past heat waves and ice storms in Ontario. In this research, the term resilience defines as the electricity grid's ability to return back to its original working state after a major weather event disturbance (Singh et al., 2015).

The model is at an early stage of development and needs to be improved to resemble the current electricity grid. There are limitations involved in this simulation model, one limitation is the incorporation of the local distribution companies. In order to ease the complexity of the model, there are 10 local distribution companies (LDCs) instead of 72 LDCs (in current electricity grid). The simulation model focuses only on Ontario's electricity grid and does not include its external power interconnection with other jurisdiction such as Manitoba, Quebec, New York, Minnesota and Michigan. 


\subsection{Research Problem}

Electricity is essential for human development and is a prime accelerator for the success of society. Due to power outages, the sustainability and reliability of the electrical system are threatened. Damage can cause the grid to fail due to extreme weather conditions, and the sudden storms and weather conditions can cause a huge loss to the economy and general assets. Extreme weather conditions can disturb the electrical production and block the transmission and production of power. Climate change adaptation measures are important more than ever to enhance system resiliency and prevent blackouts and reduce damage to the power grid in the future.

There is limited research conducted on testing the resilience of the electricity grid of Ontario during an extreme weather event using an agent-based model. This study fills the research gap by using an agent-based model technique to analyze the impact of severe weather on the electricity sector and the need for adaptation measures to build a system with high resiliency in Ontario. This thesis also provides an initial stage of simulation model to test the severity level and frequency of occurrence of a heat wave and ice storms on Ontario's grid. The electricity sector needs to develop a holistic approach, which comprises of institutional and technological approaches (Aivalioti, 2015). The power companies, transmission lines, distribution network, consumers, government and other agents all play a significant role in helping to secure the electricity grid during extreme weather events (Aivalioti, 2015). There is a high chance that future ice storms and heat waves will occur frequently and cause system vulnerability. Therefore, the electricity sector needs to adopt adequate measures that can be implemented to secure the grid. 


\subsection{Research Objective}

The research objective is to develop an agent-based model of Ontario's electricity grid to simulate extreme weather events and their impacts on electricity grid. The simulation model will analyze two extreme weather events: heat waves and ice storms. The model will assess conditions based on severity and frequency levels of the events.

\subsection{Structure of the methodology}

A power grid is a complex system, and an attempt to create a power grid faces enormous challenges which include multi-agent behaviors such as distribution, generation, consumption and storage systems by using several automation computing systems and control variables (de Durana et al., 2014).

An agent-based modeling ( $\mathrm{ABM})$ approach is used to build a dynamic computational model to address the research objective. The layout of Ontario's electricity grid is constructed along with severity and frequency as weather parameters of extreme weather events. A stress test is done on the electricity demand to check the resiliency of the system during extreme weather events. In this model, ABM initiates the heat wave and ice storm based on severity levels (low, moderate and high) and frequency of occurrence rate 1 to 10 (per month). Once the simulation runs, it shows a random behavior of the generation plant's failure and how the distributor companies are balancing the change in electricity demand during the extreme weather event. Graphs and simulation interfaces are captured to explain the outcome. 


\subsection{Organization of the Thesis}

This thesis analyzes the impact of extreme weather events on the electricity grid of Ontario. Two scenarios of extreme weather phenomena (i.e. a heat wave and ice storm) were constructed based on their severity level and frequency of occurrence in different regions of Ontario.

Chapter 2 presents a thorough literature review of the agent-based modeling approaches and compares them to other modeling approaches. Ontario's electricity grid and the major historical weather events are discussed along with their severe impact on the power grid.

In Chapter 3, Agent-based modeling is applied to Ontario power system subject to the heat wave and ice storm. A simulation was run multiple times to see the effect on the grid.

Chapter 4 shows the simulation results, which includes the main simulation interface, distributor interface and map view of the simulation for different severity level and frequency during heat waves and ice storms.

Chapter 5 discusses the key findings, challenges, recommendations and adaptation measures to help prevent blackouts and build resilience to system failures in the future. 


\section{CHAPTER 2: LITERATURE REVIEW}

This chapter includes a thorough literature review of Ontario's electricity grid, Agent-based modeling and extreme weather events impacting the electricity grid.

\subsection{Geographical location of Ontario}

Canada's second largest province is Ontario, which covers an area of approximately 1 million $\mathrm{km}^{2}$ extending from $42^{\circ} \mathrm{N}$ to $57^{\circ} \mathrm{N}$ latitude and from $75^{\circ} \mathrm{W}$ to $95^{\circ} \mathrm{W}$ longitude (Baldwin, Desloges \& Band, 2011). The climate of Ontario is usually humid, except for the areas that are influenced by Hudson Bay, which have a maritime atmosphere. There are three primary sources of air that affect Ontario's climate (as cited in Baldwin, Desloges \& Band, 2011):

- $\quad$ Dry and cold polar air which comes from the north is the leading component during the season of winter

- The polar air of Pacific passing over the western plains

- $\quad$ The moist, subtropical and warm air from the Gulf of Mexico and the Atlantic Ocean

Temperatures rise above $30^{\circ} \mathrm{C}\left(86^{\circ} \mathrm{F}\right)$ in the summer, while a drop below $-40^{\circ} \mathrm{C}\left(-40^{\circ} \mathrm{F}\right)$ is observed in winters. Ontario is surrounded by the provinces of Quebec (east), Manitoba (west) and James Bay and Hudson Bay in the North, while St. Lawrence River and the Great Lakes lie in the south (About Ontario, 2012).

\subsection{History of Ontario electricity grid}

In the 1990s, under pressure from the politicians and business leaders in London, Kitchener, Toronto and other communities, the government of Ontario and the local distribution 
utilities of the province were forced to develop the power distribution sector (Freeman, 1996).

Later on, Ontario Hydro was created in 1906 by the government of Ontario as a result of Hydro-Electric Power Commission of Ontario (HEPCO) (Bolton, 1913; Biggar, 1920; Daniels, 1996). Ontario Hydro was responsible for transmission and generation requirements of the province. Furthermore, in 1923, a total of 393 utilities were involved in distributing the electricity generated by Ontario Hydro (Nelles, 2005). The consumers paid a fixed amount as the cost of distribution, generation and transmission per kilowatt-hour ( $\mathrm{kWh}$ ) ("Ontario Distribution Sector", 2012).

Ontario started building nuclear plants in 1954. Canadian General Electric (G.E. Canada Inc.), Atomic Energy of Canada Limited (AECL) and Ontario Hydro collaborated to build Canada's first nuclear power generation plant known as "Nuclear Power Demonstration (NPD)"'(Canada's Nuclear History, 1997). In 1999, Ontario Hydro had a provincially guaranteed debt of around $\$ 38.1$ billion (Ontario's Electricity Financial Corporation, 2000). Due to the development of the Darlington plant, approximately $35 \%$ of the money paid to the utility power went towards paying interest on the provincial debt (Trebilcock \& Daniels, 2000).

The Energy Competition Act was passed in 1998, resulting in a reconstruction of Ontario Hydro, subsequently privatizing the major components (Rosenbloom \& Meadowcroft, 2014). The new companies were named as Ontario Power Generation Inc. (OPG), Ontario Electricity Financial Corporation (OEFC), Independent Market Operator (IMO), and Electrical Safety Authority (ESA). The industry standards of electricity were controlled by ESA while OEFC was responsible for governing the financial services of Ontario Hydro as well as its successors (Winfield \& Pembina Institute for Appropriate Development, 2004: Zareipour et al., 2007). 


\subsection{Ontario electricity system}

Dewees (2012), gives an overview of Ontario's electricity system, which comprises of three fundamentals: generation, transmission and distribution. Additionally, it is also comprised of a regulator, a market operator and a power purchase authority.

Key players involved are: Ministry of Energy (MOE), Ontario Power Generation (OPG), Hydro One, Ontario Energy Board (OEB), Independent Electricity System Operator (IESO), Ontario Power Authority (OPA), Local distribution companies (LDCs) (Dewees, 2012).

The Ministry of Energy (MOE) sets policies and creates system planning, which is to address conditions of procurement and planning of electricity supply.

Several Hydroelectric and nuclear generation plants are owned by Ontario Power

\section{Generation (OPG).}

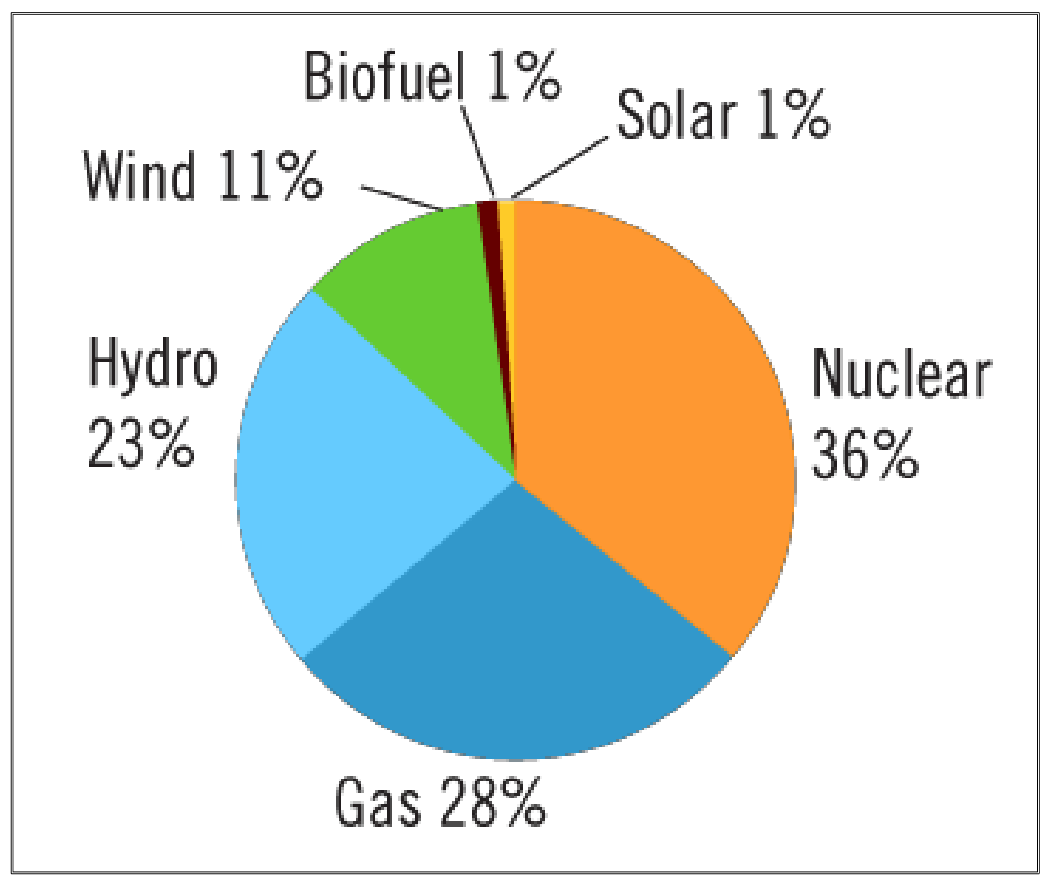

Figure 3: Generating resources as of September 22, 2016 (IESO supply mix, 2016) 
As of September 22, 2016, the current supply combination of Ontario's electricity system installed generation capacity totaled $36,050 \mathrm{MW}$. Of the total supply, 36\% or 12,978 MWof total is nuclear, $28 \%$ or $9,942 \mathrm{MW}$ of gas/oil, $24 \%$ or 9,942 of hydroelectric, $10 \%$ or $3923 \mathrm{MW}$ of wind power, 1\% or $495 \mathrm{MW}$ of biofuel and 1\% or $280 \mathrm{MW}$ of solar (Supply mix, 2016).

Around 30,662 MW (75\%) of the installed generation capacity in Ontario is owned by OPG. The total capacity of power generation in the province consists of 7,855 MW (25.6\%) of hydro and other renewable resources, 11,397 MW (37.2\%) of nuclear power plants, 4,976 MW (16.2\%) of oil/gas-fired power stations and 6,434 MW (21\%) of coal-fired generation facilities. Another important part of Ontario's portfolio is the energy imports from the neighbouring areas (Zareipour et al., 2007).

Hydro One (transmitter) has a high voltage transmission grid that is responsible for carrying the electricity produced by the generating stations and delivering to local distribution companies (LDCs) (Dewees, 2012).

Local distribution companies (LDCs) monitor low-voltage lines that distribute the electricity to the end users such as businesses and homes. There are 71 local distribution companies operating all across the province and are mainly owned by the municipalities. Hydro one is considered as local distribution company as well, the total numbers of LDCs are 72 as of December $31^{\text {st }} 2014$ (Lysyk, p. 243, 2015).

Ontario Energy Board (OEB) is a regulator and is liable for regulating the electricity prices charged by various generators, distribution utilities and the transmission company (Dewees, 2012). 
Operationally, the system is managed by the Independent Electricity System Operator (IESO), which takes bids for generation. The generations are then dispatched, advising each generator of the amount in which to generate (Dewees, 2012). It also manages self-governing planning for the generation of electricity, conservation, transmission and demand management (Lysyk, 2015).

System planning is done by Ontario Power Authority (OPA), which establishes

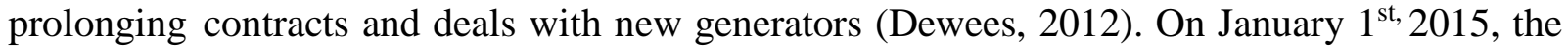
merging of IESO and OPA occurred after an amendment to the Electricity Act 1998. The new IESO became responsible for power system planning (Lysyk, 2015).

The electricity markets such as Michigan, Minnesota and New York are directly connected to the Ontario power network while the electricity markets in PJM and New England are indirectly connected to Ontario power network (Zareipour et al., 2007). Quebec and Manitoba are also connected to the Ontario power network despite having prominent energy transactions with various utilities in the US. The North East, North American and the Midwest structures and power interconnections can be directly affected by Ontario's electricity market (Zareipour et al., 2007). 


\subsection{Electricity supply and demand}

A sufficient amount of power supply is required at all times in order to meet the energy demand of the system. Components involved in the power supply are (Lysyk, 2015):

- Base load resources

- Peaking and intermediate resources

- Other reserves

Pfeifenberger, Spees \& Schumacher (2009), state that base load resources such as coal and nuclear are known for having low operating costs but high fixed costs. If they operate at full capacity, they are considered to have the most economical sources of cost. The peaking resources such as combustion turbines (CTs) are known for having greater operating costs and lower fixed costs. If they successfully run a small number of times, they can be considered to be lowest costing sources.

Intermediate resources can persistently run through the year, ensuring sufficient provision of energy to the system. Intermediate resources are adaptable and can easily ramp up and down depending upon the demand and changes observed throughout the day in other resources. Their fixed costs are lower than the high variable costs. An example of the intermediate resource is a combined cycle ("OPA resources" (a), 2016). The intermediate resources are found between the base load and peak load (Pfeifenberger et al., 2009). To meet peak demands, the system requires peaking resources. For example, the natural gas power plant is a useful resource that can meet the needs of the grid ("OPA resources" (b), 2016). The levels of generation of these resources can be changed quickly to meet the changes in demand, hence making it more flexible (Lysyk, 2015). 
The demand for electricity is periodic and cyclical on the daily, weekly and seasonal basis due to customers being highly affected by weather and commerce patterns. The hottest days are responsible for the extreme demand for most systems when the electrical load is high due to air conditioners (Pfeifenberger et al., 2009).

Load duration curve is shown in Figure 4, explaining how many hours of different load levels are reached per year. Maximum load determines the maximum expected load, which demonstrates the total quantity of generating capacity that needs to be installed in the system. The combination of generation assets that can reach the peak demand at very low cost is dependent upon the number of times it would be economical to run each unit (Pfeifenberger et al., 2009).

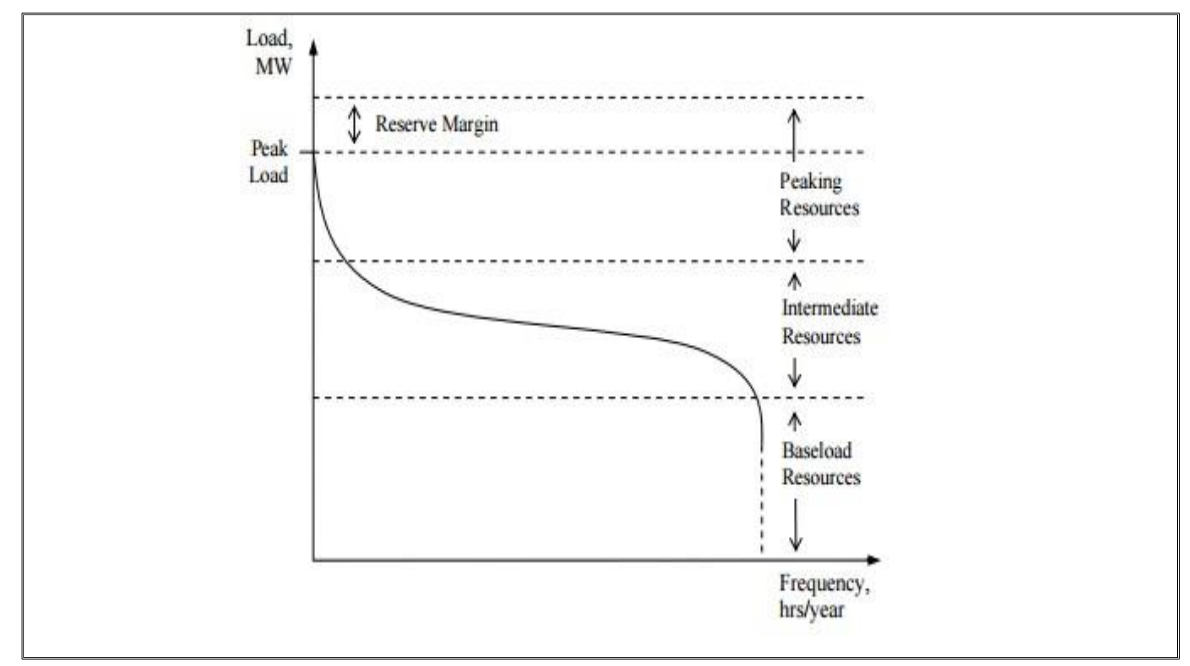

Figure 4: Illustration of a load duration curve which shows different generating resources that meet the supply demand at/or above a particular level at the lowest cost (Pfeifenberger, Spees \& Schumacher, 2009).

It is rare that the peaking resources are required to run. CTs usually supply the peaking capacity. However, the demand-side resources provide rising peak resources. During a shortage, instead of providing extra power from the power plants, some customers cut down their intake according to their contractual agreement or time varying prices (Pfeifenberger et 
al., 2009).

\section{a) Planning reserves and operation reserves}

Short \& Denholm (2006) discuss how sufficient capacity is ensured by planning reserves throughout the year. A peak reserve margin of about $10-18 \%$ is required by a typical system, which means a space of additional $10-18 \%$ as compared to their projected peak power demand is needed by a utility. It results in accuracy against failures of transmission or generator, the minimization of peak demands or events of the severe climate.

Some reserves are included as a part of Operation reserves, which respond to sudden demand fluctuations, or may be failures of generators or other systems. Generators that can ramp up their supply immediately and initiate are represented by operating reserves. A variety of categories of operating reserves is available and is also known as ancillary services (Short \& Denholm, 2006).

Ontario's operating reserve provides sufficient standby power to make up for a loss of more than one and a half of the largest generators of the province. Because of uncertainty about the expected levels of demand and the availability of supply, planning reserves are comparatively higher than the operating reserves (Lysyk, 2015).

\section{b) Surplus base load generation}

The power generated by the base load generator (such as nuclear and hydro) often exceeds the requirements of the system, which leads to a surplus base load generation (Mukherjee et al., 2015). To balance the demand and supply effectively, IESO takes the responsibility and ensures real-time operations. It can involve the request to the baseload 
generator plants to curtail (reduce) the production or shut down. It also involves exporting electricity to other jurisdictions (Lysyk, 2015).

\subsection{Introduction to Modeling and Computer Simulations}

The term modeling is known as a development of a model, which is characterized by a system (Klügl \& Bazzan, 2012). A primary target of a model is to simulate or represent an already existing or a real phenomenon (Gilbert, 2008). According to Maria (1997), simulation software helps in developing mathematical models that are expected to be used for the simulation study. The mathematical model is classified as being composed of the following (Maria, 1997):

- Deterministic: The values for the input and output are fixed.

- Stochastic: Either the input or the output may be probabilistic.

- Dynamic: These can be variable depending upon the time-varying interactions.

The simulation methods vary widely from qualitative to quantitative methods. The human and societal behaviour, along with social communications, can be investigated by social scientists. Some societies prefer models with details of parameters and variables in the quantitative method. However, others opt for simple models containing few parameters and values (Helbing, 2012).

Computer simulation is defined as the usage of a computational model to evaluate strategies for the procedure or to improve the understanding of a system's behaviour (Bandini, Manzoni, \& Vizzari, 2009). Applications of the simulation vary from organization theory to political science or sociology to economics or demography and help the user to understand 
the properties of complicated social systems (Diaz et al., 2010). There are three main features of simulation models, which are the prolongation of the system study, the durability of the state variables and the extent of randomness (Hewitt, 2002). Independent variables (as inputs) and dependent variables (as outputs) in computer programs can develop computational models (Gilbert, 2008).

The main concept of the agent-based model is to practice the simulated agents to generate a phenomenon that needs to be examined, replicated, or foreseen. This generative nature of modeling is yet a source of extreme potential to solve problems that have complications in simulation paradigms and conventional modeling to captivate the essential characteristics of the original system (Klügl \& Bazzan, 2012).

\subsection{History of Agent-Based Model}

Agent-based modeling (ABM) was developed in the 1940's. The first model developed was the cellular automata, which were initially simulated grids of on-off switches that interacted with their closest neighbours. However, the physical science community did not show much interest in ABM's until the 1990's (Buchanan, 2009).

The decade of 1970 was known to be the starting decade of ABM's practical approaches. In 1971, Thomas Schelling generated a model, which was "Dynamic models of segregation" (Schelling, 1971). The model is found to be abstract. However, in the US and some other urban centers, it has been very dominant in the recent studies to understand the perseverance of segregation (Gilbert, 2008). Firstly, the same coloured clusters of the household are 
unpredictable as well as interesting, by seeing the movement rule of the individual agents. Secondly, it is a model having a single parameter, named as "tolerance". Third, the behaviour is monitored to be robust because of the emergent clustering (Gilbert, 2008). Schelling (1971) proposed that ABMs should have autonomous and self-governing agents that assure an aggregate and observed outcome while working in a shared environment.

Later in the 1980s, Craig Reynolds developed the first biological agent-based model. His work was on flocking models that contained some social characteristics. He attempted to model the real life based on biological agents that were named as artificial life. The average motion obtained by the simulation of the flock was somehow the result of individually simulated birds and their dense interaction (Reynolds, 1987). ABM started expanding significantly in social sciences in the 1990s. Epstein \& Axtell (1996) developed a large-scale ABM, Sugarscape, which helped to explore, examine and analyze the role of certain social phenomena like combat, sexual reproduction, pollution, seasonal migrations, transmission of disease and culture.

\subsection{Agent-Based Model}

In the present day, agent-based model ( $\mathrm{ABM})$ has been profoundly gaining acceptance and avidity in many fields of social science (Bankes, 2002). Agent-based modeling is considered a form of computational social science, which involves construction of the models that are computer programs. The concept of modeling is familiar in social sciences i.e. to create a simple representation of "social reality" that helps to define a simple process in which one admits the operation of the reality (Gilbert, 2008). 
The systems of statistical modeling and differential equations are used widely. The two of these have equally played significant roles in their contributions to social science. Both of these methods are also considered to be somehow unrealistic or restrictive because of their limitations in solving detailed-oriented problems (Bankes, 2002). Many researchers consider differential equation as an alternative to $\mathrm{ABM}$, which is not correct. The set of differential equation portrays the dynamics of one of the constituent units of the system, which can also consider as an ABM (Bonabeau, 2002). Rand \& Rust (2011) proposed that marketing phenomena are complicated as they are emergent outcomes of individual agents like distributors, sellers and consumers. The actions and motivations of these agents combine, resulting in an unforeseen pattern. These typical patterns are used to evaluate and affect the choices of individuals. It is probable that the diffusion patterns arising from the cooperation of many consumers may be much more complicated than the rules of adoption of the individuals. Hence, the straightforward rules may be responsible for the generation of emergent patterns. ABM is then used to simulate these patterns.

In agent-based modeling ( $\mathrm{ABM})$, a system is developed based on a collection of autonomous decision-making entities called agents. Individually, every agent determines its situation and then according to a given set of rules, it makes a decision. Agents may propagate different behaviors for their representative systems, an example of such behaviours are production, consumption, and sale. The competitive and repeated interaction and communication among the agents are characteristics of ABM (Epstein \& Axtell, 1996; Axelrod, 1997; Bonabeau, 2002). Agent-based modeling substantially forms an artificial society that addresses reallife scenarios and challenges to it. In $\mathrm{ABM}$, there are three main components that are highlighted. These components are agents, environments and their interactions (Chan, Son \& 
Macal, 2010).

\subsection{Component of Agent-Based Model}

\section{Agents:}

There is no universal definition of the term "agent" (Macal \& North, 2005). Few modellers favour any individual constituent be it model or software or an individual as an agent (Bonabeau 2002; Macal \& North, 2005). The features and properties of agents are defined beforehand (Chhatwal \& He, 2015). An essential attribute of ABM is that the agents can communicate. They can pass on messages and information to each other and act as per the instructions received in those messages (Gilbert, pg.5, 2008). The environment plays a useful role in the interaction and communication of agents (Chhatwal \& He, 2015). Agents can decay or reproduce and can adapt and learn new behaviours from other agents (Chhatwal \& He, 2015).

Characteristics of an agent defined by Macal \& North (2005) are:

- An agent is an individual that can be identified as discrete, having a set of characteristics and guidelines dictating its behaviours as well as the decision-making skills.

- Agents are discrete and self-contained. A boundary is required isolating an agent with its unique and discrete characteristics.

- Agents communicate with other agents residing in the same habitat and environment.

- Certain protocols are available for agents to interact with other agents, for example, communication protocols and the efficiency to react to the surroundings.

- Agents can recognize and differentiate between the attributes of other agents.

- According to the behaviour of each agent, they have goals to achieve. 
- Agents are sovereign and can direct themselves. An agent can operate independently in its surroundings and while dealing with other agents in a limited area of situations.

- An agent may be adaptable, having the capability to grasp and adapt behaviours over time depending on experience. Agents having rules can also alter their behaviour.

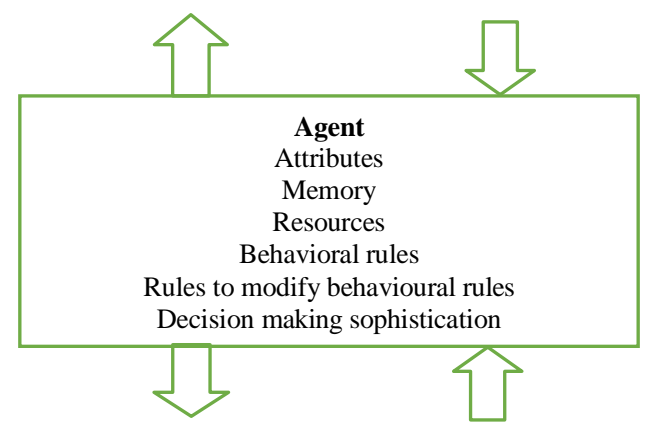

Figure 5: Conceptual description of an agent (Macal \& North, 2005)

\section{Interactions:}

The interaction and communication of the agents with each other and with their environments are designated. These agents determine the overall outcome and its conclusion. Hence the conditions engaged needs to be fundamental. It is not mandatory for the interactions inside the organizational structures to be represented explicitly, but they can occur implicitly. Although in the implemented ABM, the organizational structures may not be visible, yet it is important to consider them (Klügl \& Bazzan, 2012). There is a various amount of heterogeneous agents that are also dynamic with their characteristics and rules. The agent's behavioural rules differ in their composure. The amount of knowledge is recognized in the agent decision (cognitive load), and the amount of memory of events occurred in the past used by the agent in making decisions. Agents may also differ by their attributes, characteristics, and acquired resources (Macal \& North, 2005). 


\section{Environment:}

All the elements together are contained in one container as whole, known as the simulated environment, which is also the third part of ABM. To display the behaviour, agents always need a stage, which defines as an environment (Klügl \& Bazzan, 2012; Getchell, 2008). To execute ABM, a simulation infrastructure is necessary. The agents act in the environment, which is also their virtual world (Gilbert, pg.6, 2008). The environment provides a medium for agents to communicate with each other (Chhatwal \& He, 2015). The spatially explicit models are those in which a geographical space is represented as an environment (Gilbert, pg.6, 2008). It means that even if the agents were static, they would still occupy some location in the geometrical space (Castle \& Crooks, 2006). A few examples of such environments can be schools, hospitals, cities etc. (Chhatwal \& He, 2015). Environmental changes occurring dynamically because of the agent actions are usually passive instead of occurring based on the agent-time evolution. Hence it can be said that the environment state is always changing as per the actions of the agent rather than a fixed particular behaviour (Getchell, 2008).

\subsection{Why use Agent-Based Model?}

There are various mathematical models, which are frequently used; this includes differential equations of engineering and economic models, dynamic models of systems and statistical forecasters (Lempert, 2002). Two models that are frequently used are:

Econometric modeling: These empirical statistical models are used to fit the past data. The modeling approach can forecast for short periods of time (few quarters ahead) when the conditions remain steady. However, if more changes in the conditions are tested then the model 
fails to deliver a result (Farmer \& Foley, 2009).

Dynamic Stochastic General Equilibrium (DSGE): This type of model speculates a perfect world. DSGE models precisely specify the constraints and objectives encountered by firms and household. They also calculate the allocation and prices resulting from their market intervention in an environment that is not quite certain (Ruge-Murcia, 2007).

Agent based modeling is appropriate for the modeling systems containing individuals that can communicate frequently (Chan, Son, \& Macal, 2010). In comparison to System Dynamic (SD) and Discrete Event (DE) simulation models, ABM provides a system to mimic real life phenomena. ABM has capabilities that go beyond SD and DE simulation methods, particularly when the system contains active objects such as business units, vehicles, people, stocks and products within a time scale or individual behavior components (Borshchev \& Filippov, 2004)

ABMs are excellent at relating the agent's heterogeneous behaviour with varying information in different situations and decision rules to the large-scale behaviour of the entire system (Farmer \& Foley, 2009). Some social, biological and behavioural questions are answered by the new methods of agent-based modeling and multi-agent modeling. The examples include management of workforce, epidemics analysis and simulating the behaviour of consumers in the recent years (Khazaii, 2016).

$\mathrm{ABM}$ is chosen for its ability to handle complex scenarios and will be beneficial for future enhancement of the model. The model will allow updates of social and economic scenarios as they emerge with the addition of new variables. 


\subsection{Agent-Based Model Tools}

The simulation tools and ABM contribute to a development platform that is mature and can handle complex simulations (Niazi \& Hussain, 2009). Some Java-based software packages are available for ABM, for example, Mason, NetLogo, StarLogo (Wilensky, 1999). Software like Swarm, Repast and AnyLogic are easily accessible. ABMs can also be created using conventional programming languages like Python, C++, and Java (Chhatwal \& He, 2015).

\subsection{Agent-Based Model Software: Anylogic}

Anylogic simulation software includes agent-based modeling. The modeling language is flexible, which makes it easier for the user to captivate the complication and variety of economic, business and social systems to any particular detail level. The graphical interface of AnyLogic, library objects, and the tool helps the user to develop models in diverse areas like logistics and manufacturers; business flows, behaviours of the consumer and patient, and human resources (Anylogic, 2016). This software greatly benefits engineers, human resource managers, supply chain analysts and strategic planners. AnyLogic contains several features that aid in the development of an ABM. The features include (Anylogic, 2016):

- Agent synchronization ("steps")

- Creation of agents and model architecture

- It allows a user to develop a spatial animation and mobility of the agent

- The communication of an agent and other agents

- The native Java environment provides the multi-platform support. The platform is supported by operating systems such as Windows, Mac and Linux. 


\subsection{General advantages of Agent-Based Model}

$\mathrm{ABM}$ is a useful tool for representing complex energy demand variables such as spatial constraints and social interactions. ABM is not limited to rational agent behaviours like other modeling approaches and it can also theorize micro details into system level equations (Rai \& Henry, 2016).

The modeling of ABM includes studying the behaviours of agents and deciphering them into a set of rules for agents to follow. The social researchers very often inspect and monitor behavioural patterns, which are not easily analytically described. They can be explained in the "what if" conditions. One technique provided by ABM can replicate these patterns to study unexpected outcomes (Garcia, 2005). The main three advantages are discussed as:

i) The individual agent bodies and entities when communicated, result in emergent phenomena, which are captured by ABM (Bazghandi, 2012; Castle \& Crooks, 2006; Bonabeau, 2002).

ii) The $\mathrm{ABM}$ provides a realistic definition of a system. Sometimes, $\mathrm{ABM}$ is legitimate in representing and simulating a system that is made up of behavioural entities. The model developed by ABM is close to real-life scenarios (Bazghandi, 2012; Castle, \& Crooks, 2006; Bonabeau, 2002).

iii) $\quad \mathrm{ABM}$ is adaptable. Its flexible nature can be monitored in some dimensions. For example, it is simple to add more agents to an ABM. The complexity of agents can also be tuned by a natural framework provided by the ABM, controlling the degree of rationality, its behaviour, evolving and learning 
abilities as well as the communication rules (Bazghandi, 2012; Castle, \& Crooks, 2006; Bonabeau, 2002).

\subsection{Agent-Based Model and electricity market}

A review of past researchers shows that $\mathrm{ABM}$ can be done on energy markets.

Bollinger (2011) stated that agents are characterized as actors in the energy infrastructure. During simulation, some scenarios of policies and climate come in association with the agents. The characteristics and features of these situations significantly affect the opinions and decisions taken by these agents. It also affects the infrastructure elements that need to be developed over time.

Weildlich \& Veit (2008) discusses an agent-based electricity simulation in which the most common agents are load-serving entities, system/market operator and generators. The simulation may consist of a representation of a transmission system, regulator agents, retail customers or more, all depending on the questions of research. Agents can compose of other neighbouring agents yet forming a hierarchy similar to utilities.

Bollinger (2011) described a model called "proof-of-concept" that was designed to explore the flexibility and resilience of the Dutch infrastructure of electricity to climate change. This model contains the producers, consumers, transmission system operators, and import/export linkages. It is linked with a tool with powerful flow analysis enabling functionality captures as well as transmission grid limitations. It is determined and examined by the model how the seasonal and extreme patterns of weather can affect the flexibility of the electricity infrastructure, along with the necessary parameters of economic and grid operations. 
Macal \& North (2005) describes the application of ABM on the electric power market. Electricity Market Complex Adaptive System (EMCAS) is an agent-based model of electricity designed to investigate restructuring of the market and its deregulation. It also helps in understanding the association of a competitive market on the availability, reliability, and prices of electricity. The differences of restructured markets are captured by various types of agents, which include the demand companies, generation companies, independent system operators, regulators, consumers and transmission companies.

Rastegar, Guerci \& Cincotti (2009) discusses the Italian electricity market and how the thermal power plants influence the zonal and national price level on daily loads. A further review discusses load profile of day to day and all the thermal power plants installed are brought under observation. The cases that have been studied are a) The real situation b) Cost-based case c) Final case. In the last case, the best suitable strategy is learned by the generation companies according to some reinforcement algorithm. At the national level, the empirical validation reveals that the model has accurately cloned and replicated the historical data except for a few peak load hours.

Visudhiphan (2003), the ongoing and latest techniques and approaches that are used for modeling electricity spot markets have been discussed. These models are found to be static oligopoly models, which ensure the provision of top-down analysis with no consideration of market participants interacting dynamically. An alternate model is presented in this study, known as an agent-based model, which is used in the analysis of various market conditions. Markets, where some participants engage in different activities like sealed bid auctions to buy or sell electricity on a regular basis, are known as multi-agent systems. An 
agent-based model is chosen to represent these market characteristics. These agent-based models comprise of various power-producing agents, which possess different and non-uniform generating unit portfolios. This model could be a valuable tool for system planners, market participants, and regulators.

\subsection{Literature Review: Extreme weather event (Heat wave) and impact on electrical components}

Hines, Balasubramaniam \& Sanchez (2009) in his research defines a blackout as any unplanned interruption of electricity service to its consumers for more than 5 minutes. However, shorter outages less than 5 minutes are not to be considered because they are known to be power quality events. The outages are categorized in three dimensions, which are: time, size and cause.

The major part of the power system looks similar to what it used to be around 50 years ago. It is, however, accessible to the huge power blackouts likely to occur due to worse weather conditions. In severe climate and weather scenarios, the ice storms or heat waves are the primary impacts, which people may experience a change in climate. The general consent is that the energy requirements increases for energy demands related to heating and cooling (Wilbanks, 2007).

According to Kezunovic, Dobson \& Dong, 2008 and Beard et al., 2010, the initial disturbance in the electrical system (caused by an extreme weather event) can increase the chances of the blackouts and the extent of the disturbance spreads through cascading failures. Extreme weather conditions like the heat wave tend to increase the power load on 
the power system triggering cascading failure.

Cascading failures is a term used to explain a chain reaction of failures, which cause large blackouts of electricity transmission systems (Dobson et al., 2007). An accurate definition by North American Electric Reliability Corporation (NERC) of cascading outages is "the uncontrollable and excessive loss of any load of system facility due to voltage collapse, thermal overload or loss of synchronism, other than those generating as an outcome of fault isolation" (North American Electric Reliability Council [NERC], 2005). A regular power blackout has a primary disturbance or trigger events followed by a chain of cascading events. Furthermore, every event makes the system more stressed and weakened. Short circuits in transmission lines are the examples of initial disturbances that are caused by human error, untrimmed trees and worse weather conditions (Dobson et al., 2007).

Power outages can occur due to numerous reasons for example disasters, and natural disturbances (Fig.6). Events created by humans are responsible for one-third of the power outages such as working errors supply shortages, lack of maintenance and poor power grids (Hines et al., 2009). 


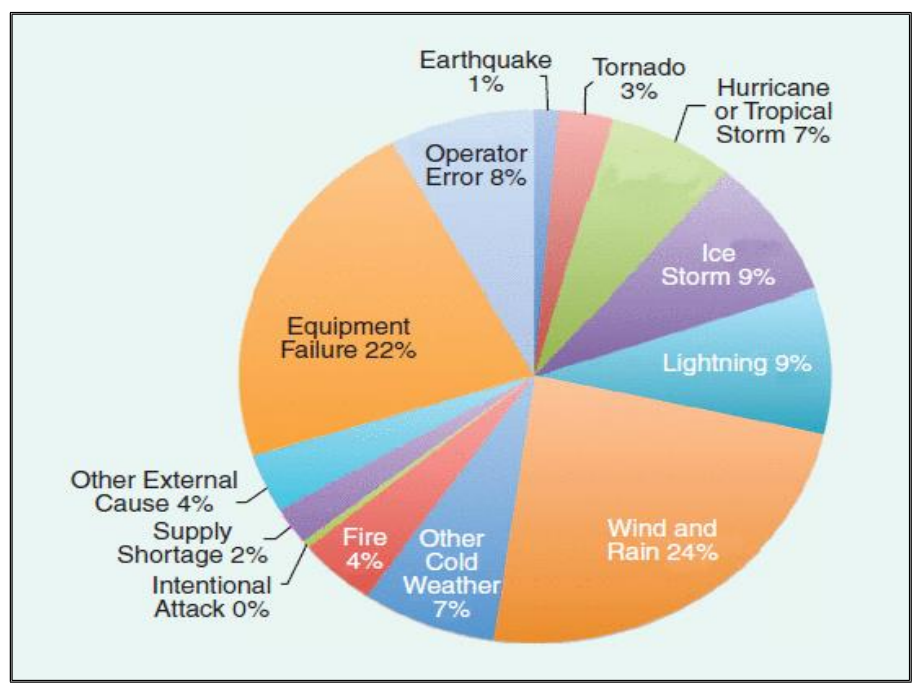

Figure 6: Causes of the power grid failure resulting in a blackout. Data from NERC records (1984-2006) (as cited in Hines, Balasubramaniam \& Sanchez, 2009)

NERC has assembled data of power blackouts that have previously affected 50,000 customers or 300 MW of load. Figure 7 shows the historical data of blackouts from 1984 to 2006 (Hines et al., 2009)

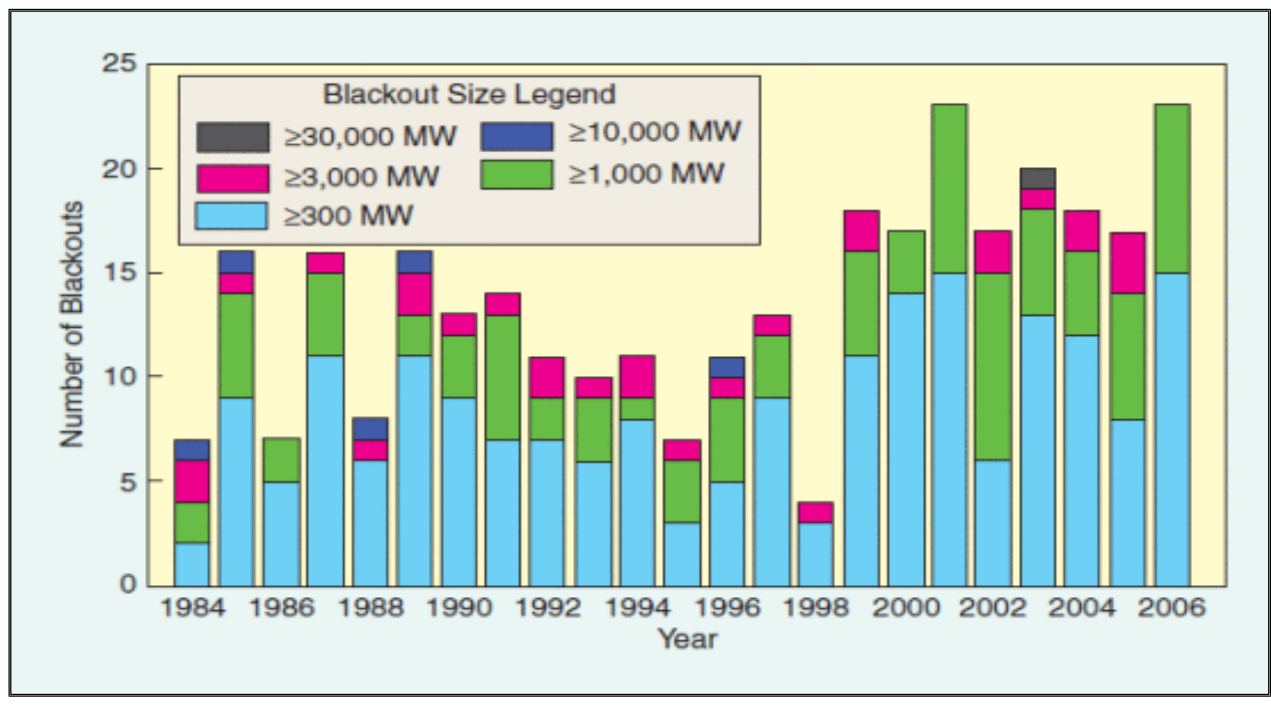

Figure 7: The number of major blackouts in North America for 1984-2006 (data from NERC) (as cited in Hines, Balasubramaniam \& Sanchez, 2009) 


\subsubsection{Heat wave}

Heat waves have vast impacts on the various stakeholders associated with human development. No consensus is available on a single heat wave definition as various heatmonitoring systems have a different threshold. Usually, hot periods of unusually long duration are considered to be a heat wave (Nairn \& Fawcett, 2011). Environment Canada offers a methodical and absolute definition of a heat wave i.e. "a period of more than three consecutive days of extreme temperature at or above $32{ }^{\circ} \mathrm{C} "$ (Weather Glossary, 2013). Intense positive withdrawals from maximum normal temperature derive heat waves in summer season (De, Dube, $\&$ Rao, 2005).

According to Smoyer-Tomic, Kuhn \& Hudson (2003), there are three key features of heat waves which are responsible for altering their impact: 1) Frequency 2) Duration 3) Intensity.

Frequency is a given number of events during the summer season for an extended period. Intensity and duration are considered in several definitions of a heatwave, such as the absolute definition of a heat wave defined above by Environment Canada. The severity of a heat wave influence is not dependent on higher frequencies of hot and humid conditions (Smoyer-Tomic et al., 2003). In the early season of summers, the heat waves are found to be much more intense, and they often last for long times. 


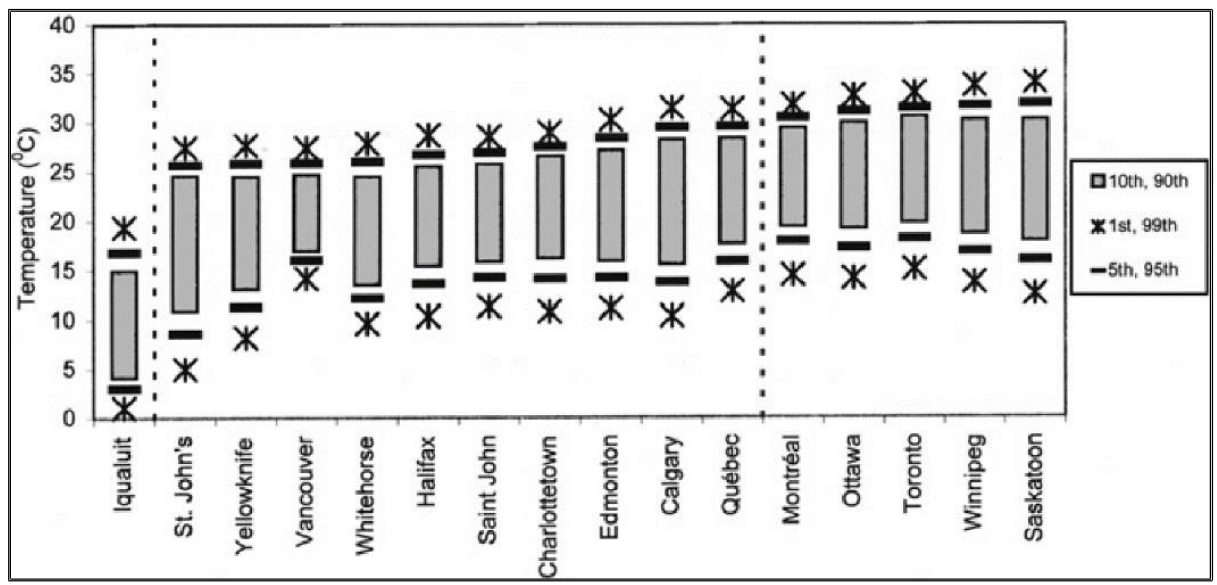

Figure 8: Maximum temperature percentile is shown during the summer ( $1^{\text {st }} \mathrm{June}-31^{\text {st }}$ August. $)$ the data is recorded for Canadian cities (1961-1990). Temperature data is recorded close/within the city or the airport's weather station. The dashed line on the right-hand side represents cities with maximum temperature percentile $\left(95^{\text {th }}\right.$ percentile), temperature $>25^{\circ} \mathrm{C}$ and $30^{\circ} \mathrm{C}$ (as cited in Smoyer-Tomic, Kuhn \& Hudson, 2003).

Figure 8 shows an analysis of intervals and cycles for 16 stations from $1^{\text {st }}$ June to $31^{\text {st }}$ August. The periods represent central cities from all three territories and ten provinces. The outcomes exhibit that the events of high heat stress have mostly affected major areas of Canada. These events were mainly occurring in Quebec and Ontario. The highest number of intense heat events in Canada is in Toronto, with an average of 4 episodes each year for a period record of 62 years (Smoyer-Tomic et al., 2003).

The efficiency and reliability of the power systems are often threatened by the intense and frequent seasonal heat waves. The generation, distribution, transmission and demand of electricity are significantly affected by the increased temperatures. Such high temperatures are responsible for blackouts and are highly costly for the economy (Aivalioti, 2015). Due to the intense and frequent heat wave, the electrical equipment gets affected which reduces cool-down time thus exceeding the designed limits set for safety causing a failure (Singh et al., 
2015).

Vine (2012) addresses California's electricity sector, which faces three significant challenges. The primary challenge is the increase in energy demand as the temperature increases. Presently, air conditioning is the main reason for the increasing electricity demand in peak summer hours. The next challenge is the capability of the electricity generation system according to the changes in climate. A few renewable sources of power such as hydropower are exposed to climate changes. The third challenge is due to the risk posed by climate change on distribution and transmission networks and few other constituents of electricity framework.

System capacity can be affected by high temperatures to produce adequate electricity supply to meet the demand, which sometimes results in a failure throughout the system. Renewable energy generators are also affected by heat waves. The production of electricity is slowed down if the generation facilities work at a decreased capacity or lower efficiency which can result in a shut down for a short duration (Aivalioti, 2015).

Mansur et al., 2008, concludes that high consumption of energy like gas, electricity and oil is used during winter and summer time. The overall change in climate might probably increase the use of electricity consumption on cooling, but it will lower the use of other fuels for heating.

Figure 9, Ke et al., 2016 illustrates the effects of a heat wave on the power grid. Heat waves could have substantial impacts on power system process, such as increased peak loads, and mitigate transmission and generation capacity, as conceptually illustrated (Ke et al., 2016) 


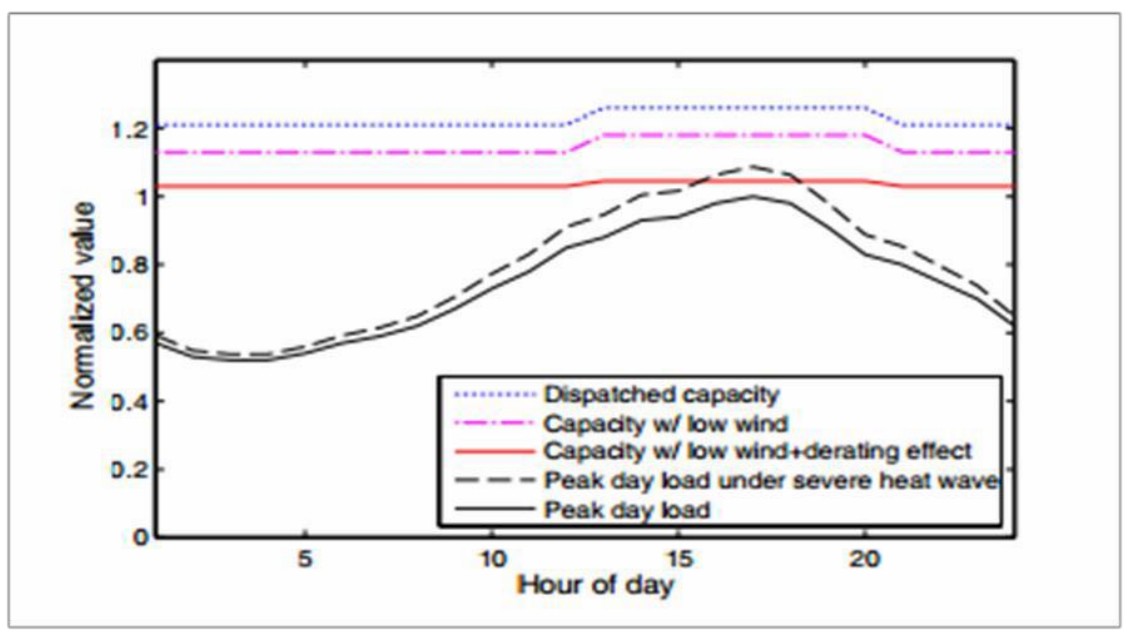

Figure 9: Illustration of impacts of heat waves on power system operation (Ke et al., 2016)

Beard et al., 2010, stated that the peak load and as stressed power system components would increase during warm and hot summer day. Furthermore, thermal limits are restrictive during high-temperature days. If the components are not derated, then they may age faster or fail more frequently, requiring much more maintenance and sooner replacements. Severe weather may reduce the availability of the generation sources. For instance, the wind generation plant can shut down due to high winds. An extreme wind gust causes conductor and tower damages.

The warm temperatures of night time and electric-powered cooling seasons can be fulfilled by the same amount of power generation capacity needed to balance the demand on a hot day in summer. During nighttime, the energy demand levels are low compared to the energy demand in the daytime (Hammer \& Parshall, 2009).

In the major outage event of 2003, a huge number of transmission lines were set off, and failures were generated across the entire grid of electricity. The relatively small generating plant failures can be attributed to damages caused by trees falling on transmission lines. 
Cascading failure was triggered; it eliminated nearly all the power transmission lines in a large area (Abraham, Efford \& U.S.-Canada Power System Outage Task Force, 2004). Cascading failures caused a series of generation and transmission blackouts, which spread throughout New York, Michigan, Ontario, Connecticut, Northern Ohio and few parts of Pennsylvania (Talukdar et al., 2003).

When the electrical load is high, there are more chances of power dissipation as the current flowing through the transmission lines is in a greater amount. The metal conductors usually expand under high temperatures in high voltage transmission lines. It causes the transmission lines to incline more towards the ground (Abraham, Efford \& U.S.Canada Power System Outage Task Force 2004).

\subsection{Literature Review: Extreme weather event (Ice storm) and impact on electrical components}

Environment Canada defines criteria of weather conditions to issue a warning for the winter storms which are "a significant snowfall (warning criteria amount of snowfall) and a major snowfall ( $25 \mathrm{~cm}$ of ice or more within 24 hours) along with other types of cold weather parameters such as strong winds, freezing rain and extreme cold" ("Public Alerting Criteria", 2016).

According to American Meteorological Society, an ice storm is represented by "a fall of freezing liquid precipitation" ("Ice storms", 2012). Ice storms are caused by the formation of a layer of clear and smooth ice, also known as a glaze. It is formed on open objects like doors, trees, etc. by liquid precipitation of the freezing film (Klima \& Morgan, 
2015). One of the most destructive hazards of winter is the freezing rain, which occurs when the snow falls through two different layers in the atmosphere. The layers are a cold (below freezing) layer that freezes the water droplets forming an ice layer when it hits the ground and a warm (above freezing) layer, which melts the snow (Kerry et al., 1999). Ice deposits and the freezing rain are caused by warm moist air being submerged by cold, shallow air resulting in an inversion of temperature (Klima \& Morgan, 2015). Environment Canada uses alerting specifications to issue a warning when freezing rain occurs for two hours ("Public Alerting Criteria”, 2016).

In winter, occasional freezing rains are observed in the central areas of Canada. Eastern Canada experiences a higher rate of ice storms as compared to Western Canada because the air masses of maritime and arctic polar tends to meet there frequently (Kerry et al., 1999).

Klaassen et al., 2003, defines the characteristics of severe ice storms. The severity of an ice storm is dependent on the accumulation of ice, the span of the event, and the extent and location of the affected area. The accumulated ice is directly proportional to the amount of the freezing rain that fell during the storm. Events with less duration (1-2 hours), lower amounts of ice accumulate than the long-term events, which take place for 6-12 hours. An ice storm can impact an area ranging from a few hundreds of square kilometers to different regions that include provinces in Canada and the United States.

Ice storms can cause damages in the power grids due to ice accumulation on the poles and pylons, wirings and the trees in their surroundings (Druez, McComber \& Farzaneh, 1999; Wong and Miller, 2010; Campbell, 2012), results in prolonged blackouts for days, or sometimes weeks to get restored (Hines, Apt \& Talukdar, 2009). Ice storm causes significant damage to 
the electric power systems, which involve repair costs, direct restoration, inconvenience, business interruption and permanent loss of food, data, and perishable goods. A small blackout can compromise the state of the security system (Liu, Davidson \& Apanasovich, 2008).

Eastern Canada (Ontario, Quebec and the Maritimes) is vulnerable to ice storms. General weather patterns have a significant impact on the result of the ice formation process (Mirza, 2004). An ice storm in January 1998 was struck in the south-western Quebec and eastern Ontario. It is considered as a major historical ice storm due to its severity. There were 3 million people without electricity and around 600,000 people faced power failures in Ontario (Klaassen et al., 2003). Mirza (2004) discusses the aftereffects of 1998 ice storm as the power distribution and transmission experienced a loss of about 3 billion CAD. The devastation to high voltage distribution systems, transmission towers and transformers raised serious concerns about the durability of the distribution of power in Quebec and Ontario. The ice storm of 1998 caused massive damages to the distribution systems and electricity transmission in eastern Canada, which exhibits the susceptibility of the systems to the intense weather events.

During February $1^{\text {st }}$ and $3^{\text {rd }}, 2011$, the southern Canada, northeastern and central of US were struck by a massive winter storm. It was named as the "Groundhog's Day Blizzard of 2011 '. More than 20 inches $(50.8 \mathrm{~cm})$ of the snowfall was reported throughout the area. A few regions in the southern Ontario, Canada received 7.9 inches $(20 \mathrm{~cm})$ of snow ("Global Hazards", 2011). The storm brought ice and freezing rain to Ohio River Valley and Great Lakes as well. On $2^{\text {nd }}$ February, the damages were noticed due to heavy ice accumulation and high winds which left about 375,000 households in southern Canada and the US without electricity (“Global Hazards”, 2011). 
During $20^{\text {th }}$ to $23^{\text {rd }}$ December 2013, an extreme ice storm struck the eastern and central portions of Canada and the northeastern United States. The storm majorly hit southern and eastern Ontario. It was the second severe ice storm since 1998 to affect southern Quebec and eastern Ontario. More than 130,000 power blackouts were observed by Hydro One (which mostly serves in rural areas of Ontario). The ice storm in 2013 mainly affected Toronto (largest city of Canada). The heavy weight ice accumulation collapsed the utility poles and tree branches (Abi-Samra et al., 2014). Around 300,000 people were left with the power outage for three days and approximately tens of thousands for a week or more. The city of Toronto faced an average cost of over $\$ 106$ million. The cost of losses insured was around \$200 million (Armenakis \& Nirupama, 2014).

Chang et al., (2007) discusses a general structure to characterize the nature, severity and extent of the impact of infrastructure failure interdependencies (IFIs) for a major ice storm disaster in Canada. The electricity grid is an important example for exploring infrastructure failure interdependencies (IFIs). The rising electricity demand in extreme weather leads to the risk of large-scale electrical failures. The system is unable to produce enough electricity supply to meet the demand making the system vulnerable to disturbance.

Weak, broken and sagged tree limbs are often responsible for the power outages and damages in the electricity distribution network. The branches can fall down on the electrical distribution lines due to ice accumulation (Klaassen et al., 2003). Large capacities of power plants without the off-site power are difficult to start up. Restoration of the electricity supply takes a longer period, even if there is no damage to the equipment. Some power outages need extended periods of restoration. Several days or weeks can be taken to restore the consumer supply after an extreme weather event. Hence it seems acceptable to find 
a relationship between the duration and the size of the power outage (Hines et al., 2009). 


\section{CHAPTER 3: METHOD}

The method includes a data set, which is imported in the software (Anylogic), construction of agent-based modeling and detailed steps of applying ABM in Anylogic.

\subsection{Software}

Anylogic was used to analyze the effect of extreme weather events on the electricity grid. It is a popular agent-based modeling software. A free trial of the latest version, Anylogic 7.3.6, was used in this simulation (Anylogic, 2016). As the software was not purchased, the simulation model is developed based on the limited resources available in the free trial package.

\subsection{Data set}

The simulation model used secondary data, which includes reports published by Independent Electricity System Operator (IESO).

The analyzed components in the simulation includes:

1) Historical extreme weather event: ice storm and heat wave (as discussed in the literature review).

2) An excel file of the hourly zonal electricity demand of Ontario in 2013 is imported in Anylogic ("Data Directory", 2016).

3) A total number of generation plants based on their capacity and location (Lysyk, 2015) was created and imported as an excel file as well. 
4) A shapefile of transmission lines of Ontario is imported in the simulation model (DMTI Spatial Inc, 2015) with the help of ArcGIS, which is a Geographic Information System (GIS) software that allows a user to create, share and design analytics of a map (ESRI, 2015).

5) Temperature data was collected from weather stations per zone for 2013 (Historical Data, 2016).

6) The interactive zonal map of Ontario retrieved from IESO (IESO Zonal Map, 2016).

\section{Assumptions in the simulation model:}

- There are 72 local distribution companies in Ontario's electricity system. To ease the complexity of the system, a consolidation process is introduced. In this process, 72 local distribution companies are reduced to 10 local distribution companies ("Ontario Distribution Sector", 2012). Although the distribution companies are reduced in the simulation but the data remains the same as if there were 72 because the electricity generated by the generation plants provides the distribution companies to manage their zonal demand. The main purpose of the local distribution company is to provide electricity supply to the region. The simulation outcome based on this theory should not be effected as the generation plants are all connected to the local distribution company in the region and it would be easier to monitor the status of the region at a same time.

- The transmission lines are connecting the generation plant agent to the distributor agent. They are uploaded as shape file (.shp file) using ArcGIS software. The transmission lines are not considered as an agent and are manually connected.

- The generation plants are producing electricity supply to meet the system demand. There is no differentiating between the fuel types of the generator (Bollinger, 2011). 


\subsection{Agent-Based Model}

The simulation model is comprised of three elements: agents, decision rules, and an environment. In the simulation model, agents are the social component of the system; each agent has assigned a decision rule (Bollinger, 2011). Agents with their decision rules are allocated to a simulated environment in which they act according to the decision rules (Bollinger, 2011).

Agents: There are two agents in the simulated environment, which are:

- Generation plants: There are 148 generation plants in Ontario, which produce electricity. The number of generation plant remains constant.

- Local distribution companies: In this simulation model there are ten local distribution companies, which are assigned to monitor the zonal electricity demand as well as imports and exports.

\section{Decision Rules:}

Each agent allocated in the simulation model has a decision rule to follow. Generation plants produce the electricity to meet the daily demand during an extreme weather event and normal weather days. Each generation plant is connected to the main distributor of the zone, and the transfer of electricity is sent through the transmission lines. The local distribution companies are assigned to provide the electricity in their region and monitor the imports and exports of the neighbouring regions during an extreme weather event. 


\section{Environment:}

The environment is characterized by the extreme weather events based on severity level and frequency. The agents along with their decision rules exist in the simulated environment. The zonal GIS map of Ontario incorporates properties such as extreme weather events which are ice storms and heat waves based on their severity level. The severity level is further categorized based on low, moderate and extreme levels. Each severity level is based on temperature, duration, and change in electricity demand and supply. The behaviour of the electricity grid is analyzed by increasing the frequency of ice storms and heat waves as well as increasing the severity level. Heat waves and ice storms occur at different geographical locations which cause failure in the generation plants subsequently causing electricity demand to vary. However, the agents use the severity level to assess production and demand of electricity depending on the needs of the region (Bollinger, 2011).

\subsection{Designing of simulation model}

\section{Detailed Steps:}

- The programming language used in this simulation is Java.

- To build the electricity grid of Ontario in the simulation software. GIS space was used which helps to place the agents into a geospatial environment. It is defined by a GIS map which develops a network of agents to interact with other agents within allocated regions (Anylogic, 2016). The map of Ontario was located on the GIS map. 
- IESO interactive map (java.script) was used to extract the GIS regions for the zones division and mapping on the GIS map. The map of Ontario was divided into ten zones as defined by IESO (IESO Zonal Map, 2016).

- After defining zones, the next step was to assign agents on the GIS map:

Generation plants: There are 148 generation plants in the simulation along with their capacity rate $(\mathrm{MW})$. The generation plants are not differentiated by the type of energy fuel (such as nuclear, hydro, solar etc.) (Bollinger, 2011). The generation plant agents are assigned by their geographical coordinates. They are represented by white circles as shown in Figure 10.

Distribution companies: Although there are 72 local distribution companies in Ontario, in this model, there are 10 local distribution companies placed as the main distributor agent, assigned as one agent per zone. The distributor agents are shown as yellow icons in the ten zones, which are connected to generation plants in Figure 10. 


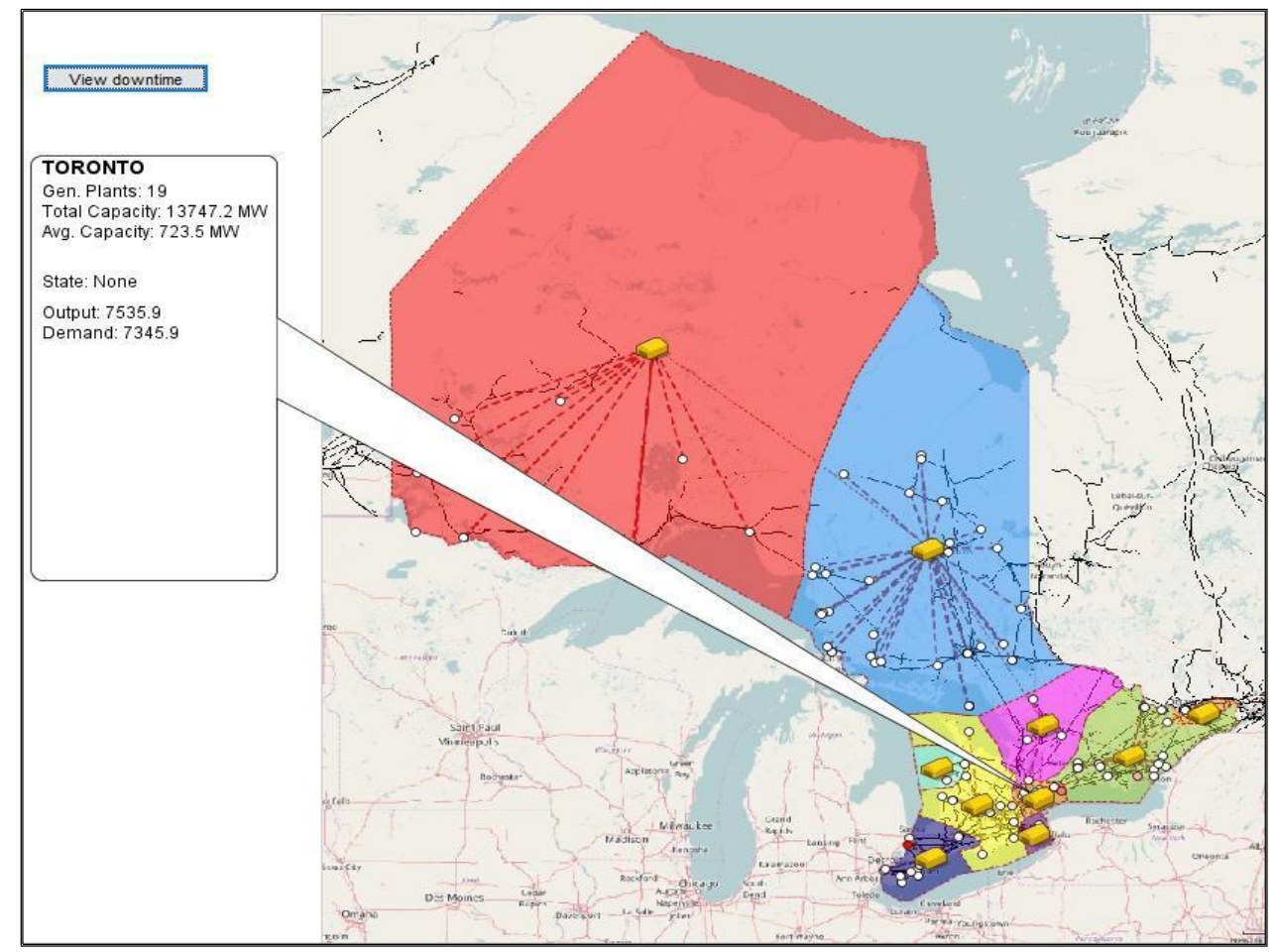

Figure 10: Map view of the electricity grid of Ontario on Anylogic, ten zones, generation plants (white circles) are connected by transmission lines (dotted lines) to distributor agents (yellow icon) (Anylogic, 2016)

In Figure 10, each region in the simulation shows the status of the grid displaying the number of the generation plants, total capacity produced by the generation plants and their average capacity, following with the demand and output rate of the region. The status shows "NONE" which means the region is meeting the demand and supply.

- After defining agents on the GIS map, each agent was allocated its decision rules which are:

- The generation plant agent produces the electricity in the region. The tables imported as an excel file in the software shows the generation capacity (MW), fuel type and location of each plant (Lysyk, 2015). Each zone shows the number of generation plants, 
total production (output), total capacity and the average capacity of the generation plant.

- Zonal electricity demand (2013) is used to analyze the electricity demand (Data Directory, 2016). It is also imported as an excel file in the software. The distributor agent handles the generation plants production (output) and monitors the internal and external demand to meet the zonal demand requirement. The distributor agent also handles import and export of electricity from the neighbouring zones. In the simulation, the local distributor agents are connected to each generation plant in the region as well as they are connected to their neighbouring zones through transmission lines. During an extreme weather event, if the electricity supply from generation plants cannot meet the electricity demand, the zone will send a help request to its neighboring zones to provide electricity to meet the increased demand.

A safety output level is defined to answer the help request, once a zone is producing $90 \%$ of its total capacity, it will start sending a help request to its neighbouring zones. There is a reserve output usually known as a reserve margin of $10 \%$, which is to be used only in emergencies such as failure to import power from neighbouring zone to the required zone. The reserve output is $10 \%$ of internal production that must not be used unless necessary (i.e. if importing more power is impossible). 


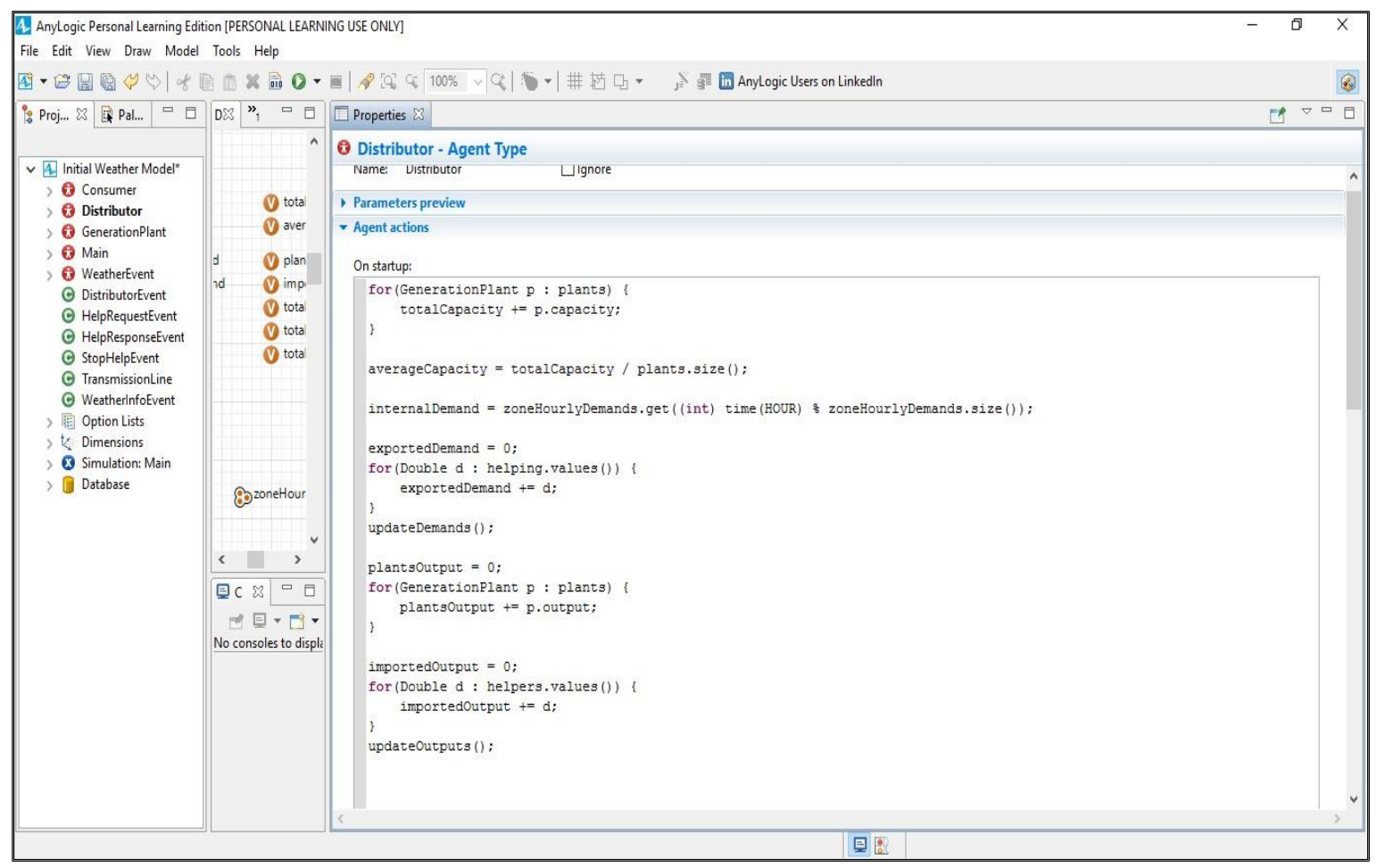

Figure 11: Setup of a distributor agent in Anylogic (Anylogic, 2016)

- The next step is to trigger an extreme weather event to affect the agents in the simulation. The heat wave occurs in May, June, July and August whereas ice storms take place in January, February and December.

- The input in the simulation, which will trigger the extreme weather event, is categorized by severity level (low, moderate and extreme) and frequency level on a scale of 1-10 per month in a region. Each severity category can be measured based on duration, change in demand and temperature for each zone. Frequency level "2" means that the heat wave/ ice storm occurs twice.

- The duration of the event is defined based on the definitions of the heat wave and ice storm. For low severity, the duration of the event will last up to 36 hours. For moderate and extreme severity level, the duration of event is up to 60 hours and 84 hours. The event in the simulation is considered to run for 12 hours per day. The reason for using 12 hours 
per day is due to the duration of an event not lasting up to 24 hours.

- A stress test is conducted on the change in demand/supply and temperature of the extreme weather event. During a heat wave, the consumers tend to use electricity which leads to a significant increase in the electricity demand. In order to test the additional demand requirement, the percentage scale of change in demand is taken into account. The change in demand percentages are tested and assigned to each severity level as shown in Table 3.

- Similar approach is used for an ice storm. During an intense ice storm, the primary reason for disturbance is ice accumulation on the lines which causes a shortage of electricity supply. A stress test is conducted on the supply to see if the electricity grid can handle the decrease of electricity supply. The change in supply are tested and assigned to each severity level as shown in Table 4.

- Below is an example of the Greater Toronto Area (GTA) zone. Table 2 is used to trigger a weather event in the simulation. 


\section{Greater Toronto Area:}

Table 2: Severity level (low, moderate and extreme) based on duration of heatwave and ice storm

\begin{tabular}{|c|c|c|c|c|}
\hline Severity & Duration (Hours) & $\begin{array}{c}\text { Minimum } \\
\text { Duration }\end{array}$ & $\begin{array}{c}\text { Average } \\
\text { Duration }\end{array}$ & $\begin{array}{c}\text { Maximum } \\
\text { Low }\end{array}$ \\
\hline Moderate & $0-60$ hours & 36 hours & 48 hours & 60 hours \\
\hline Extreme & $0-84$ hours & 60 hours & 72 hours & 84 hours \\
\hline
\end{tabular}

*Taking 12 hours per day (Heat wave and Ice Storm 7:00 am - 7:00 pm)

Table 3: Severity level (low, moderate and extreme) based on change in demand for heat wave

\begin{tabular}{|c|c|}
\hline Severity & Change in demand (additional demand) \\
\hline Low & $0 \%$ to $20 \%$ \\
\hline Moderate & $0 \%$ to $40 \%$ \\
\hline Extreme & $0 \%$ to $60 \%$ \\
\hline
\end{tabular}

*To test the change in demand, the multiplier is taken into account in the simulation to add the desired amount of additional demand. 
Table 4: Severity level (low, moderate and extreme) based on change in demand for Ice storm

\begin{tabular}{|c|c|}
\hline Severity & $\begin{array}{c}\text { Change in supply (Decrease in electricity } \\
\text { supply) }\end{array}$ \\
\hline Low & $0 \%$ to $10 \%$ \\
\hline Moderate & $0 \%$ to $30 \%$ \\
\hline Extreme & $0 \%$ to $50 \%$ \\
\hline
\end{tabular}

*To test the change in demand, the multiplier is taken into account in the simulation to add the desired amount of additional demand.

Table 5: Severity level (low, moderate and extreme) based on temperature for heat wave

\begin{tabular}{|c|c|}
\hline Severity & Temperature $^{\circ} \mathbf{C}$ \\
\hline Low & 34.7 \\
\hline Moderate & $34.7+4=38.7$ \\
\hline Extreme & $36.7+6=44.7$ \\
\hline
\end{tabular}

*Stress test for moderate and extreme temperature: increase of $4^{\circ} \mathrm{C}$ and $6^{\circ} \mathrm{C}$

Table 6: Severity level (low, moderate and extreme) based on temperature for ice storm

\begin{tabular}{|c|c|}
\hline Severity & Temperature $^{\circ} \mathbf{C}$ \\
\hline Low & -18.2 \\
\hline Moderate & $-18.2-4=-22.2$ \\
\hline Extreme & $-22.2-6=-28.2$ \\
\hline
\end{tabular}

${ }^{*}$ Stress test for moderate and extreme temperature: decrease of $4{ }^{\circ} \mathrm{C}$ and $6^{\circ} \mathrm{C}$. 
- The inputs based on the severity level have a direct impact on the agents. If the electricity does not meet the demand rate during an extreme weather event, the generation plant shows failure, whereas the distributor agent will monitor the zonal import and export and ramp their electricity supply to meet the change in zonal demand and fulfill the help request from the impacted zone.

- A random number generator is used to create randomness such as failure in a generation plant, frequency level (1-10), downtime of the generation plant, supply shortage, increase in demand and duration of the event which leads to a power failure. The random generator is applied through Anylogic using the Stochastic modeling approach. A scale of values is used as an independent variables (input) i.e. severity and frequency level. The random numbers are generated by seed values assigned by the user, example of this method is applied to severity level based on change in demand is $0 \%$ to $20 \%$ (low), $0 \%$ to $40 \%$ (moderate) and $0 \%$ to $60 \%$ (extreme). The random generator uses the seed values based on the variables chosen by the user to generate an outcome based on randomness in the simulation.

- In Table 7, a standard downtime of a generation plant is defined. The downtime of a generation plant when it fails during an extreme weather is described based on the size (capacity rate in MW) and duration. The size of the generation plant was categorized as small, medium and large. A random number generator is used to create randomness of a failure in generation plants. The outcome shows a state in the simulation, if the state is "NONE" it means that there are no failures during the extreme weather phenomena. If the state is "ERROR" it means that the generation plant has failed during 
an extreme weather event. Figure 12 shows an example of error state during an ice storm. The blue circle shows the distributor agent sending a help request to neighbouring regions to import and export the power.

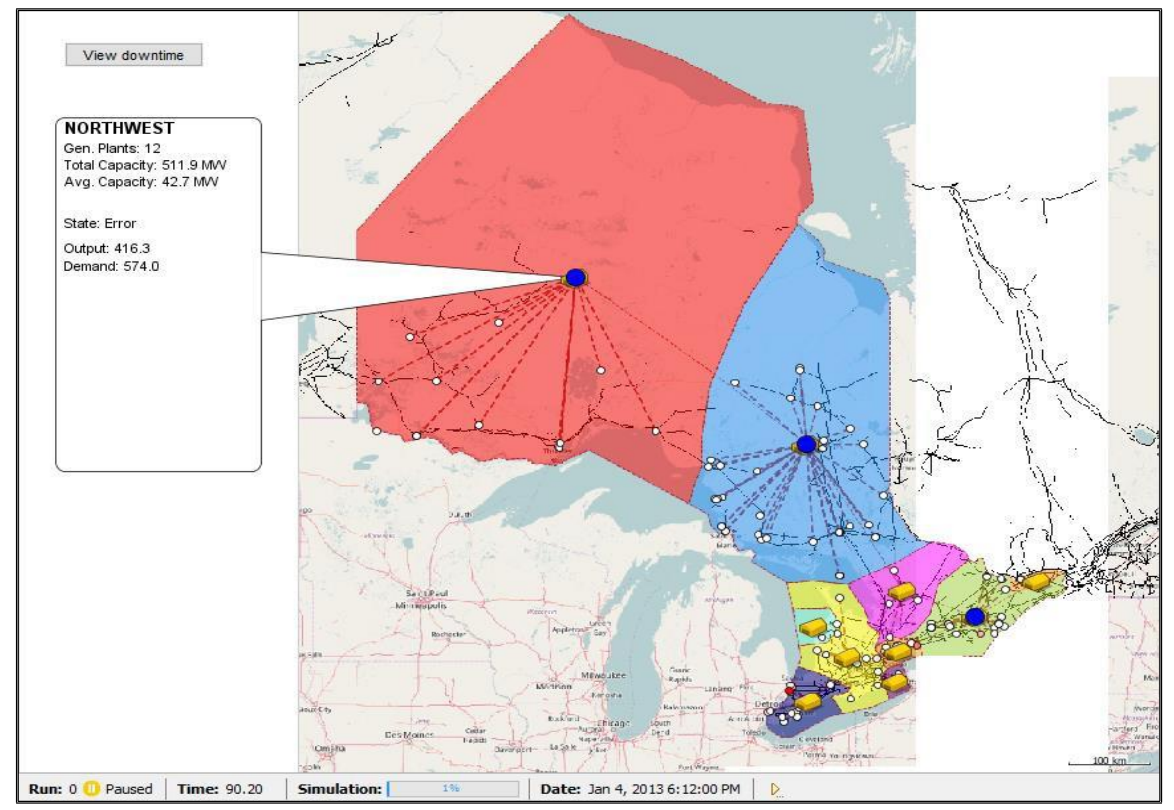

Figure 12: Map view of Northwest region shows an error state (Anylogic, 2016) 
Table 7: Downtime of 148 generation plants based on the size (capacity in MW)

\begin{tabular}{|c|c|c|c|}
\hline Severity & $\begin{array}{l}\text { Duration } \\
\text { (Hours) }\end{array}$ & MW (capacity) & Downtime (hours) \\
\hline Low & $\begin{array}{l}0-36 \\
\text { hours }\end{array}$ & $\begin{array}{l}\text { Small plant }=0.1 \mathrm{MW}-99 \\
\text { MW } \\
\text { Medium plant }=100 \mathrm{MW}-942 \\
\text { MW } \\
\text { Large plant }=1153 \mathrm{MW}-6426 \\
\text { MW }\end{array}$ & $\begin{array}{l}=0 \mathrm{hrs} \\
=0 \mathrm{hrs} \\
=0 \mathrm{hrs}\end{array}$ \\
\hline Moderate & $\begin{array}{l}0-60 \\
\text { hours }\end{array}$ & $\begin{array}{l}\text { Small plant }=0.1 \mathrm{MW}-99 \\
\text { MW } \\
\text { Medium plant }=100 \mathrm{MW}-942 \\
\text { MW } \\
\text { Large plant }=1153 \mathrm{MW}-6426 \\
\text { MW }\end{array}$ & $\begin{array}{l}=20 \mathrm{hrs} \\
=0 \mathrm{hrs} \\
=0 \mathrm{hrs}\end{array}$ \\
\hline Extreme & $\begin{array}{l}0-84 \\
\text { hours }\end{array}$ & $\begin{array}{l}\text { Small plant }=0.1 \mathrm{MW}-99 \\
\mathrm{MW} \\
\text { Medium plant }=100 \mathrm{MW}-942 \\
\text { MW } \\
\text { Large plant }=1153 \mathrm{MW}-6246 \\
\text { MW }\end{array}$ & $\begin{array}{l}=25 \mathrm{hrs} \\
=30 \mathrm{hrs} \\
=0 \mathrm{hrs}\end{array}$ \\
\hline
\end{tabular}

- Capacities for all small plants are set between 0.1 MW and 99 MW.

- Capacities for all medium plants are set between $100 \mathrm{MW}$ and $942 \mathrm{MW}$.

- Capacities for all large plants are set between $1153 \mathrm{MW}$ and $6246 \mathrm{MW}$.

- The geographical distribution of heat wave and ice storm is manually selected before running the simulation as shown in Figure 13. There are ten zones available on the interface for the simulation run. These zones can be tested based on different level of severity and frequency of the extreme weather event. Due to the weather events not occurring throughout the entire province, manual selection of zones is required. 
- The simulation is tested several times based on the low, moderate and extreme severity and frequency level. The graph and simulation interface are added in the results chapter.

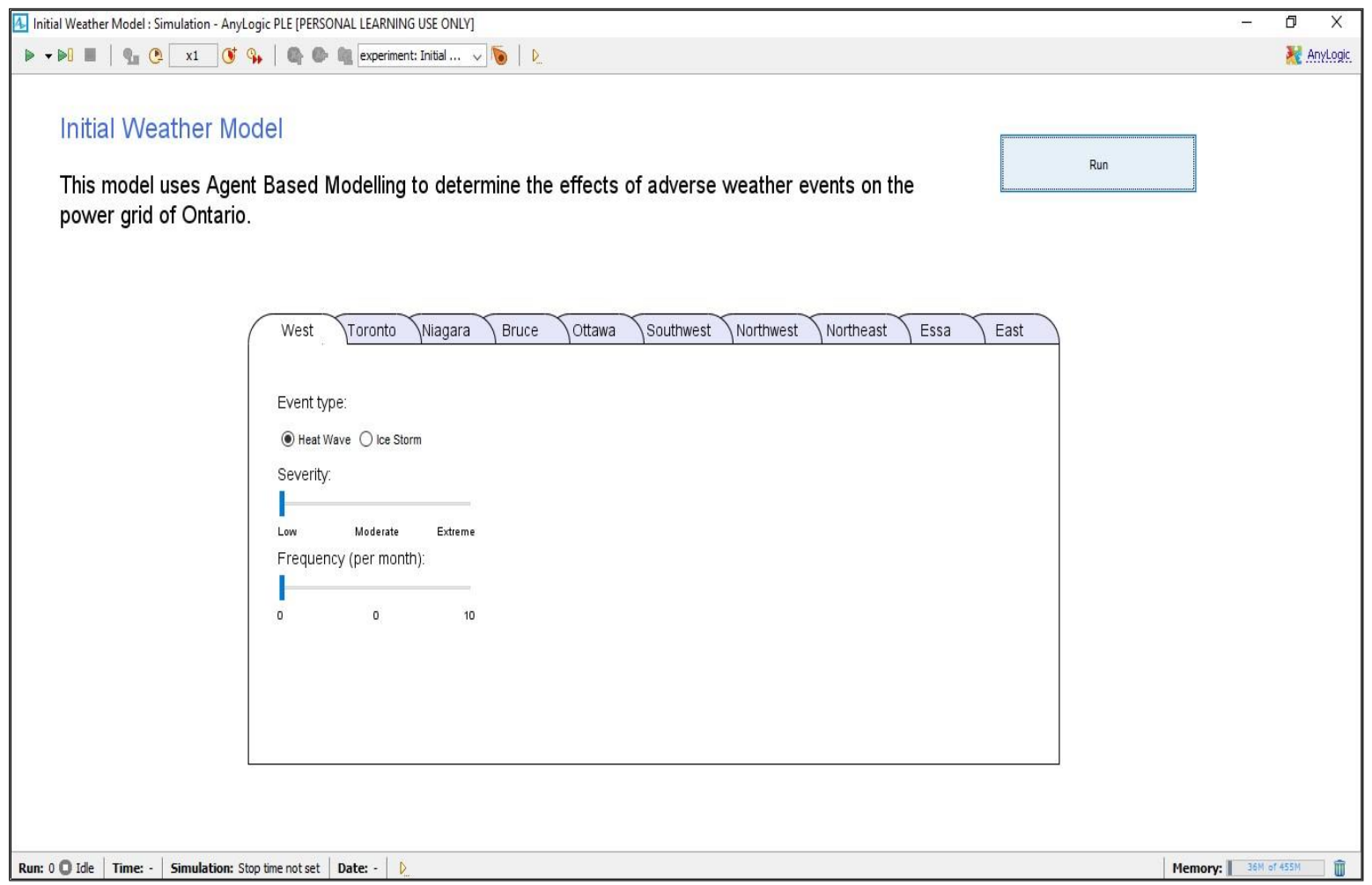

Figure 13: User-friendly interface which can test several scenarios with the help of the primary interface of the simulation, which defines the event type, severity, frequency for ten regions in Ontario (Anylogic, 2016) 


\section{Chapter 4: RESULTS}

This chapter shows the results obtained from the simulated model for heat waves and ice storms. The simulation tested the effect of these extreme weather events on the electricity grid.

Each region on the main simulation interface has a distributor agent interface which shows the status of the region displaying how the electricity is distributed throughout the region. There are three interfaces in the simulation showing results:

Main simulation interface: There are two color outputs in the main simulation interface, which indicate the grid's status. Figure 14A shows a green color output, which represents that the system is stable. A well-balanced grid indicates the energy production is meeting the electricity demand with the help of internal production, imports and exports from neighboring zones.

Figure 15A shows a red color output in the simulation interface, which represents the region is not meeting the electricity demand. Thus, the system is in a state of potential failure that may cause a blackout.

Map view of the simulation: The map view in Figure 14B shows ten regions of Ontario, each region shows its status of electricity production (output) and demand, the number of generation plants per region and their production capacity. 
Distributor agent interface: The distributor interface shows the status of the grid in the simulation (Figure 15B) of the selected region. It displays a graph of the following terms which are denoted as:

- Total power (total output production): Total internal production plus imports from the neighbouring zone

- Total Demand: Internal Demand plus exported demand

- Imports and exports: Imports and export from the neighbouring zone

- Internal demand: Internal demand of the specific zone

There are two cases for extreme weather event (heat wave and ice storm) which are discussed in this section.

\section{Case A: Heat wave}

The heat wave is triggered by the levels of severity: low, moderate and extreme. Two frequency levels are tested at 2 and 3 to observe failure (blackout) and resilience of the electricity grid. Heat waves occur from May to August (seasonal). The simulation model is configured with electricity demand/supply and weather station data for the duration of the year 2013 . The heat wave simulation was tested for May, June, July and August at different frequencies and severity levels. 
Simulation Run: Frequency level: 2 and 3, Severity level: Low, Regions: West, Greater Toronto Area, Bruce, Ottawa, Southwest, Essa and East

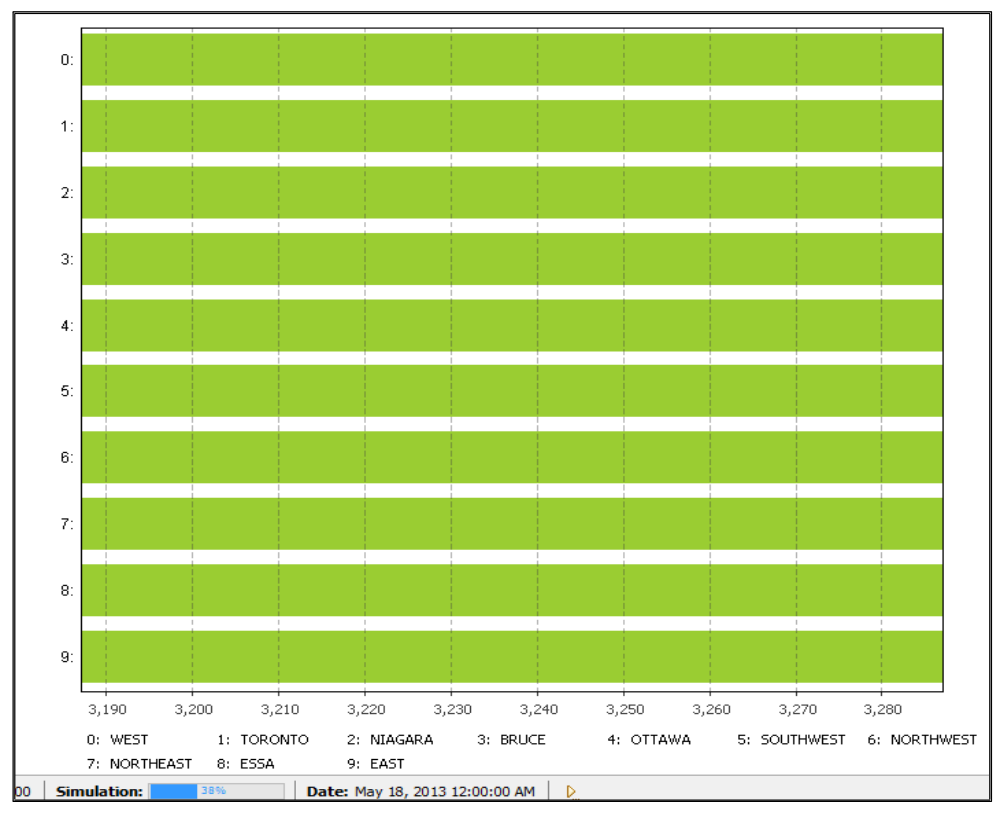

Figure 14A: For May 2013, Simulation interface shows the output of the electricity grid at severity level: low and frequency: 2 and 3, the system is handling the heat wave for the selected regions. No errors observed throughout the month (Anylogic, 2016).

Figure 14A demonstrates a simulation run for the month of May. The green output shows that the electrical grid for the regions of West, Greater Toronto Area, Bruce, Ottawa, Southwest, Essa and East are balancing the electricity demand and supply along with exports and imports during a heat wave based on severity level low and frequency level of 2 and 3. 


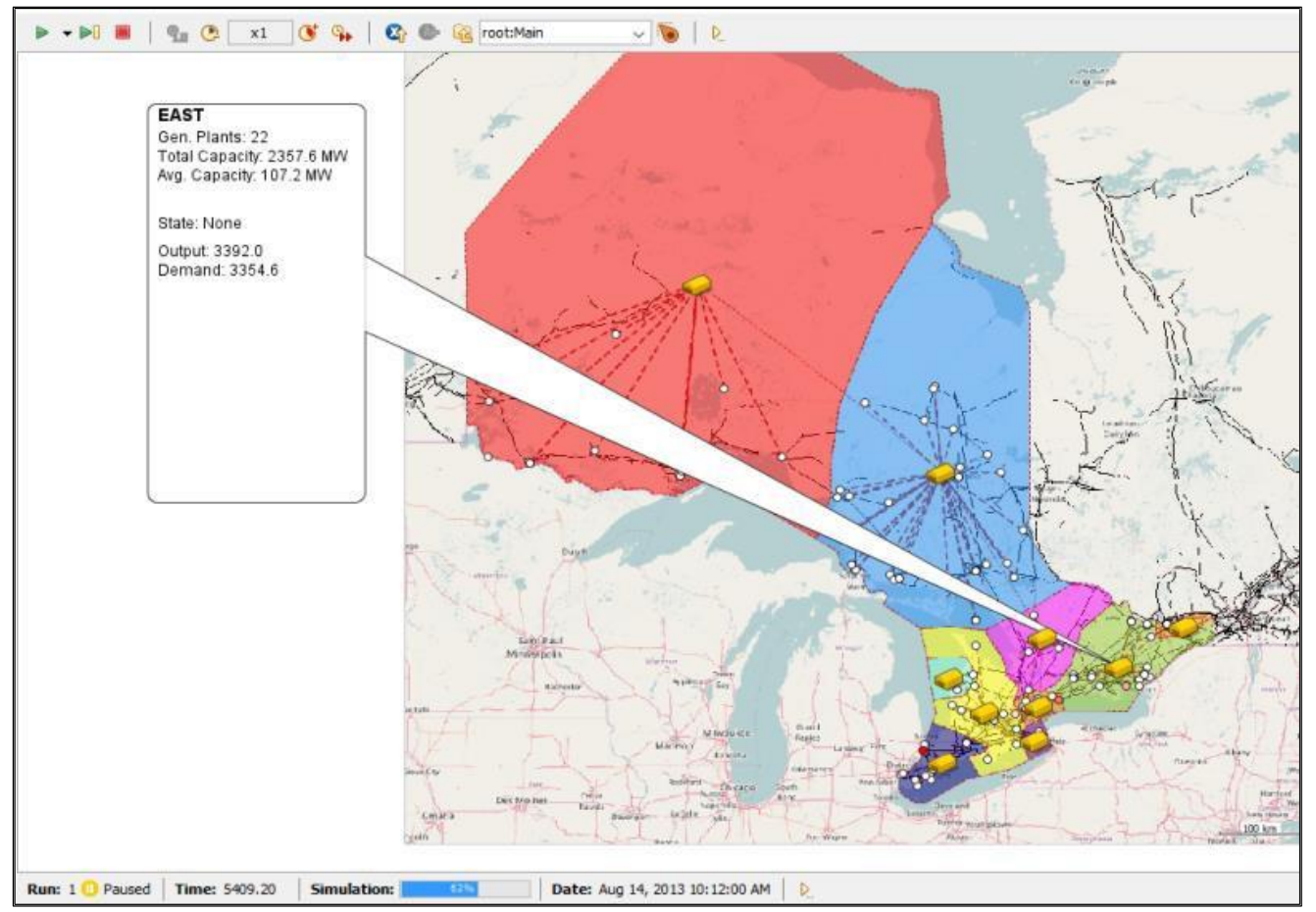

Figure 14B: Map view for August 2013, Simulation interface shows the output of the electricity grid at severity level: low and frequency: 2 , the system is handling the heat wave for the selected regions. State: None, no errors observed throughout the month (Anylogic, 2016).

Figure $14 \mathrm{~B}$ is a map view of the simulation. A region (East) is selected which shows the status of electricity production (output) and demand rate, the number of generation plants per region and their production capacity. The electrical grid is well balanced and is meeting required demand during a heat wave. 
Simulation Run: Frequency: 2, Severity level: Moderate, Regions: West, Greater Toronto Area, Bruce, Ottawa, Southwest, Essa and East

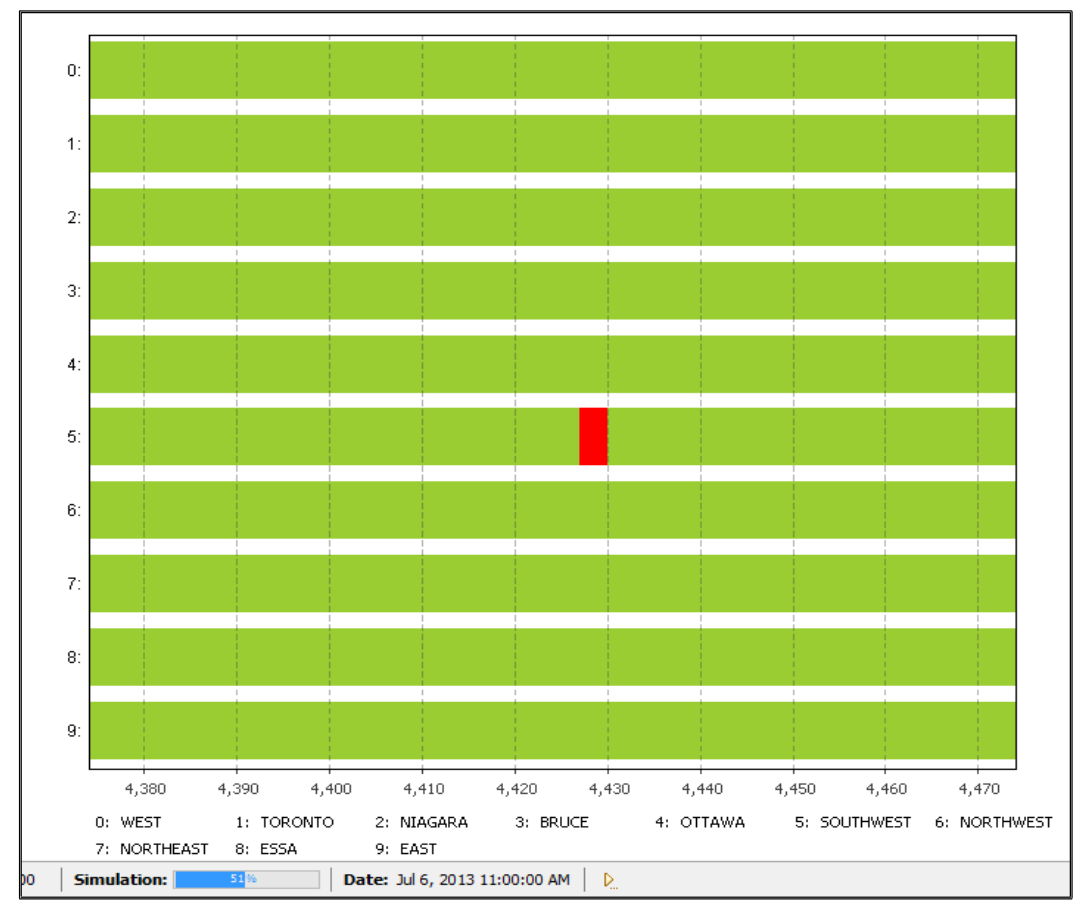

Figure 15A: For July 2013, Simulation interface shows the output of the electricity grid at severity level: moderate and frequency: 2, the system is handling the heat wave for the selected regions. One error in Southwest is observed throughout the month (Anylogic, 2016).

Figures $15 \mathrm{~A}$ demonstrates a simulation run for the month of July. The green output shows that the electrical grid for the regions of West, Greater Toronto Area, Bruce, Ottawa, Essa and East are managing the electricity demand and supply along with exports and imports during a heat wave based on moderate severity level and frequency level of 2. The Southwest region shows a red output (failure) for the duration of 4 hours. 


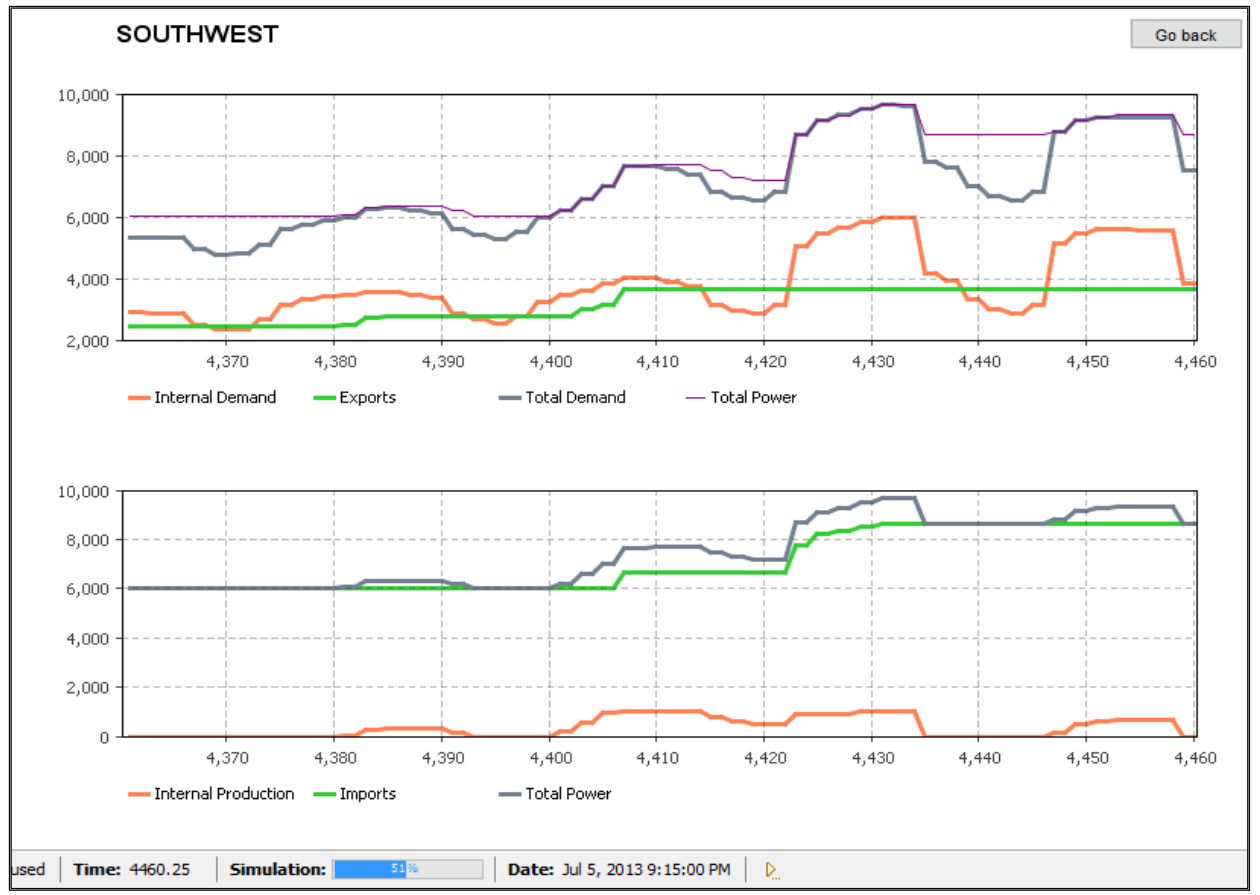

Figure 15B: Distributor interface shows the output of the electricity grid on severity level: moderate and frequency: 2, the system is handling the heat wave for the selected regions (Anylogic, 2016).

Figure 15B shows the distributor simulation interface of Southwest region, displaying the total power, total demand, imports and exports, internal demand and production. Figure $15 \mathrm{~B}$ shows on July $6^{\text {th }}$, between 4426 and 4430 hours of the month, the Southwest region showed a high increase in demand compared to the total power (total output production) for the duration of 4 hours. It means the generation plant is reaching close to its supply showing an alerting state of the system. As previously mentioned in the method for distributor agent logic, when distributor agents reach $90 \%$ of its total capacity, it is supposed to send a help request to its neighbouring zone to provide a supply to meet the zonal demand. As shown in the second graph, it received an import but it is not enough to meet the regional demand causing the system to go in a potential failure state. 


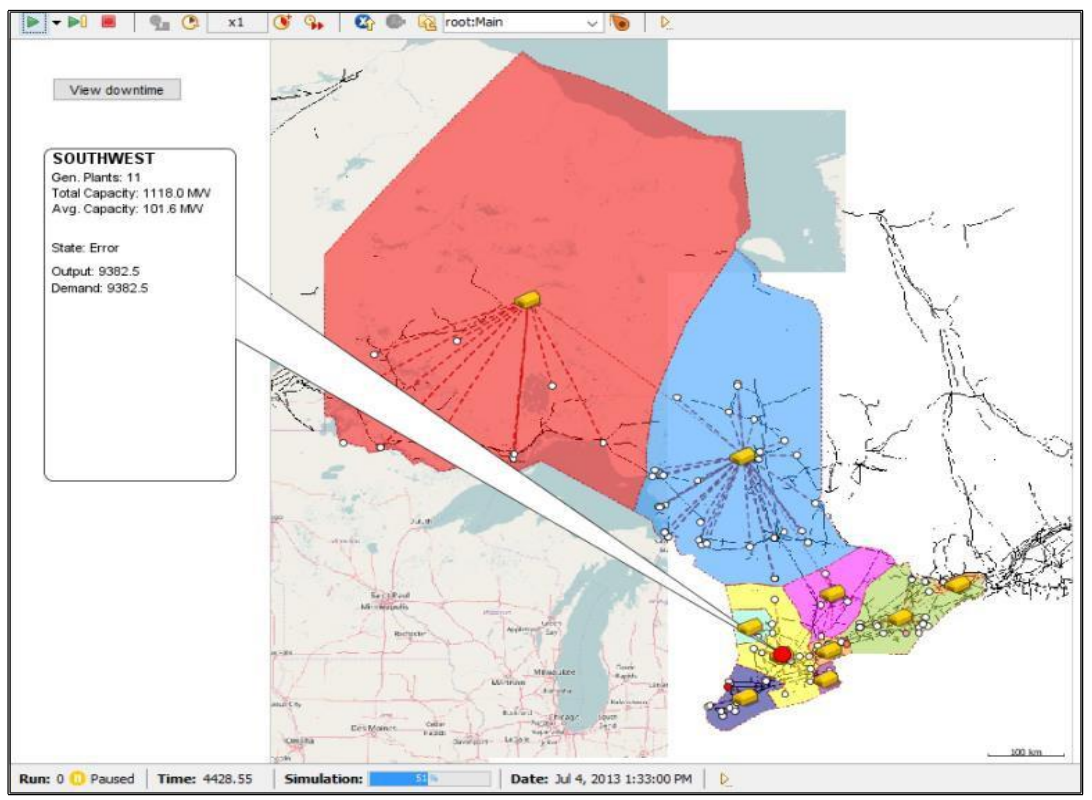

Figure 15C: Map view for July 2013, Simulation interface shows the output of the electricity grid at severity level: moderate and frequency: 2, the system is handling the heat wave for the selected regions. State: Error, one error is observed throughout the month (Anylogic, 2016).

Figure $15 \mathrm{C}$ is a map view of the simulation. Southwest region is selected which shows a status of electricity production (output) and demand, the number of generation plants per region and their production capacity. The region status of the electricity grid shows an "error" state which means a few generation plants have failed to produce electricity and there are not sufficient imports from neighboring zone to meet the required electricity demand. 


\section{Simulation Run: Frequency: 3, Severity level: Moderate, Regions: West, Greater Toronto Area, Bruce, Ottawa, Southwest, Essa and East}

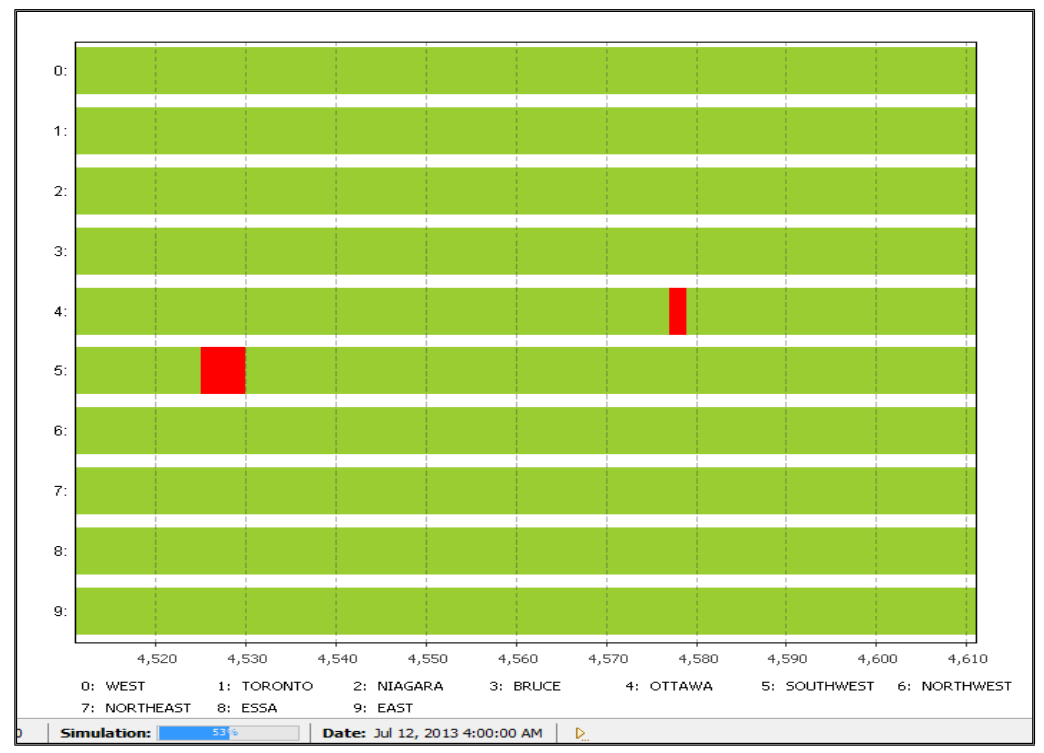

Figure 16A: For July 2013, Simulation interface shows the output of the electricity grid at severity level: moderate and frequency: 3 , the system is handling the heat wave for the selected regions. Two errors in Ottawa and Southwest are observed throughout the month (Anylogic, 2016).

Figures 16A demonstrates a simulation run for the month of July. The green output in the figure shows that the electrical grid for the regions of West, Greater Toronto Area, Bruce, Essa and East are balancing the electricity demand and supply along with exports and imports during a heat wave based on severity level moderate and frequency level of 3. Southwest and Ottawa regions show a red output (failure) for the duration of 5 hours and 2 hours. This failure can cause by a generation plant's equipment failure and due to high electricity demand which is not balanced by the electricity production, resulting in a potential blackout. 


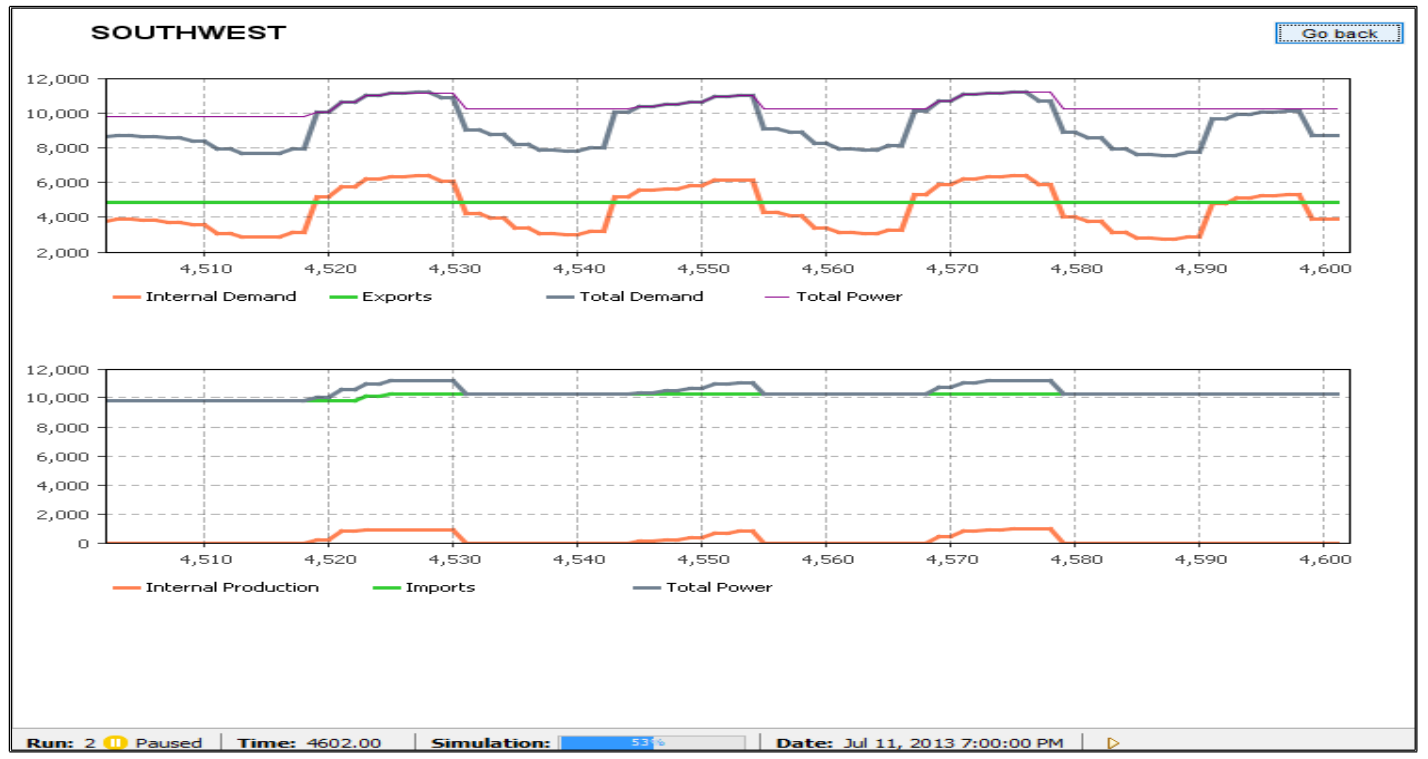

Figure 16B

Figure 16B: Distributor interface shows the output of the electricity grid on severity level: moderate and frequency: 3 , the system is handling the heat wave for the selected regions (Anylogic, 2016).

Figure 16B shows distributor simulation interface of Southwest region, displaying total power, total demand, imports and exports, internal demand and production. Figure 16B shows that on July $11^{\text {th }}$, between 4526 and 4530 hours of the month, Southwest region showed a high increase in demand compared to the total power (total output production) for the duration of 4 hours. It means the generation plant is reaching close to its supply showing an alerting state of the system. 


\section{Simulation Run: Frequency: 2, Severity level: Extreme, Regions: West, Greater Toronto Area, Bruce, Ottawa, Southwest, Essa and East}

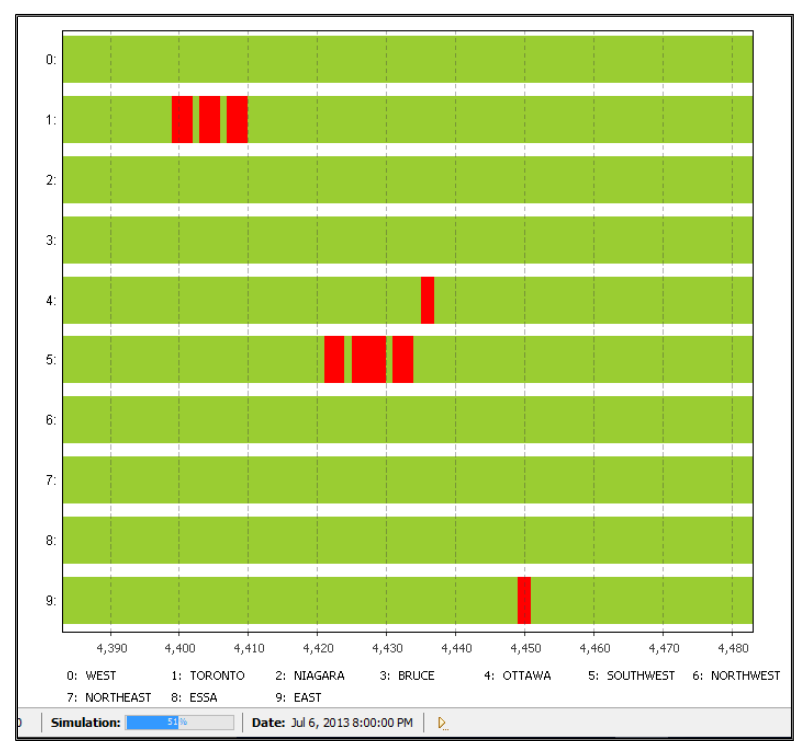

Figure 17A

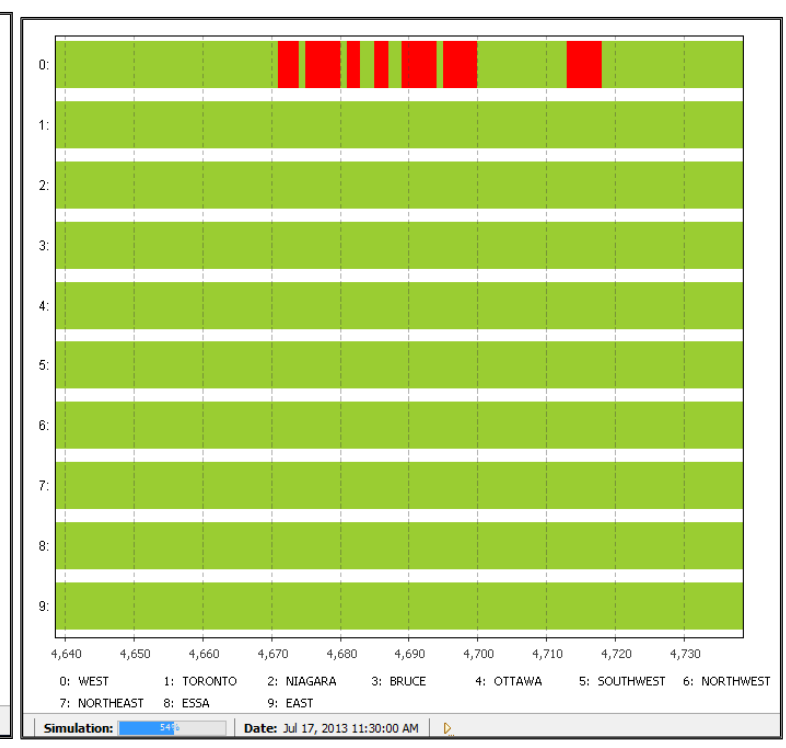

Figure 17B

Figure 17A and 17B: For July 2013, Simulation interface shows the output of the electricity grid at severity level: extreme and frequency: 2, the system is handling the heat wave for the selected regions. Five errors in West, GTA, Ottawa, East and Niagara are observed throughout the month (Anylogic, 2016).

Figures 17A and 17B demonstrate a simulation run for the month of July which shows the electrical grid for the regions of West, Greater Toronto Area, Bruce, Ottawa, Southwest, Northwest, Northeast, Essa and East. The heat wave is based on extreme severity level and frequency of 2. The figures show multiple red outputs (failures) in the region of West, Toronto, Ottawa, Southwest and East outlined in the main simulation interface. The failure can cause by a generation plant's equipment failure and due to high electricity demand which is not balanced by the electricity supply, resulting in a potential blackout. 


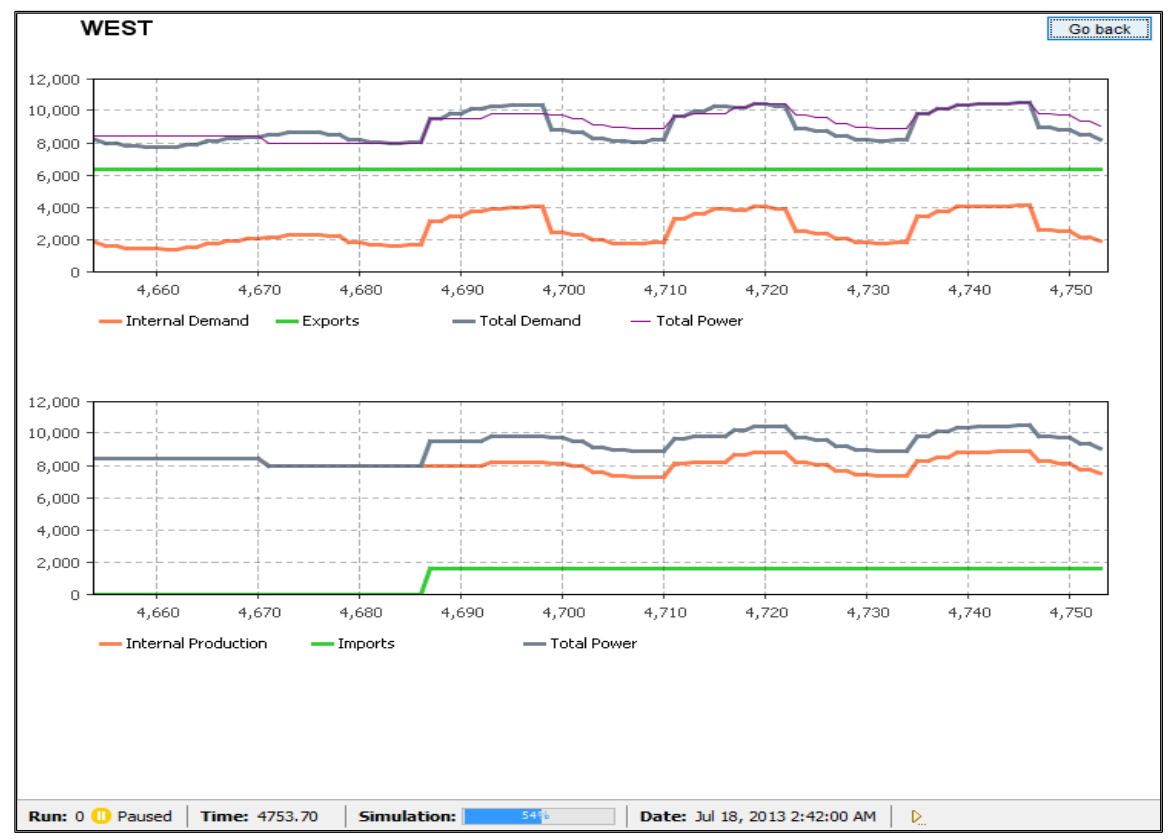

Figure 17C: For July 2013 Distributor interface shows the output of the electricity grid at severity level: extreme and frequency: 2, the system is handling the heat wave for the selected regions (Anylogic, 2016).

Figure 17C shows the distributor simulation interface of West region, displaying total power, total demand, imports and exports, internal demand and production. Figure 17C shows that on July $18^{\text {th }}$, between 4690 and 4700 hours of the month, West region showed a high increase in demand compared to the total power (total output production) for the duration of 10 hours. This means the generation plant is either reaching close to its supply or has reached the level where it cannot supply enough power to the region, causing a potential failure. 


\section{Simulation Run: Frequency: 3, Severity level: Extreme, Regions: West, Greater Toronto}

Area, Bruce, Ottawa, Southwest, Essa and East

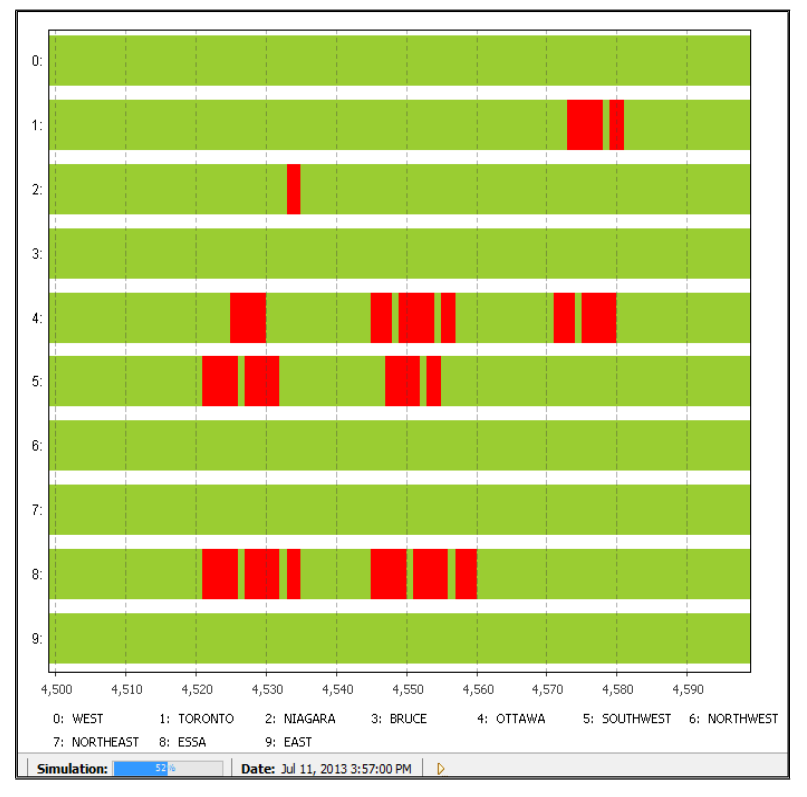

Figure 18A

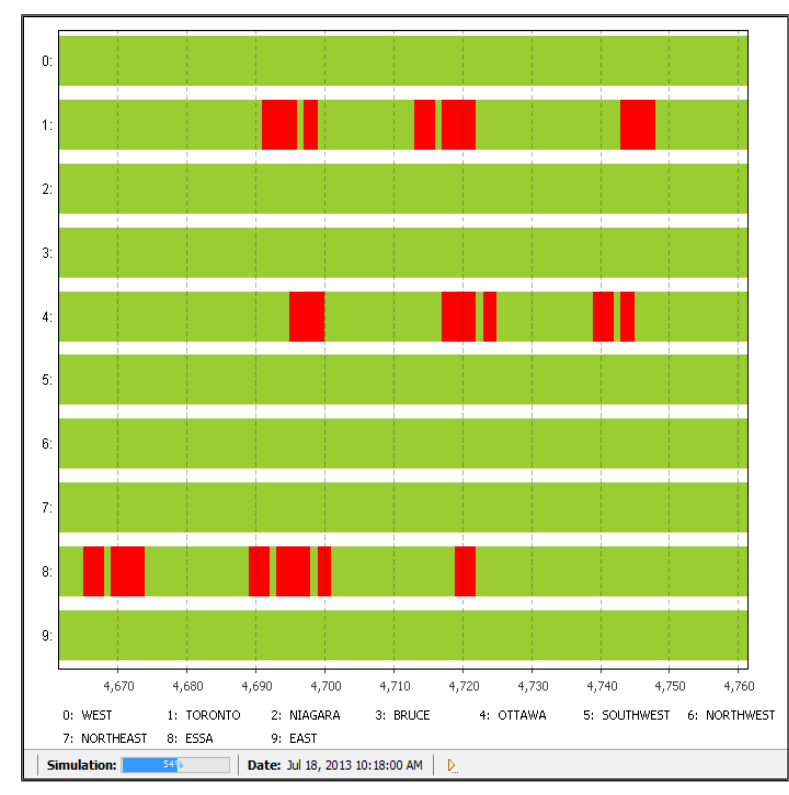

Figure 18B

Figure 18A and 18B: For July 2013, Simulation interface shows the output of the electricity grid at severity level: extreme and frequency: 3 , the system is handling the heat wave for the selected regions. Errors in GTA, Niagara, Ottawa, Southwest and Essa, are observed throughout the month (Anylogic, 2016)

Figures 18A and 18B demonstrate a simulation run for the month of July which shows the electrical grid for the regions of West, Greater Toronto Area, Bruce, Ottawa, Southwest, Northwest, Northeast, Essa and East. The heat wave is based on extreme severity level and frequency of 3. The figures show multiple red outputs (failures) in the region of Toronto, Niagara, Ottawa, Southwest and Essa outlined in the main simulation interface. The failure can cause by a generation plant's equipment failure and due to high electricity demand which is not balanced by the electricity supply, resulting in a potential blackout. 


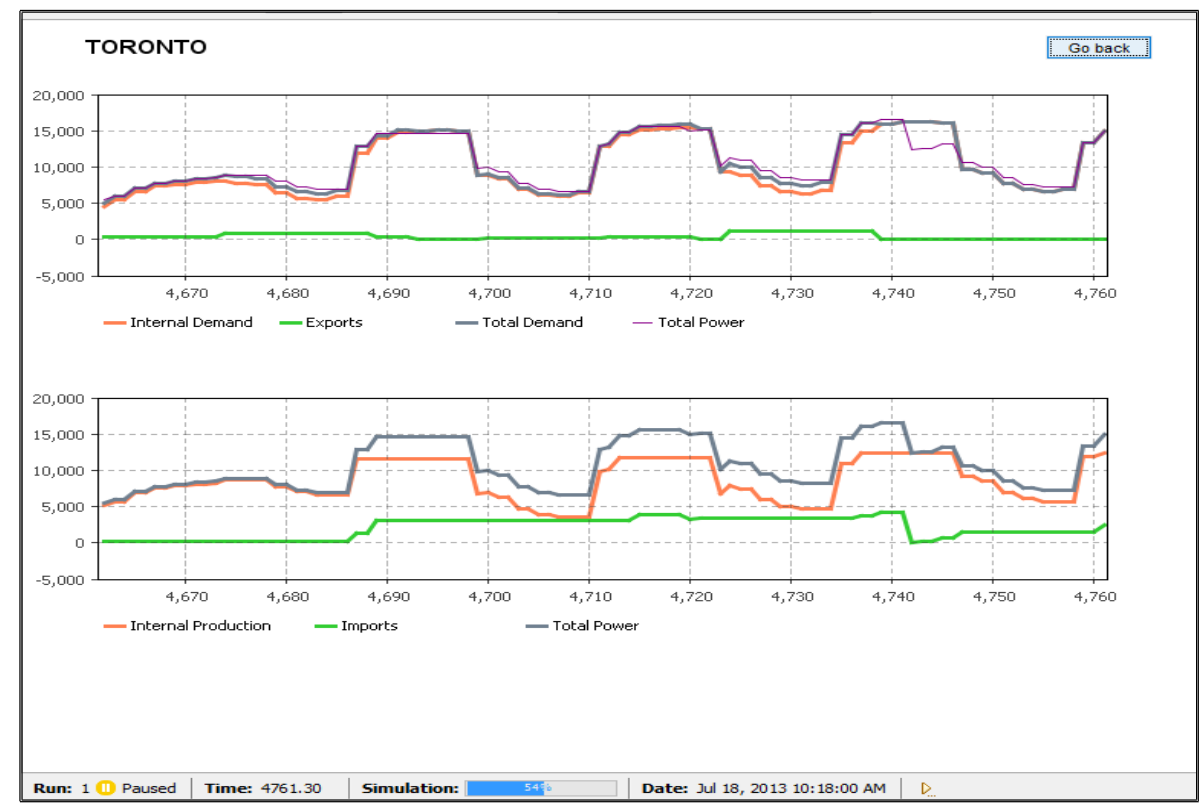

Figure 18C

Figure 18C: For July 2013 Distributor interface shows the output of the electricity grid at severity level: extreme and frequency: 3, the system is handling the heat wave for the selected regions (Anylogic, 2016)

Figure 18C shows the distributor simulation interface of Greater Toronto Area region, displaying total power, total demand, imports and exports, internal demand and production. Figure $18 \mathrm{C}$ shows on July $11^{\text {th }}$, between 4745 and 4750 hours of the month, Greater Toronto Area (GTA) region showed a higher increase in demand compared to the total power (total output production) for the duration of 5 hours. The imports were decreased from the neighbouring zone as they were under the impact of heat wave. GTA reduced exports because the internal demand of the region was high. The generation plants have reached to the level where it cannot supply enough power to the region, causing a potential blackout. 
Case B: Ice Storm

An ice storm is triggered by the levels of severity: low, moderate and extreme along with the frequency level of 2 , which is used to observe failure (blackout) and resilience of the electricity grid. Ice storms occur from December to February (seasonal). The simulation model is configured with the electricity demand/supply and weather station data for the duration of the year 2013. The ice storm simulation was tested for January, February and December at different frequencies and severity levels.

Simulation Run: Frequency: 2, Severity level: Low, Regions: West, Greater Toronto Area, Bruce, Ottawa, Southwest, Essa and East

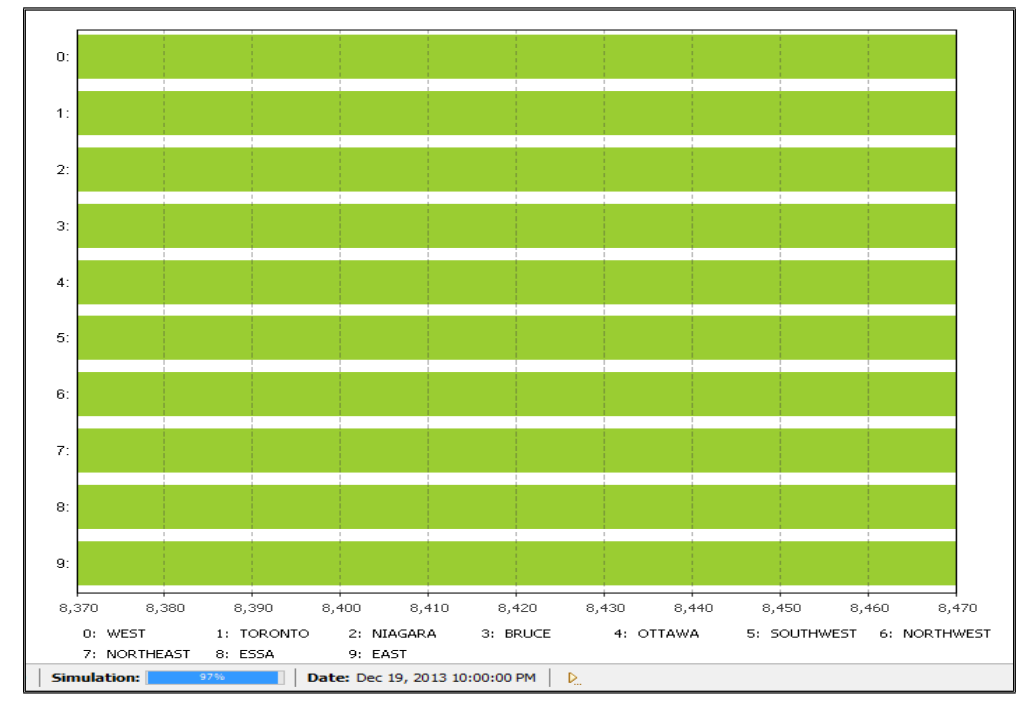

Figure 19A: For December 2013, Simulation interface shows the output of the electricity grid at severity level: low and frequency: 2, the system is handling the ice storm for the selected regions. No errors observed throughout the month (Anylogic, 2016) 
Figure 19A demonstrates a simulation run for the month of December. The green output shows that the electrical grid for the regions of West, Greater Toronto Area, Bruce, Ottawa, Southwest, Essa and East are balancing the electricity demand and supply along with exports and imports during an ice storm based, on low severity levels and a frequency level of 2 .

\section{Simulation Run: Frequency: 2, Severity level: Moderate, Regions: West, Greater Toronto} Area, Bruce, Ottawa, Southwest, Northwest, Northeast, Essa and East

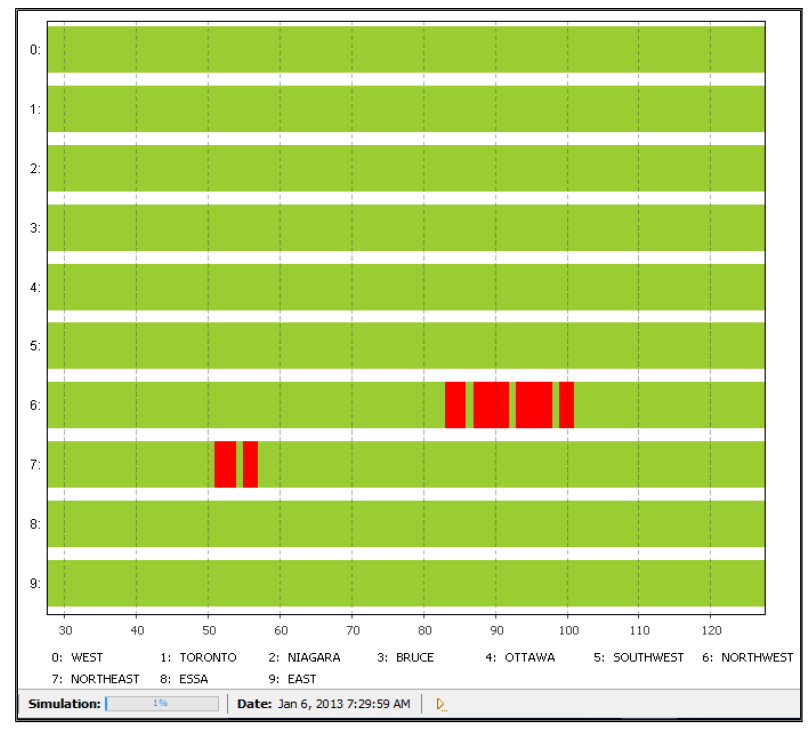

Figure 20A

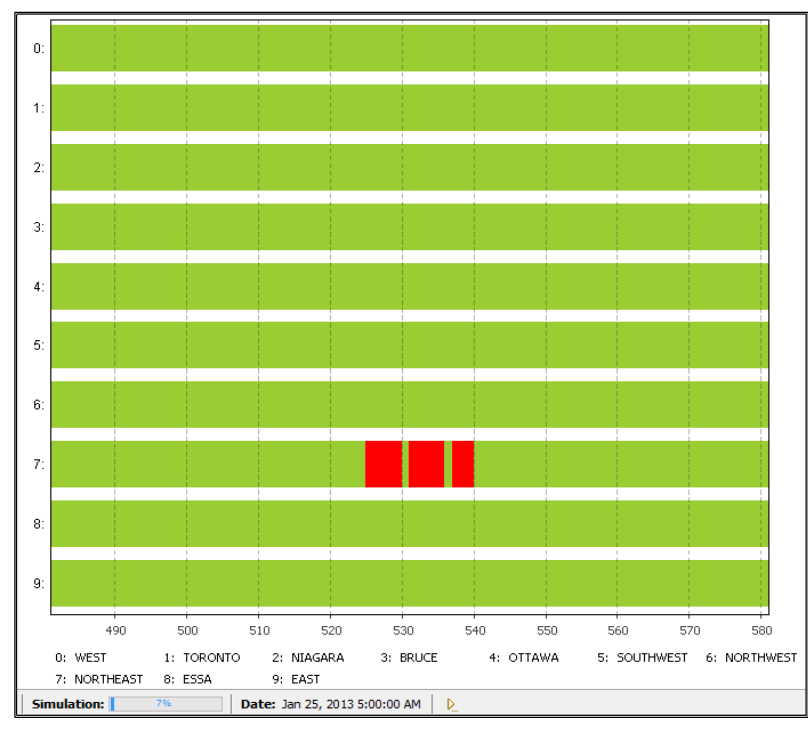

Figure 20B

Figure 20A and 20B: For January 2013, Simulation interface shows the output of the electricity grid at severity level: moderate and frequency: 2, the system is handling the ice storm for the selected regions. Errors are observed in Northwest and Northeast throughout the month (Anylogic, 2016)

Figures $20 \mathrm{~A}$ and $20 \mathrm{~B}$ demonstrate a simulation run for the month of January which shows the electrical grid for the regions of West, Greater Toronto Area, Bruce, Ottawa, Southwest, Northwest, Northeast, Essa and East. The ice storm is based on moderate severity level and frequency of 2 . The figures show multiple red outputs in the several regions outlined 
in the main simulation interface. The failure can be caused by a generation plant's equipment failure and reduction in the electricity supply which resulted in high electricity demand, causing a power outage.

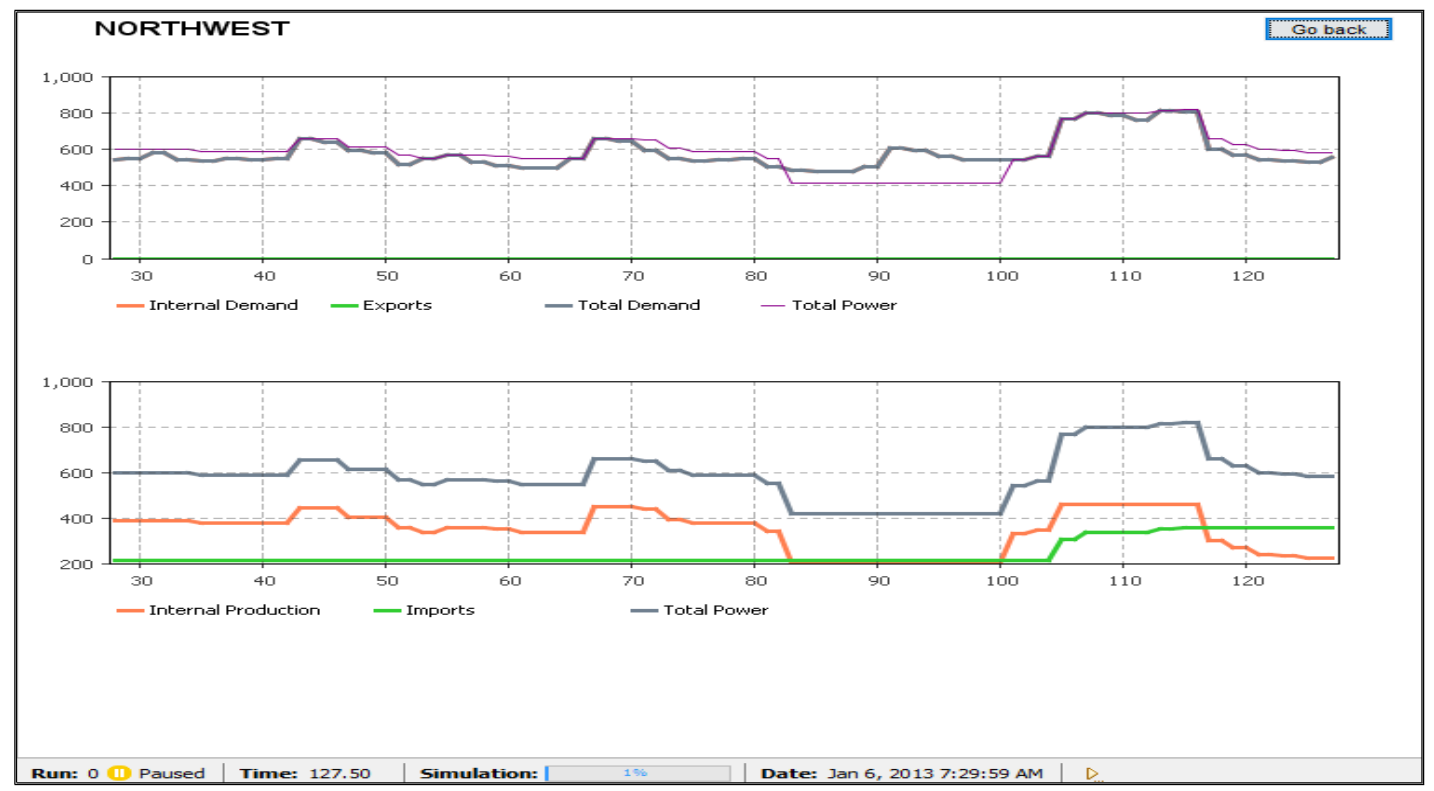

Figure 20C

Figure 20C: Distributor interface shows the output of the electricity grid at severity level: moderate and frequency: 2, the system is handling the ice storm for the selected regions (Anylogic, 2016)

Figure 20C shows the distributor simulation interface of Northwest region displaying, total power, total demand, imports and exports, internal demand and production. Figure 20C shows that on January $6^{\text {th }}$, between $80^{\text {th }}$ and $100^{\text {th }}$ hours of the month, Northwest region showed a high increase in demand compared to the total power (total output production) for the duration of 20 hours. It means the generation plant is either reaching close to its supply or has come to the level where it cannot supply enough power to the region, causing a potential blackout. 


\section{Simulation Run: Frequency: 2, Severity level: Extreme, Regions: West, Greater Toronto Area, Bruce, Ottawa, Southwest, Essa and East}

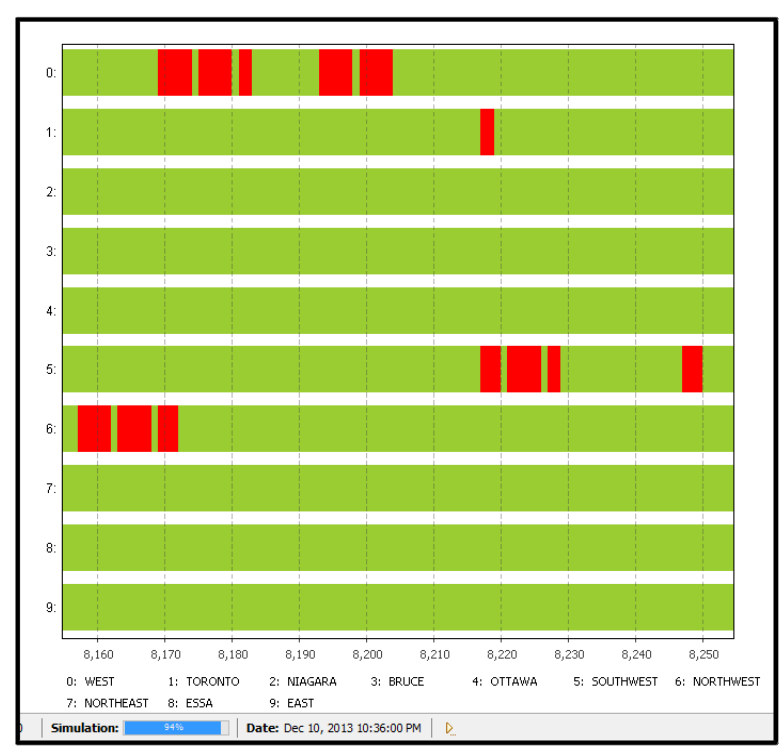

Figure 21A

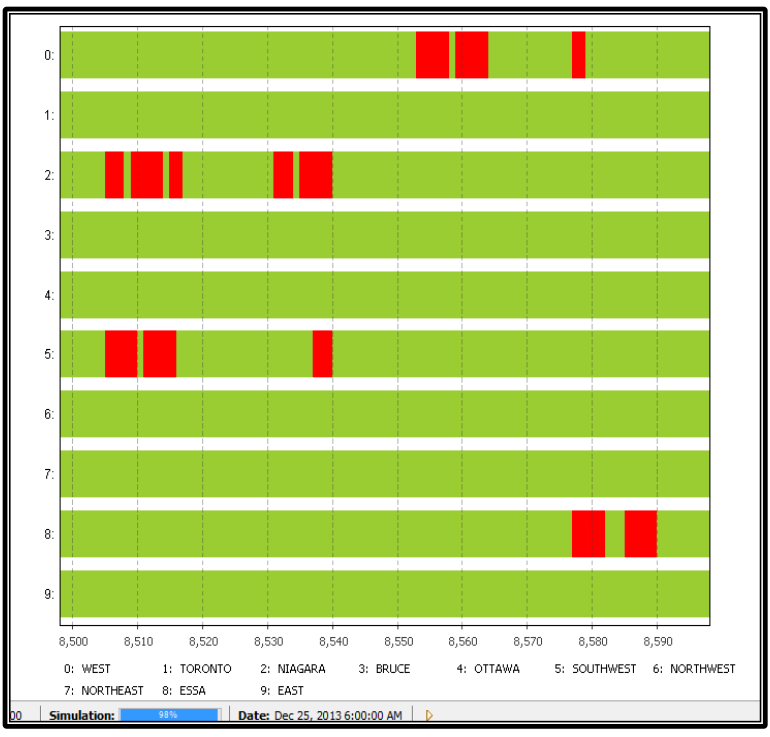

Figure 21B

Figure 21A and 21B: For December 2013, Simulation interface shows the output of the electricity grid at severity level: extreme and frequency: 2, the system is handling the ice storm for the selected regions. Errors observed in West, GTA, Niagara, Southwest and Essa throughout the month (Anylogic, 2016)

Figures 21A and 21B demonstrate a simulation run for the month of December which shows the electrical grid for the regions of West, Greater Toronto Area, Bruce, Ottawa, Southwest, Essa and East. The ice storm is based on extreme severity level and frequency of 2 . The figures show multiple red outputs in the several regions outlined in the main simulation interface. The failure can cause by a generation plant's equipment failure and reduction in the electricity supply which resulted a high electricity demand causing a potential power outage. 


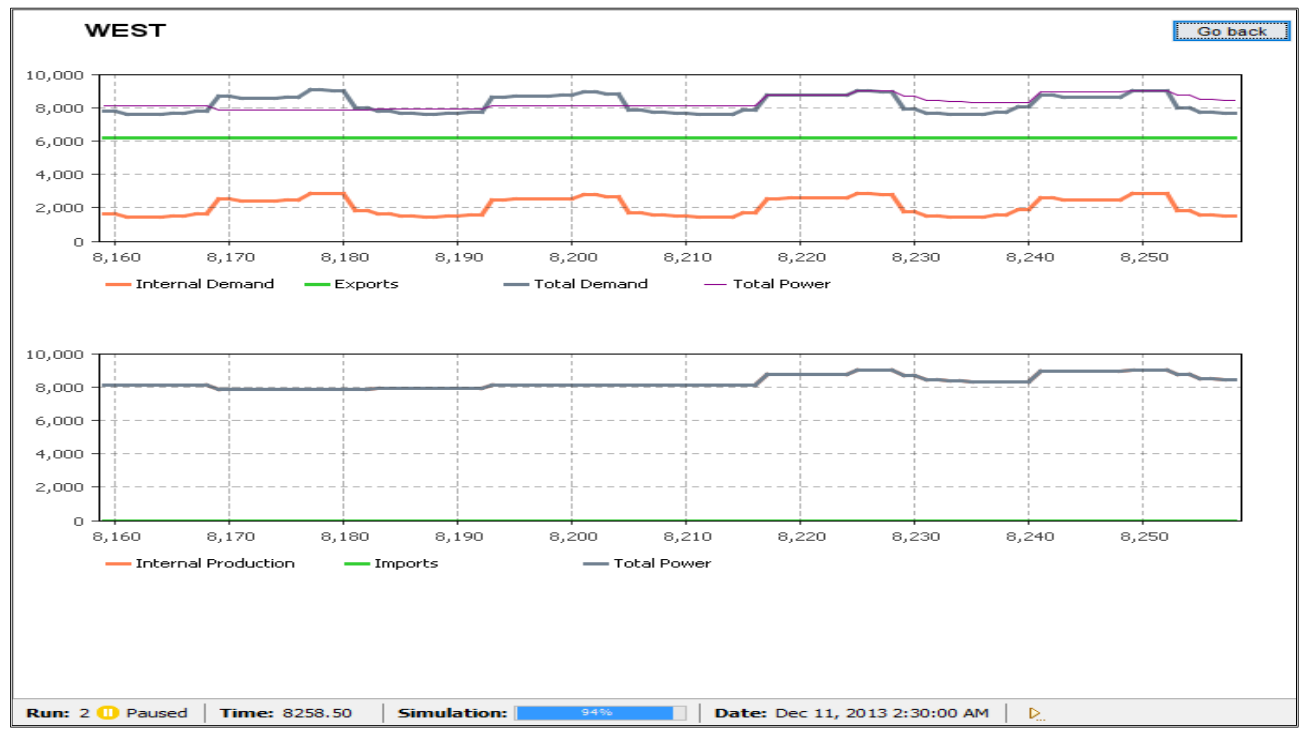

Figure 21C

Figure 21C: Distributor interface shows the output of the electricity grid at severity level: extreme and frequency: 2, the system is handling the ice storm for the selected regions (Anylogic, 2016)

Figure $21 \mathrm{C}$ shows the distributor simulation interface of West region, displaying total power, total demand, imports and exports, internal demand and production. Figure 21C shows on December $11^{\text {th }}$, between 8170 and 8180 hours of the month, the West region showed a high increase in demand compared to the total power (total output production) for the duration of 10 hours. It means the generation plant is either reaching close to its supply capacity or has reached the level where it cannot supply enough power to the region, causing a potential blackout. 


\section{CHAPTER 5: DISCUSSION AND CONCLUSION}

\subsection{Summary}

An increase in frequency and severity of extreme weather events results in failure of the electrical components, such as power generation plants, transmission lines, and the distribution network. The focus of this research is to assess the resilience of Ontario's electricity grid during intense ice storms and heat waves. An initial stage of agent-based simulation model was constructed using Anylogic software. The model used secondary data sources (2013) to build a basic artificial electricity grid. The model needs further development to resemble Ontario's current electricity system. Recommendations to improve the model are made in this section. The results of this study were conducted based on multiple simulation runs for each extreme weather event based on their severity level and frequency.

Singh et al., 2015 describes a resilient energy system as one that can maintain equilibrium between its supply and demand regardless of internal and external disturbances such as extreme weather conditions. From the perspective of a complex electricity infrastructure, when a severe heat wave or an ice storm occurs in a region, it creates several disturbances such as an increased electricity demand, reduction in electricity supply, transmission line failure, generation plant equipment failures and cascading failures.

Due to the complexity of the electrical power grid, development of an artificial electricity grid is challenging. The limitation of developing such a model is due to the inability to incorporate all aspects of an existent electrical grid. These aspects include components such as multi-agents behaviours and their sub-components that include generation plants, transmission network, distribution system and other key players, which are involved in 
handling of the power grid. This research focuses on only two components, which are the generation plants and the distribution network. The relationship between an extreme weather event and two electrical components is tested and studied under severity levels and frequency conditions.

\subsection{Research results}

Table 8: Simulation results based on frequency and severity level of heat waves and ice storm

\begin{tabular}{|c|c|c|c|c|}
\hline Severity level & $\begin{array}{c}\text { FREQUENCY 2 } \\
\text { Heat wave } \\
\text { (May - August) }\end{array}$ & $\begin{array}{c}\text { FREQUENCY 3 } \\
\text { Heat wave } \\
\text { (May - August) }\end{array}$ & $\begin{array}{c}\text { FREQUENCY 2 } \\
\text { Ice storm } \\
\text { (January, February } \\
\text { and December) }\end{array}$ & $\begin{array}{c}\text { FREQUENCY 3 } \\
\text { Ice storm } \\
\text { (January, February } \\
\text { and December) }\end{array}$ \\
\hline Low & No failure & No failure & No failure & No failure \\
\hline Extreme & Many failures & $\begin{array}{c}\text { More failures } \\
\text { observed compared } \\
\text { to frequency 2 }\end{array}$ & Few failures & Few failures \\
\hline & Two or more failure & $\begin{array}{c}\text { More failures } \\
\text { observed } \\
\text { compared to } \\
\text { frequency of } 2\end{array}$ \\
\hline
\end{tabular}

The results of the simulation show that during a heatwave, at low severity and frequency 2 and 3 for each month, the grid can handle up to $20 \%$ rise in electricity demand and shows no failure. The imports and exports of the electricity from the neighboring zone fill the requirement of the demand by supplying an adequate amount of electricity.

The moderate severity level and frequency of 2 was tested, and there were two or more system error that lasted for 4-6 hours. It shows that the grid can handle up to $40 \%$ of additional electricity demand. When the frequency was increased to 3 heat waves per month, there was an increase in power disruption for a short period in different regions. 
This observation concludes that the frequency of a heat wave has a significant influence on the severity of the weather event, if the severity of the heat wave continues at a moderate severity level and the frequency is reduced, then the system may continue to handle the electricity demand.

Under the conditions of extreme severity level and frequencies of 2 and 3 per month, during the month of July, the grid had several failures up to $60 \%$ electricity demand and July was observed as the hottest month having multiple power outages which lasted for longer duration before the grid return to its original working state. An additional strain on the system during a heat wave can be attributed to the overuse of air conditioners, the reduction of distribution and transmission capacity due to increasing in thermal losses (Bollinger, 2015).

Whereas the results of the simulation during an ice storm at a low severity level and frequency of 2 (per month) show that the grid is well balanced and can function up to $10 \%$ reduction of electricity supply. The percentage scale of the decrease in electricity supply is used to test the grid resilience during extreme weather events. The failure of the grid during an ice storm can be caused by reasons such as ice accumulation on transmission lines and increase usage of heat appliances for an extended period. The ice accumulation breaks the power lines, utility poles and tree branches which cause a reduction of electricity supply thus leading to a power outage.

When the simulation was tested with a decrease electricity supply represented by a moderate severity level and frequency of 2 , which is a longer duration lasting up to 5 days, the simulated grid functioned similarly as it did during a heat wave except for seasonal change. 


\section{Validation of the model:}

The simulation run of an ice storm with extreme severity level and a frequency of 2 and 3 showed major outages and failure for longer durations. In 2013, Ontario experienced a historical ice storm that caused a blackout in southern and eastern regions of Ontario. The simulation model showed several power generation failures in the southern and eastern Ontario, and the downtime of the generation plant was more than a day. Simulation of the ice storm in the model showed the same failure resultant as it occurred for Ontario's grid in 2013 during an ice storm. The failure was caused by high ice accumulation, affecting transmission lines and an insufficient electricity supply not meeting a regional demand, which subsequently caused a massive blackout lasting more than 48 hours.

\subsection{Limitations}

The limitation of the simulation model is that it is not connected to the neighbouring power jurisdictions. The current electricity system is connected to Quebec, Manitoba, Midwest, and New York's electrical systems through transmission lines. This model does not include these external power interconnections. There are imports and exports of electricity on a daily basis, but the model only displays Ontario's electrical grid exclusive of any external zones. Although the neighbouring jurisdictions are not included, their influence with regards to imports and exports are included because it is a part of the data set incorporated in the model. Due to this limitation, simulation outcomes may differ. If these external power interconnections are included, then the power disruption caused by a heat wave or ice storm in the simulation could have been reduced, meaning there would be fewer state errors if these external power interconnections are present in the model. 
According to current statistics, there are approximately 72 local distribution companies in Ontario and a report of the "Ontario Distribution Sector Review Panel" suggests that the structures of these LDCs are one of the contributing factors to the high cost of living and business in Ontario ("Ontario Distribution Sector", 2012). The electricity distribution sector of Quebec and Manitoba is well maintained. Manitoba Hydro (a distribution company) is a single utility, which provides electricity supply to the entire province. Similarly, Quebec runs Hydro Quebec, which manages the electricity consumption and production of the entire province accompanied by some few local distribution companies. The introduction of consolidated systems will help to shift Ontario's economy towards a sustainable and costeffective growth accompanied by saving a significant amount annually ("Ontario Distribution Sector", 2012). A limitation of this model includes the distributor agents. To ease the complexity of the electricity grid, ten distributor agents were selected for ten regions in the model, whereas in the current system, there are 72 local distribution companies, which are responsible to deliver the electricity to the end users. Due to this limitation, the model demonstrated how Ontario's electrical grid would respond to the consolidation process, that is, to reduce the 72 current local distribution companies into 10 local distribution companies. It was observed that 10 distributor agents assigned in each zone were handling electricity production, supply, imports and export efficiently. The reduction of the local distribution companies from 72 to 10 does not change the overall handling of the electrical grid, it only reduces the number of companies distributing the electricity in the simulation model. 


\subsection{Research Recommendations and Application}

Recommendations to improve the simulation model includes the incorporation of neighbouring agents to simulate the current Ontario electricity grid as it contains power interconnections with regions including Michigan, Minnesota, New York, Quebec, and Manitoba.

Another recommendation is to add a transmission network as an agent, which will include buses, substations and different voltage lines to transmit electricity. The addition of a transmission network as an agent will demonstrate transmission line failures during heat waves and ice storms. Another addition in the model is to include the population as agents (end-user) as they are distributed in Ontario to monitor the effects of an outage on the population per region. To improve the simulation model, parameters such as humidity, wind gust, precipitation, and ice accumulation can be included to monitor the effect of real-time heat waves and ice storms.

Singh et al., 2015 states that the current electricity grid of Ontario is vulnerable and contains resilience gaps. Such gaps include increasing storm severity, in which the current transmission, distribution, and electricity generation system are not equipped to maintain. An issue that needs attention is the increase in population. The electricity grid will eventually need to be updated to keep up with current and future population growth, which will further increase the power consumption resulting in strain on the electricity grid.

A further recommendation is to study the incorporation of an electrical storage component to Ontario's electricity grid. Electricity storage can provide benefits such as providing electricity during an outage and alleviating strains on the grid caused by high 
demands. Furthermore, the surplus electricity generated by the plants can be stored during low electricity consumption periods. It has the potential to save millions of dollars, which are spent by Ontario's government to sell the surplus electricity to neighboring regions, which increases the end user's electricity bill.

The model has shown the possible failures of the electricity grid due to extreme weather event. If extreme weather events were to increase, it is recommended that the electricity sector needs to adopt a strategy in order to develop a stable and reliable system. To reduce the vulnerability, it is important to reduce the high electricity demand by encouraging energy consumers to adopt conservation techniques. Conservation and demand management helps to cut down the consumption rate during peak hours (Lysyk, 2015). Another recommendation is to conduct a risk assessment of the transmission, generation and distribution network. Each sector needs a detailed analysis to prevent the failures caused by an extreme weather event. Vegetation management should be strictly applied in the province to reduce the risk of transmission lines failure as well.

A start-up model is constructed at this stage, but additions of the other electrical sectors as well as the key players of the grid to the model are essential in order to provide a comprehensive insight of the electricity grid. Once the model is fully constructed and includes all the parameters of Ontario's grid, then the simulation model could be valuable for system planners, energy analysts and consultant companies, market participants, and regulators, policymakers, local distribution companies, and consumers. 


\subsection{Conclusion}

This study concluded that the simulated grid of Ontario could handle up to $30 \%$ reduction in electricity supply during an ice storm and up to $40 \%$ additional demand during a heat wave before reaching levels of potential failure. The model also demonstrated that heat waves and ice storms behaved differently depending on the month, extreme temperature months were more prone to failures than average temperature months. The electricity grid was experiencing more failures due to increased frequency levels of events as compared to the severity level of the event. This shows that if the frequency of extreme weather events increases in the future, the grid resilliency will be low. 


\section{APPENDIX A: Java code for main interface logic}

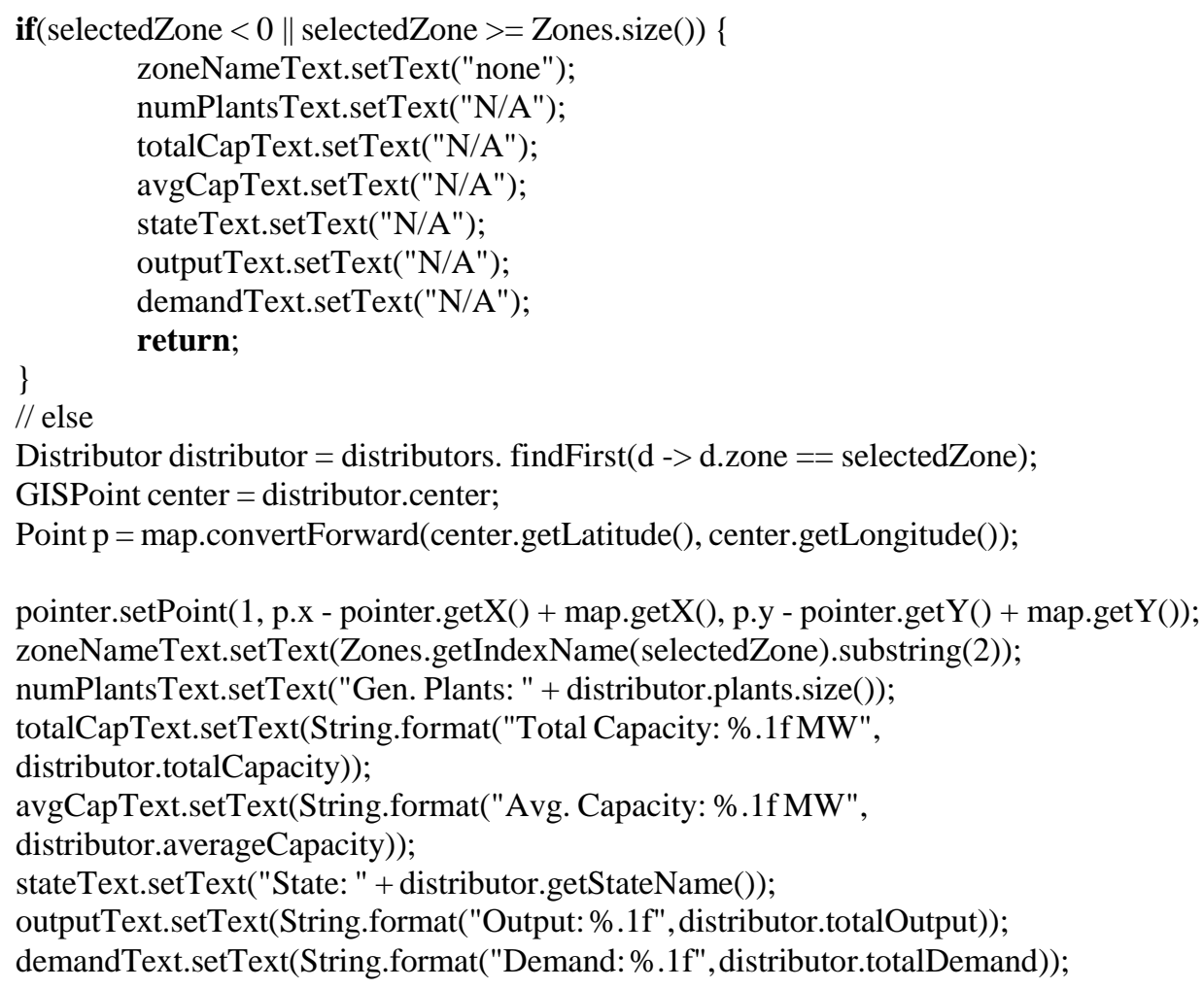

InitializeDistributors(); InitializeTransmissionLines();

//defaultViewArea.navigateTo(); map.setMouseNavigationEnabled(false);

//setup statistics chart

for(Distributor distr : distributors) \{ chart.addDataSet(distr.stateDataset, distr.name); \}

mapView.navigateTo(); 


\section{APPENDIX C: Java code for distributor agent}

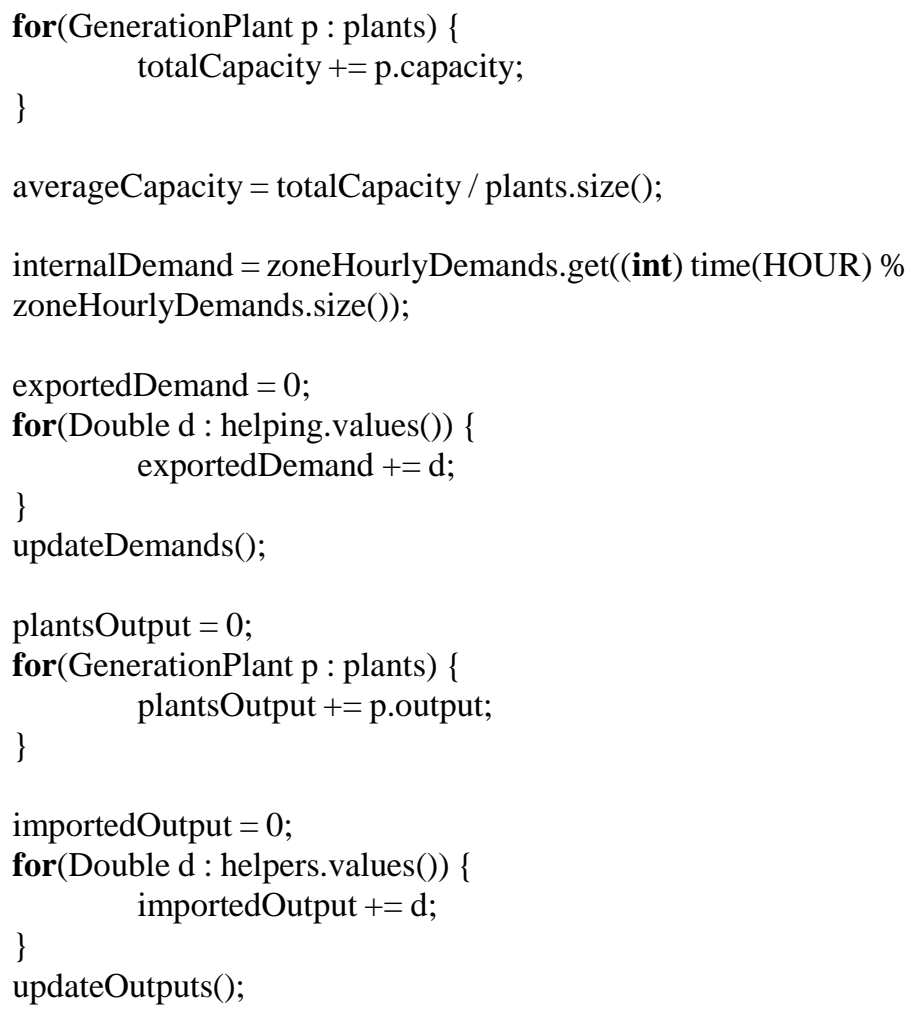




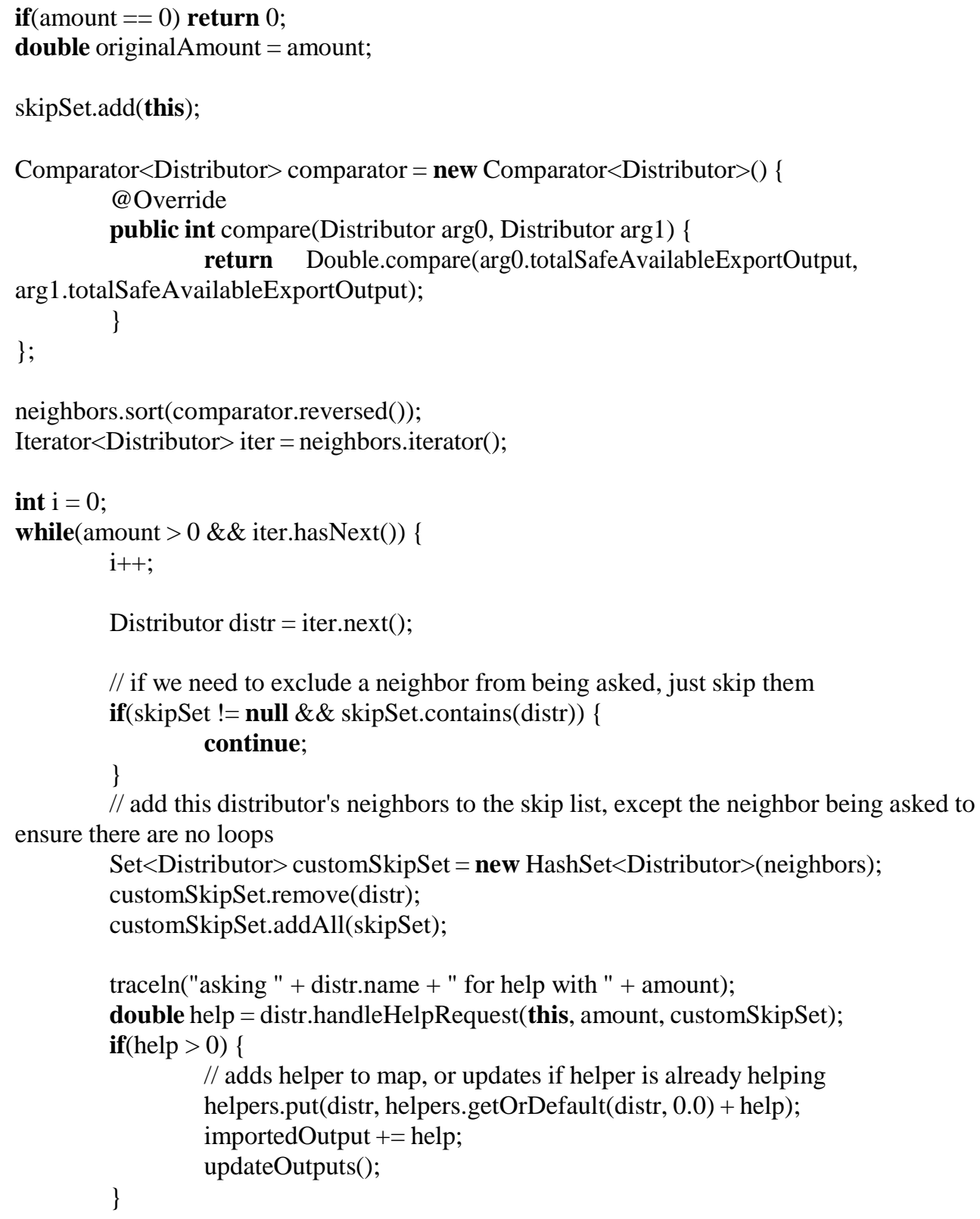




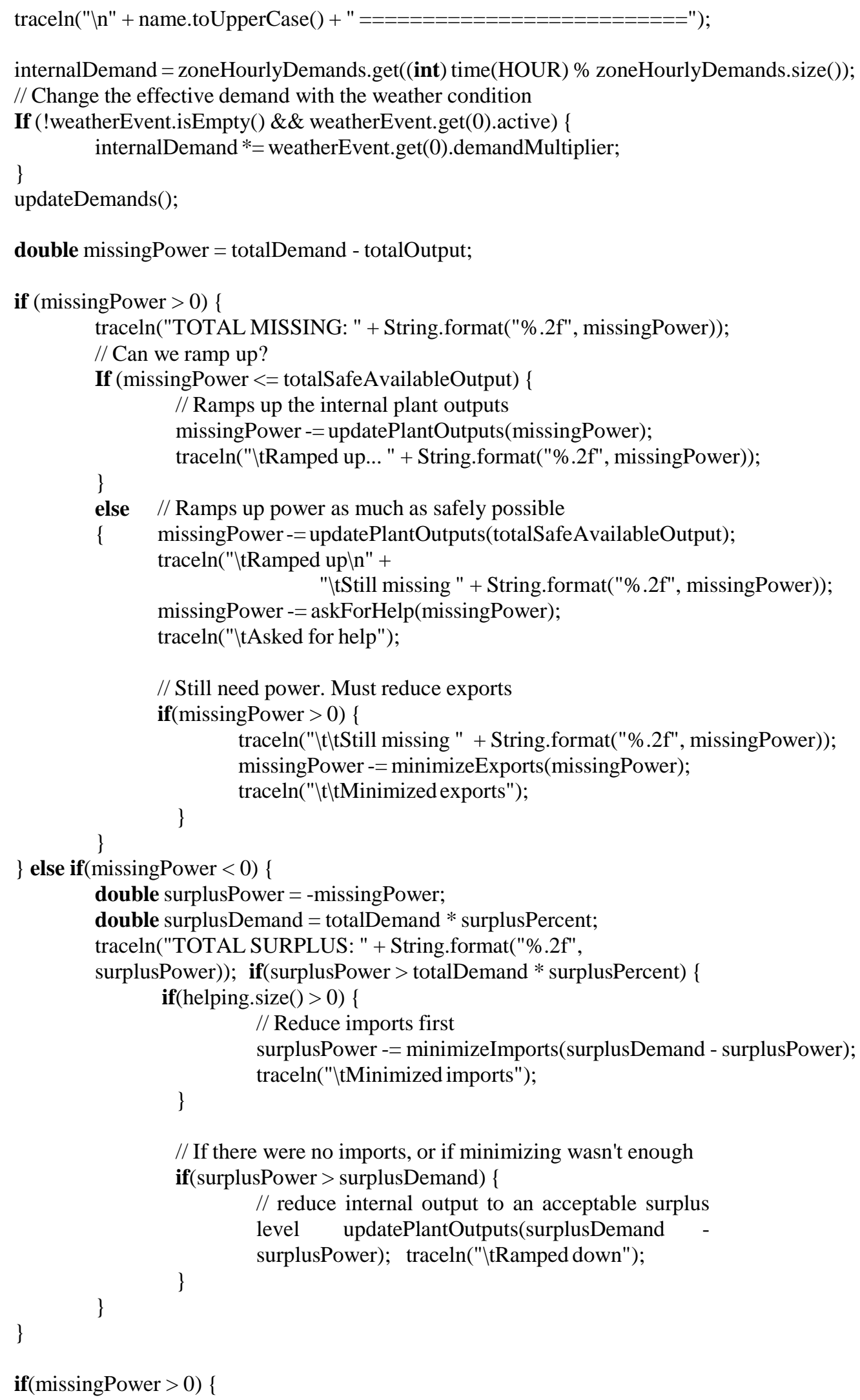




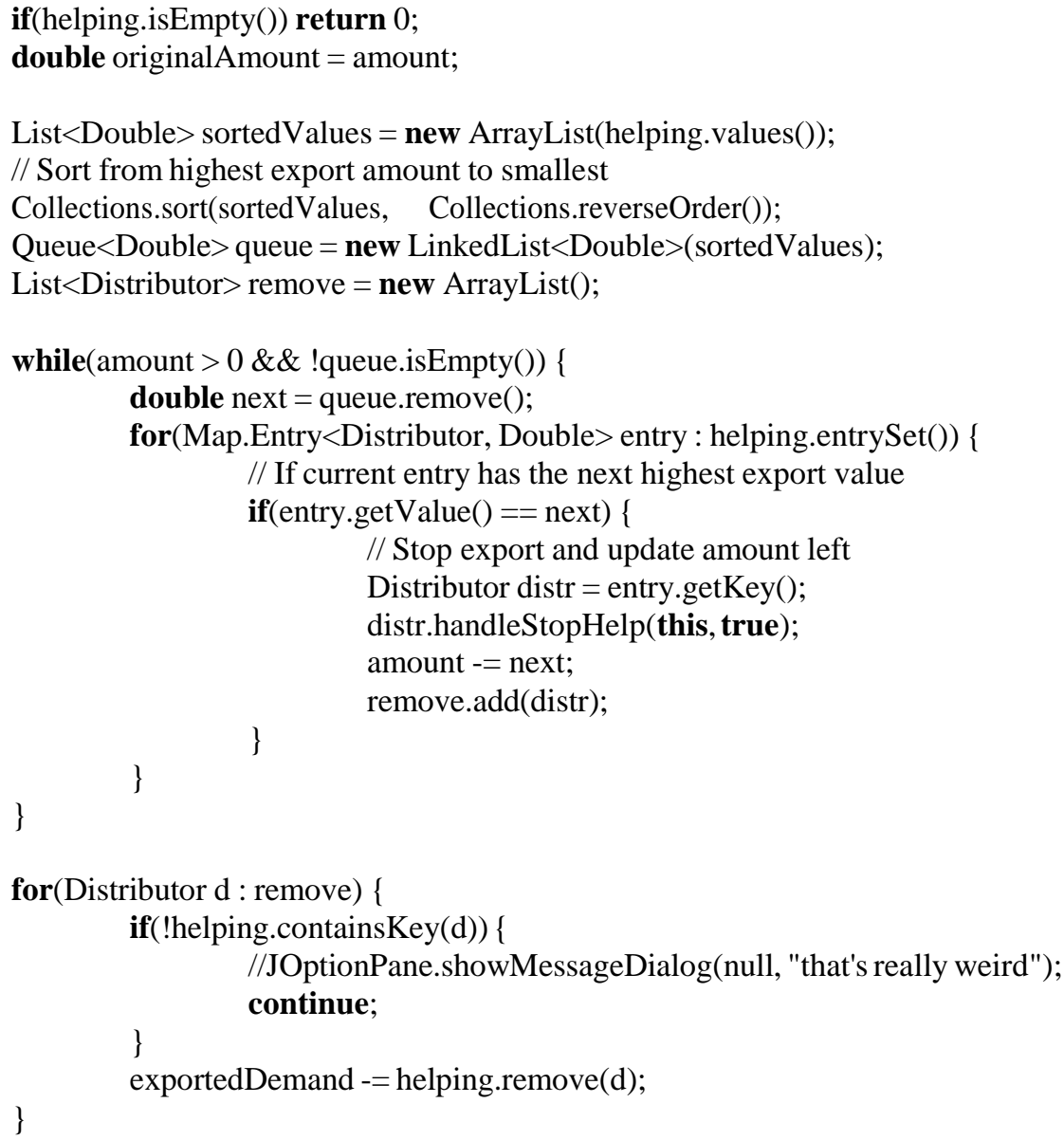




\section{APPENDIX D: Java code for generation plant agent}

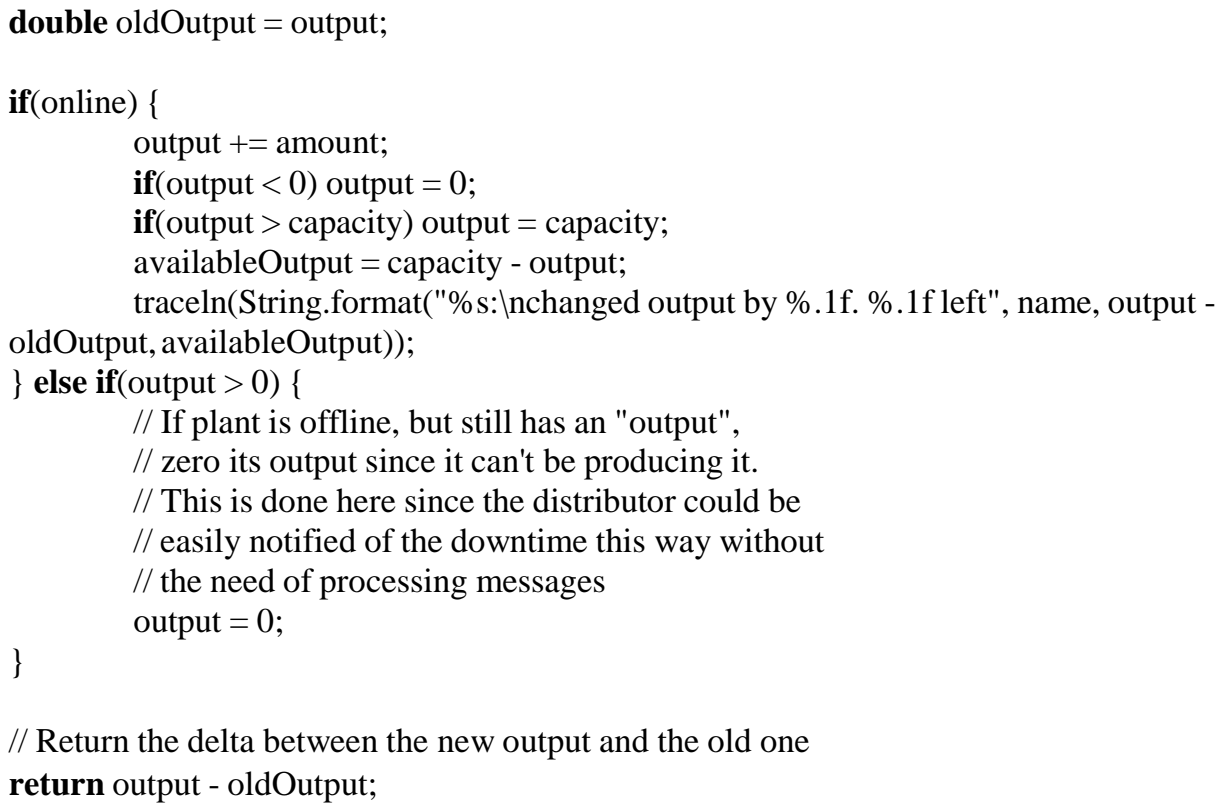




\section{REFERENCES:}

Abi-Samra, N., McConnach, J., Mukhopadhyay, S., \& Wojszczyk, B. (2014). When the bough breaks: Managing extreme weather events affecting electrical power grids. IEEE Power and Energy Magazine, 12(5), 61-65.

About Ontario. (2012). Retrieved December 11, 2016, from https://www.ontario.ca/page/aboutontario.

Abraham, S., Efford, R. J., \& U.S.-Canada Power System Outage Task Force. (2004). Final report on the august 14, 2003 blackout in the United States and Canada: Causes and recommendations U.S.-Canada Power System Outage Task Force.

Aivalioti, S. (2015). Electricity Sector Adaptation to Heat Waves. Columbia Law School, Sabin Center for Climate Change Law White Paper.

AnyLogic. (2016). Multimethod Simulation Software The only simulation tool that supports

Discrete Event, Agent Based, and System Dynamics Simulation. Retrieved from http://www.anylogic.com/features.

Armenakis, C., \& Nirupama, N. (2014). Urban impacts of ice storms: Toronto December 2013. Natural Hazards, 74(2), 1291-1298.

Axelrod, R. (1997). The Complexity of Cooperation: Agent-Based Models of Competition and Collaboration (Princeton Univ. Press, Princeton, NJ).

Baldwin, D. J., Desloges, J. R., \& Band, L. E. (2011). Physical Geography of Ontario.

Ecology of a managed terrestrial landscape: patterns and processes of forest landscapes in Ontario, 12. 
Bandini, S., Manzoni, S., \&Vizzari, G. (2009). Agent based modeling and simulation: an informatics perspective. Journal of Artificial Societies and Social Simulation, 12(4), 4.

Bankes, S. C. (2002). Agent-based modeling: A revolution? Proceedings of the National Academy of Sciences, 99(suppl 3), 7199-7200.

Barben, R. (2010). Vulnerability assessment of electric power supply under extreme weather conditions.

Bazghandi, A. (2012). Techniques, advantages and problems of agent based modeling for traffic simulation. Int J ComputSci, 9(1), 115-119.

Beard, L. M., Cardell, J. B., Dobson, I., Galvan, F., Hawkins, D., Jewell, W., \& Tylavsky, D. J. (2010). Key technical challenges for the electric power industry and climate change. IEEE Transactions on Energy Conversion, 25(2), 465-473.

Biggar, E. (1920). Hydro-electric development in Ontario a history of water-power administration under the Hydro-Electric Power Commission of Ontario. Toronto.

Bollinger, L. (2011). Balancing the demands of climate change adaptation and mitigation in energy infrastructures - a modeling framework. Delft University of Technology Faculty

Bollinger, L. A. (2015). Fostering climate resilient electricity infrastructures. TU Delft, Delft University of Technology.

Bollinger, L. A., \& Dijkema, G. P. (2016). Evaluating infrastructure resilience to extreme weather-the case of the Dutch electricity transmission network. European Journal of Transport and Infrastructure Research (EJTIR), 16 (1), 2016. 
Bolton, R. (1913). An expensive experiment; the Hydro-electric power commission of Ontario,.New York: The Baker \& Taylor.

Bonabeau, E. (2002). Agent-based modeling: Methods and techniques for simulating human systems. Proceedings of the National Academy of Sciences, 99(suppl 3), 7280-7287.

Borshchev, A., \& Filippov, A. (2004). From system dynamics and discrete event to practical agent based modeling: reasons, techniques, tools. In Proceedings of the 22nd international conference of the system dynamics society ( Vol 22).

Buchanan, M. (2009). Meltdown modelling: Could agent-based computer models prevent another financial crisis? Nature, 460(7256), 680.

Campbell, R. J. (2012). Weather-related power outages and electric system resiliency. Congressional Research Service. Report 7-5700, R42696, 18.

Canada's Nuclear History. (1997). University of Waterloo.

Castle, C. J., \& Crooks, A. T. (2006). Principles and concepts of agent-based modelling for developing geospatial simulations.

Chang, S. E., McDaniels, T. L., Mikawoz, J., \& Peterson, K. (2007). Infrastructure failure interdependencies in extreme events: power outage consequences in the 1998 Ice Storm. Natural Hazards, 41(2), 337-358.

Chan, W., Son, Y., \& Macal, C. (2010). Agent-based simulation tutorial - simulation of emergent behavior and differences between agent-based simulation and discrete-event simulation. Proceedings of the 2010 Winter Simulation Conference, 135-150. 
Chhatwal, J., \& He, T. (2015). Economic evaluations with agent-based modelling: An introduction. Pharmacoeconomics, 33(5), 423-433.

Climate Change Impacts \& Adaptation in Ontario: The Energy Sector. (2015). Ontario Centre for Climate Impacts and Adaptation Resources (OCCIAR). Retrieved April 15, 2016.

Daniels, R. (1996). Ontario Hydro at the millennium: Has monopoly's moment passed? Montreal: Published for University of Toronto Faculty of Law by McGill-Queen's University Press.

Data Directory. (2016). Retrieved January 23, 2017, from http://www.ieso.ca/Pages/PowerData/Data-Directory.aspx

de Durana, J. M. G., Barambones, O., Kremers, E., \& Varga, L. (2014). Agent based modeling of energy networks. Energy Conversion and Management, 82, 308-319.

Dewees, D. N. (2012). What Is Happening to Ontario Electricity Prices. University of Toronto, 24.

De, U. S., Dube, R. K., \& Rao, G. P. (2005). Extreme weather events over India in the last 100 years. Journal of the Indian Geophysical Union, 9(3), 173-187.

DMTI Spatial Inc. Transmission Lines Line. (2015); using Scholars GeoPortal. http://geo.scholarsportal.info.ezproxy.lib.ryerson.ca/\#r/details/_uri@=2731396105

Dobson, I., Carreras, B. A., Lynch, V. E., \& Newman, D. E. (2007). Complex systems analysis of series of blackouts: Cascading failure, critical points, and self-organization. Chaos: An Interdisciplinary Journal of Nonlinear Science, 17(2), 026103. 
Druez J, McComber P, Farzaneh M. (1999). Correlation between measurement of an ice detector and the mass of ice accreted on two different sized conductors. Can J Civ Eng 26(6):869-875.

Diaz, B. A., Fürnkranz-Prskawetz, A., Feichtinger, G., \& Kappel, G. (2010). Agent based models on social interaction and demographic behaviour.

Epstein, J., \& Axtell, R. (1996). Growing Artificial Societies: Social Science from the Bottom Up. Brookings Institution Press, (208).

ESRI, 2015. ArcGIS Desktop: Release 10.4 Redlands, CA: Environmental Systems Research Institute.

Farmer, J. D., \& Foley, D. (2009). The economy needs agent-based modelling. Nature, 460(7256), 685-686.

Franco, G., \& Sanstad, A. H. (2008). Climate change and electricity demand in California. Climatic Change, 87(1), 139-151.

Freeman, N. B. (1996). The politics of power: Ontario Hydro and its government, 1906-1995. Toronto: University of Toronto Press.

Garcia, R. (2005). Uses of agent-based modeling in innovation/new product development research. Journal of Product Innovation Management, 22(5), 380-398.

Getchell, A. (2008). Agent-based modeling. Physics, 22(6), 757-767.

Gilbert, G. N. (2008). Agent-based models (Vol. 153, p. 112), SAGE.

Global Hazards - February 2011. (2011). Retrieved December 11, 2016, from https://www.ncdc.noaa.gov/sotc/hazards/201102. 
Hammer, S. A., \& Parshall, L. (2009). Climate change and New York city's energy sector: vulnerabilities, impacts and adaptation strategies, 16, 32 .

Helbing, D. (2012). Agent-based modeling. In Social self-organization. Springer Berlin Heidelberg, 25-70.

Hewitt, S. (2002). Comparing analytical and discrete-event simulation models of manufacturing systems (Doctoral dissertation, University of Maryland).

Hines, P., Balasubramaniam, K., \& Sanchez, E. C. (2009). Cascading failures in power grids. IEEE Potentials, 28(5), 24-30.

Hines, P., Apt, J., \& Talukdar, S. (2009). Large blackouts in North America: Historical trends and policy implications. Energy Policy, 37(12), 5249-5259.

Historical Data. $\quad$ (2016). $\quad$ Retrieved January $\quad 23, \quad$ 2017, from http://climate.weather.gc.ca/historical_data/search_historic_data_e.html.

Ice storm. (2012). Retrieved 2016, from http://glossary.ametsoc.org/wiki/Ice_storms.

IESO Zonal Map. (2016). Retrieved January 23, 2017, from http://www.ieso.ca/zonal.map/index.html

IPCC, 2014: Annex II: Glossary [Mach, K.J., S. Planton and C. von Stechow (eds.)]. In: Climate Change. (2014). Synthesis Report. Contribution of Working Groups I, II and III to the Fifth Assessment Report of the Intergovernmental Panel on Climate Change [Core Writing Team, R.K. Pachauri and L.A. Meyer (eds.)]. IPCC, Geneva, Switzerland, 117-130. 
Ke, X., Wu, D., Rice, J., Kintner-Meyer, M., \& Lu, N. (2016). Quantifying impacts of heat waves on power grid operation. Applied Energy, 183, 504-512.

Kerry, M., Kelk, G., Etkin, D., Burton, I., \& Kalhok, S. (1999). Glazed over: Canada copes with the ice storm of 1998. Environment: Science and Policy for Sustainable Development, 41(1), $6-11$.

Kezunovic, M., Dobson, I., \& Dong, Y. (2008). Impact of extreme weather on power system blackouts and forced outages: New challenges. In 7th Balkan Power Conf.

Khazaii, J. (2016). Agent-based modeling. ASHRAE Journal, 58(2), 62.

Klaassen, J., Cheng, S., Auld, H., Li, Q., Ros, E., Geast, M., ... \& Lee, R. (2003). Estimation of severe ice storm risks for South-Central Canada. Report prepared for Office of Critical Infrastructure Protection and Emergency Preparedness.

Klima, K., \& Morgan, M. G. (2015). Ice storm frequencies in a warmer climate. Climatic Change, 133(2), 209-222.

Klügl, F., \& Bazzan, A. L. C. (2012). Agent-based modeling and simulation. AI Magazine, $33(3), 29-40$

Lempert, R. (2002). Agent-based modeling as organizational and public policy simulators. Proceedings of the National Academy of Sciences of the United States of America, 99(10), 71957196.

Liscouski, B., \& Elliot, W. (2004). Final report on the august 14, 2003 blackout in the united states and canada: Causes and recommendations. A report to US Department of Energy, 40(4). 
Liu, H., Davidson, R. A., \& Apanasovich, T. V. (2008). Spatial generalized linear mixed models of electric power outages due to hurricanes and ice storms. Reliability Engineering \& System Safety, 93(6), 897-912.

Lysyk, B. (2015). Annual Report of the Office of the Auditor General of Ontario. Toronto: Provincial Auditor of Ontario.

Macal, C. M., \& North, M. J. (2005). Tutorial on agent-based modeling and simulation. In Proceedings of the 37th conference on Winter simulation, 2-15.

Macal, C. M., \& North, M. J. (2005). Validation of an agent-based model of deregulated electric power markets. In Proc. North American Computational Social and Organization Science (NAACSOS) 2005 Conference, South.

Mansur, Erin T., Mendelsohn, Robert, Morrison, Wendy. (2008). Climate change adaptation: a study of fuel choice and consumption in the US energy sector. Journal of Environmental Economics and Management 55 (2), 175-193.

Maria, A. (1997). Introduction to modeling and simulation. In Proceedings of the 29th conference on Winter simulation, 7-13.

McGillivray, D., Conway, S., \& Marchionda, S. (2014). Centre for Urban Energy Round table VI the ice storm: extreme weather and urban energy. Centre for urban energy roundtable vi the ice storm: extreme weather and urban energy, 4-16.

McLinn, J. (2009). Major Power Outages in the US, and around the World. IEEE Reliability Society. 
Mideksa, T. K., \& Kallbekken, S. (2010). The impact of climate change on the electricity market: A review. Energy Policy, 38(7), 3579-3585.

Mirza, M. (2004). Climate change and extreme climate events: vulnerability and adaptation of the Canadian energy sector. Climate Change: Building the Adaptive Capacity. Meteorological Service of Canada, Environment Canada, 216-234.

Mukherjee, U., Elsholkami, M., Walker, S., Fowler, M., Elkamel, A., \&Hajimiragha, A. (2015). Optimal sizing of an electrolytic hydrogen production system using an existing natural gas infrastructure. International Journal of Hydrogen Energy, 40(31), 9760-9772.

Nairn, J., \& Fawcett, R. (2011). Defining heatwaves: heatwave defined as a heat-impact event servicing all. Europe, 220, 224.

Nelles, H. (2005). Biography - BECK, Sir ADAM - Volume XV (1921-1930) - Dictionary of Canadian Biography.

Niazi, M., \& Hussain, A. (2009). Agent-based tools for modeling and simulation of selforganization in peer-to-peer, ad hoc, and other complex networks. IEEE Communications Magazine, 47(3), 166-173.

North American Electric Reliability Council, (2005). "Evaluation of criteria, methods, and practices used for system design, planning, and analysis response to nerc blackout recommendation 13c [online]," Retrieved from: http://www.nerc.com/docs/pc/tis/.

Ontario Distribution Sector Review Panel, \& Ontario. Ministry of Energy. (2012). Renewing Ontario's electricity distribution sector: Putting the consumer first Ontario Ministry of Energy. Ontario's Electricity Financial Corporation. (2000). Annual Report, (31). 
OPA resources to meet capacity and flexibility needs: peaking resources (a). (2016). Retrieved May 10, 2016, from http://www.powerauthority.on.ca/about-us/electricity-pricing-ontario/opageneration-and-conservation-resource-costs/resources-peaking.

OPA resources to meet energy needs: base load and intermediate resources (b). (2016). Retrieved May 10, 2016,from http://www.powerauthority.on.ca/about-us/electricity-pricing-ontario/opageneration-and-conservation-resource-costs/resources-peaking.

Pfeifenberger, J., Spees, K., \& Schumacher, A. (2009). A comparison of PJM's RPM with alternative energy and capacity market designs. Prepared for PJM Interconnection, Inc. September.

Population by year, by province and territory (Number). (2016). Retrieved December 11, 2016, from http://www.statcan.gc.ca/tables-tableaux/sum-som/101/cst01/demo02a-eng.htm.

Power Data. (2016). Retrieved May 10, 2016, from http://www.ieso.ca/Pages/PowerData/default.aspx\#data

Public Alerting Criteria. (2016). Retrieved 2016, from http://www.ec.gc.ca/meteoweather/default.asp?lang=En\&n=D9553AB5-1

Rai, V., \& Henry, A. D. (2016). Agent-based modeling of consumer energy choices. Nature Climate Change

Rand, W., \& Rust, R. T. (2011). Agent-based modeling i n marketing: Guidelines for rigor. International Journal of Research in Marketing, 28(3), 181-193.

Rastegar, M., Guerci, E., \&Cincotti, S. (2009). Agent-based model of the Italian wholesale electricity market. 2009 6th International Conference on the European Energy Market, 1-7. 
Reynolds, C. (1987). Flocks, herds and schools: A distributed behavioral model. Proceedings of the 14th Annual Conference on Computer Graphics and Interactive Techniques SIGGRAPH, 21(4).

Rosenbloom, D., \& Meadowcroft, J. (2014). The journey towards decarbonization: Exploring socio-technical transitions in the electricity sector in the province of Ontario (1885-2013) and potential low-carbon pathways. Energy Policy, 65, 670-679.

Ruge-Murcia, F. J. (2007). Methods to estimate dynamic stochastic general equilibrium models. Journal of Economic Dynamics and Control,31(8), 2599-2636.

Schelling, T. (1971). Dynamic models of segregation† $†$. The Journal of Mathematical Sociology, 143-186.

Short, W., \& Denholm, P. (2006). A preliminary assessment of plug-in hybrid electric vehicles on wind energy markets. National Renewable Energy Laboratory.

Singh, B., Roy, P., Spiess, T., \& Venkatesh, B. (2015). Achieving electricity grid resiliency. Centre for Urban Energy, 1-25.

Smoyer-Tomic, K. E., Kuhn, R., \& Hudson, A. (2003). Heat wave hazards: an overview of heat wave impacts in Canada. Natural hazards, 28(2-3), 465-486.

Supply mix. (2016). Retrieved November 10, 2016, from http://www.ieso.ca/Pages/PowerData/Supply.aspx

Talukdar, S. N., Apt, J., Ilic, M., Lave, L. B., \& Morgan, M. G. (2003). Cascading failures: survival versus prevention. The Electricity Journal, 16(9), 25-31.

Trebilcock, M. J., \& Daniels, Ron (American presidential candidate). (2000). Electricity 
restructuring: The Ontario experience. Canadian Business Law Journal, 33(2), 161.

Understanding the Impact of Summer Weather on your Electricity Bill. (2012). Retrieved May 10, 2016, fromhttp://www.ieso.ca/Pages/Power-Data/default.aspx\#data

Vine, E. (2012). Adaptation of California's electricity sector to climate change. Climatic Change, 111(1), 75-99.

Visudhiphan, P. (2003). An agent-based approach to modeling electricity spot markets. 407-412 Weather Glossary. (2013). Retrieved 2016, from https://ec.gc.ca/meteoaloeilskywatchers/default.asp? lang=En\&n=7884CDEA-1\&def=show1BED14A34\#BED14A34.

Weidlich, A., \& Veit, D. (2008). A critical survey of agent-based wholesale electricity market models. Energy Economics, 30(4), 1728-1759.

Wilbanks, T. J. (2007). Introduction in Effects of Climate Change on Energy Production and Use in the United States, A Report by the US Climate Change Science Program and the subcommittee on Global Change Research.

Wilensky, U. (1999). NetLogo. http://ccl.northwestern.edu/netlogo/. Center for Connected Learning and Computer-Based Modeling, Northwestern University, Evanston, IL.

Winfield, M., \& Pembina Institute for Appropriate Development. (2004). Power for the future: Towards a sustainable electricity system for Ontario, Pembina Institute for Appropriate Development. 
Wong, C. J., Miller M. D. (2010). Guidelines for electrical transmission line structural loading ASCE manuals and reports on engineering practice No. 74.

Zareipour, H., Cañizares, C. A., \& Bhattacharya, K. (2007). The operation of Ontario's competitive electricity market: overview, experiences, and lessons. IEEE Transactions on Power Systems, 22(4), 1782-1793. 